\title{
ANVIL CHARACTERISTICS AS SEEN BY C-POL DURING THE TROPICAL WARM POOL INTERNATIONAL CLOUD EXPERIMENT (TWP-ICE)
}

\author{
A Thesis \\ by \\ KAYCEE LORETTA FREDERICK \\ Submitted to the Office of Graduate Studies of \\ Texas A\&M University \\ in partial fulfillment of the requirements for the degree of \\ MASTER OF SCIENCE
}

December 2006

Major Subject: Atmospheric Sciences 


\title{
ANVIL CHARACTERISTICS AS SEEN BY C-POL DURING THE TROPICAL WARM POOL INTERNATIONAL CLOUD EXPERIMENT (TWP-ICE)
}

\author{
A Thesis \\ by \\ KAYCEE LORETTA FREDERICK \\ Submitted to the Office of Graduate Studies of \\ Texas A\&M University \\ in partial fulfillment of the requirements for the degree of \\ MASTER OF SCIENCE
}

\begin{abstract}
Approved by:
Chair of Committee, Courtney Schumacher

Committee Members, Larry Carey

Andrew Klein

Head of Department, Richard Orville
\end{abstract}

December 2006

Major Subject: Atmospheric Sciences 


\begin{abstract}
Anvil Characteristics as Seen by C-POL during the Tropical Warm Pool International Cloud Experiment (TWP-ICE). (December 2006)

Kaycee Loretta Frederick, B.S., University of North Dakota

Chair of Advisory Committee: Dr. Courtney Schumacher
\end{abstract}

The Tropical Pacific Warm Pool International Cloud Experiment (TWP-ICE) took place in Darwin, Australia in early 2006. C-band radar data from this experiment were used to characterize tropical anvil areal coverage, height, and thickness during the month-long field campaign. The morphology, evolution, and longevity of the anvil were analyzed as well as the relationship of the anvil to the rest of the precipitating system. In addition, idealized in-cloud radiative heating profiles were created based on the anvil observations.

The anvil was separated into mixed (i.e., echo base below $6 \mathrm{~km}$ ) and ice only categories. The experiment areal average coverage for both types of anvil was between $4-5 \%$ of the radar grid. Ice anvil thickness averaged $2.8 \mathrm{~km}$ and mixed anvil thickness averaged $6.7 \mathrm{~km}$. No consistent diurnal signal was seen in the anvil, implying that the life cycle of the parent convection was of first order importance in determining the anvil height, thickness, and area. Areal peaks show that mixed anvil typically formed out of the stratiform region. Peak production in ice anvil usually followed the mixed anvil peak by 1-3 hr. Anvil typically lasted 4-10 hr after the initial convective rain area peak. The TWP-ICE experienced three distinct regimes: the active monsoon, dry monsoon, and 
break periods. During the entire experiment (except the active monsoon period) there was a strong negative correlation between ice anvil thickness and ice anvil height, a strong positive correlation between ice anvil area and thickness, and a greater variance in ice anvil bottom than ice anvil top. Anvil produced during the active regime had the most dramatic in-cloud radiative response with a maximum cooling of $0.45^{\circ} \mathrm{K} \mathrm{day}^{-1}$ at $12 \mathrm{~km}$, a maximum heating of $3^{\circ} \mathrm{K}$ day $^{-1}$ at $9 \mathrm{~km}$, and a secondary maximum heating of $1.2^{\circ} \mathrm{K} \mathrm{day}^{-1}$ at $5 \mathrm{~km}$. 


\section{ACKNOWLEDGEMENTS}

I thank my advisor, Dr. Courtney Schumacher, for her patience and continuous support and encouragement throughout my past two years at Texas A\&M. I also thank my committee members, Dr. Larry Carey and Dr. Andrew Klein, for their helpful suggestions in this research. A big thank you goes out to everyone who made TWP-ICE a successful and enjoyable field campaign. Shane, thanks for making the videos possible, enjoying afternoon cups of coffee, and sharing in late night TV dinners. Jason, thanks for not letting me complain. Melodi, thanks for encouraging me throughout the process and celebrating with me afterwards. To all the rest of my amazing friends and family, thank you for your love and support. 
TABLE OF CONTENTS

Page

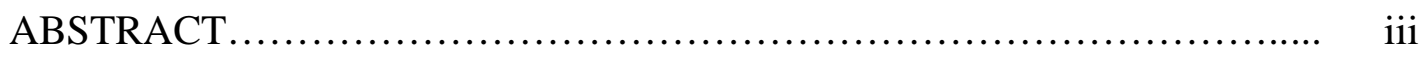

ACKNOWLEDGEMENTS.......................................... $\mathrm{v}$

TABLE OF CONTENTS ............................................... vi

LIST OF FIGURES............................................... vii

LIST OF TABLES................................................... $\mathrm{x}$

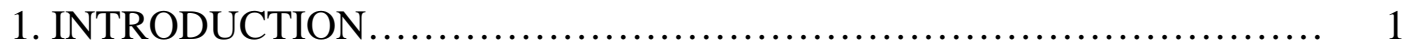

2. DATA AND METHODOLOGY ....................................... 12

a. Tropical Warm Pool International Cloud Experiment................ 12

b. C-band polarmetric/Doppler meteorological radar system............. 14

c. Analysis of C-POL data................................................................. 19

3. RESULTS..................................................... 21

a. Case studies.................................................. 21

b. Entire field experiment....................................... 48

4. DISCUSSION ....................................................... 56

a. Diurnal signals.............................................. 56

b. Convective pattern and longevity............................... 60

c. Correlations between thickness, height, and area................... 61

d. Variance in ice anvil base....................................... 63

e. Radiative heating profiles.................................... 65

5. CONCLUSIONS .................................................. 69

REFERENCES................................................. 73

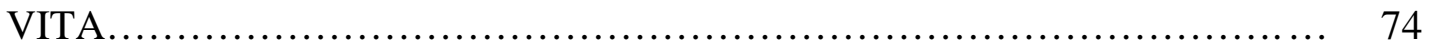




\section{LIST OF FIGURES}

FIGURE Page

1 Schematic thunderstorm with cirrus outflow at the upper right....... 3

2 Vertical distribution of radiative heating in the visible (dashed) and infrared (solid) relative to a cloud slab between 200 and $350 \mathrm{mb} . . . .$.

3 Radar reflectivity ( $\mathrm{dBZ})$, vertical velocity of the air $\left(\mathrm{m} \mathrm{s}^{-1}\right)$, and Doppler spread $\left(\mathrm{m} \mathrm{s}^{-1}\right)$ in the anvil from the University of Miami vertically pointing cloud radar.

4 Schematic vertical cross section of convective and stratiform precipitation regions and non-precipitating anvil.................. 10

5 Map of instruments used during TWP-CE....................... 14

6 Scan strategy for C-POL during TWP-ICE...................... 16

7 Comparison of precipitation radar observations to cloud radar observations over the ARM site on 24 January $2006 \ldots \ldots \ldots \ldots \ldots \ldots . .17$

8 C-POL horizontal cross sections at $2.5 \mathrm{~km}$ AMSL on 23 January 2006 at a) 0700 UTC, b) 1200 UTC, c) 1500 UTC, and d) 2000 UTC 24

9 Percentage of radar grid covered by rain and anvil on 23 January 2006

10 Anvil top, bottom, and thickness on 23 January 2006.

11 C-POL horizontal and vertical cross sections on 23 January 2006 for a) ice anvil at 0930 UTC and b) mixed anvil at 1030 UTC.

12 C-POL horizontal cross sections at $2.5 \mathrm{~km}$ AMSL on 24 January 2006 at a) 0600 UTC, b) 0800 UTC, c) 1200 UTC, and d) 1800 UTC

13 Percentage of radar grid covered by rain and anvil on 24 January 2006.

14 Anvil top, bottom, and thickness on 24 January 2006

15 C-POL horizontal and vertical cross sections on 24 January 2006 for 
FIGURE Page

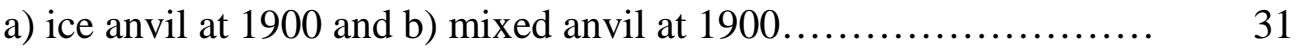

16 C-POL horizontal cross sections at $2.5 \mathrm{~km}$ AMSL on 31 January 2006 at a) 0400 UTC, b) 1000 UTC, c) 1200 UTC, and d) 1700 UTC 33

17 Percentage of radar grid covered by rain and anvil on 31 January 2006.

18 Anvil top, bottom, and thickness on 31 January $2006 \ldots \ldots \ldots \ldots \ldots \ldots . . . . .34$

19 C-POL horizontal and vertical cross sections on 31 January 2006 for a) ice anvil at 1800 and b) mixed anvil at $1730 \ldots \ldots \ldots \ldots \ldots \ldots \ldots . . . \ldots . \ldots$

20 C-POL horizontal cross sections at $2.5 \mathrm{~km}$ AMSL on 1 February 2006 at a) 0200 UTC, b) 0400 UTC, c) 0600 UTC, and d) 1500 UTC 36

21 Percentage of radar grid covered by rain and anvil on 1 February 2006.

22 Anvil top, bottom, and thickness on 1 February 2006

23 C-POL horizontal and vertical cross sections on 1 February 2006 for

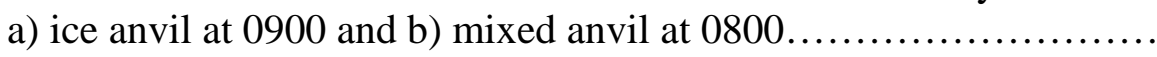

24 C-POL horizontal cross sections at $2.5 \mathrm{~km}$ AMSL on 10 February 2006 at a) 0600 UTC, b) 0800 UTC, c) 1100 UTC, and d) 2100 UTC

25 Percentage of radar grid covered by rain and anvil on 10 February 2006.

26 Anvil top, bottom, and thickness on 10 February 2006

27 C-POL horizontal and vertical cross sections on 10 February 2006 for a) ice anvil at 1200 and b) mixed anvil at 0900 .

28 C-POL horizontal cross sections at $2.5 \mathrm{~km}$ AMSL on 11 February 2006 at a) 0700 UTC, b) 1300 UTC, c) 1800 UTC, and d) 2100 UTC

29 Percentage of radar grid covered by rain and anvil on 11 February 2006.

30 Anvil top, bottom, and thickness on 11 February 2006. 
FIGURE Page

31 C-POL horizontal and vertical cross sections on 11 February 2006 for a) ice anvil at 1830 and b) mixed anvil at $1930 \ldots \ldots \ldots \ldots \ldots \ldots \ldots . . . . . . . . . .48$

32 Percentage of radar grid covered by rain and anvil for the whole TWP-ICE time period.......................................... 50

33 Average anvil thickness during TWP-ICE...................... 52

34 Diurnal comparison in anvil area during TWP-ICE................ 55

35 Diurnal comparison in anvil top and thickness during TWP-ICE..... 55

36 A series of vertical cross sections from 10 February 2006 at 1130 UTC-1300 UTC........................................... 63

37 In-cloud radiative heating profiles during TWP-ICE for the a) active regime, b) dry regime, and c) break............................. 66

38 In-cloud radiative heating during each regime during TWP-ICE..... 68

39 Figure 4 with added values based on observations of this study....... 70 


\section{LIST OF TABLES}

TABLE

Page

1 C-POL system characteristics (Keenan et al. 1998).

2 QC parameters used in TWP-ICE............................. 18

3 UTC to Darwin Local Time conversion table......................... 23

4 Average values for anvil properties during TWP-

ICE.

5 Average percent of the radar grid area covered

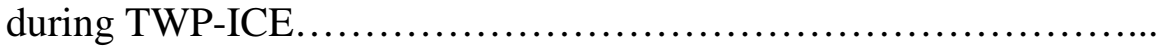

6 Correlations during TWP-ICE for ice anvil: a) between anvil thickness and mean height and $b$ ) between anvil area and anvil mean height.

7 Variance in anvil properties during TWP-ICE. 


\section{INTRODUCTION}

Cirrus clouds cover more than $70 \%$ of the tropics and have a major impact on the atmospheric radiative balance and hence global climate change (Liou 2002, p. 404). While it is still unknown how much of the cirrus comes from deep convection, some studies have made attempts to determine this amount. For example, Massie et al. (2002) calculated five-day back trajectories of isentropic parcels from the Halogen Occulation Experiment (HALOE) over the Maritime Continent from 1995-2000 and estimated that half of the cirrus formed from convective blow-off. Due to the difficulty of these measurements and the uncertainty in the calculations, we still lack a concrete notion of how much cirrus is formed from deep convection across the tropics, but it is assumed to be significant. This study focuses on analyzes of macro properties of thick tropical cirrus still attached to its convective source, hereafter referred to as anvil. C-band radar data from the Tropical Pacific Warm Pool International Cloud Experiment (TWP-ICE) that occurred in Darwin, Australia in early 2006 was used to characterize tropical anvil areal coverage, height, and thickness during the month-long field campaign as well as create idealized in-cloud radiative heating profiles in the anvil regions.

Hydrometeors are generated and lofted to upper levels by deep convection. With updrafts exceeding several meters per second, some of these hydrometeors grow by coalescence/riming and fall out as convective precipitation. As the updrafts weaken, hydrometeors grow by vapor diffusion and precipitate out more slowly as stratiform rain. In both of these scenarios, some hydrometeors can be left aloft to form anvil. In a strong

This thesis follows the style of the Journal of Atmospheric Sciences. 
updraft situation, small precipitation-size particles may be lifted to the level of neutral buoyancy and then spread out to form anvil. In a weaker updraft situation, cloud particles may simply be left aloft after the parent convective or stratiform rain regions have moved away or dissipated. The horizontal and vertical extent of the resultant anvil depends on a number of factors, such as the duration and intensity of the initial convection, upper level wind shear and moisture, and radiative interactions.

Lilly (1988) developed a two-stage theoretical framework for how anvil or convective outflow spreads laterally. In the first stage, the outflow undergoes a collapse. The outflow plume is considered to be nearly neutral while entering into a stably stratified environment. The top of the outflow plume is denser than the environment and sinks, while the bottom of the outflow plume is warmer than the environment and rises (Fig. 1). Continuity requires a horizontal expansion for this vertical compression. In the second stage, radiative destabilization occurs in the anvil when the top of the anvil cools by emitting infrared radiation and the bottom of the anvil warms from absorbing infrared radiation from the earth (Fig. 2). This destabilization causes turbulent mixing throughout the depth of the layer. 

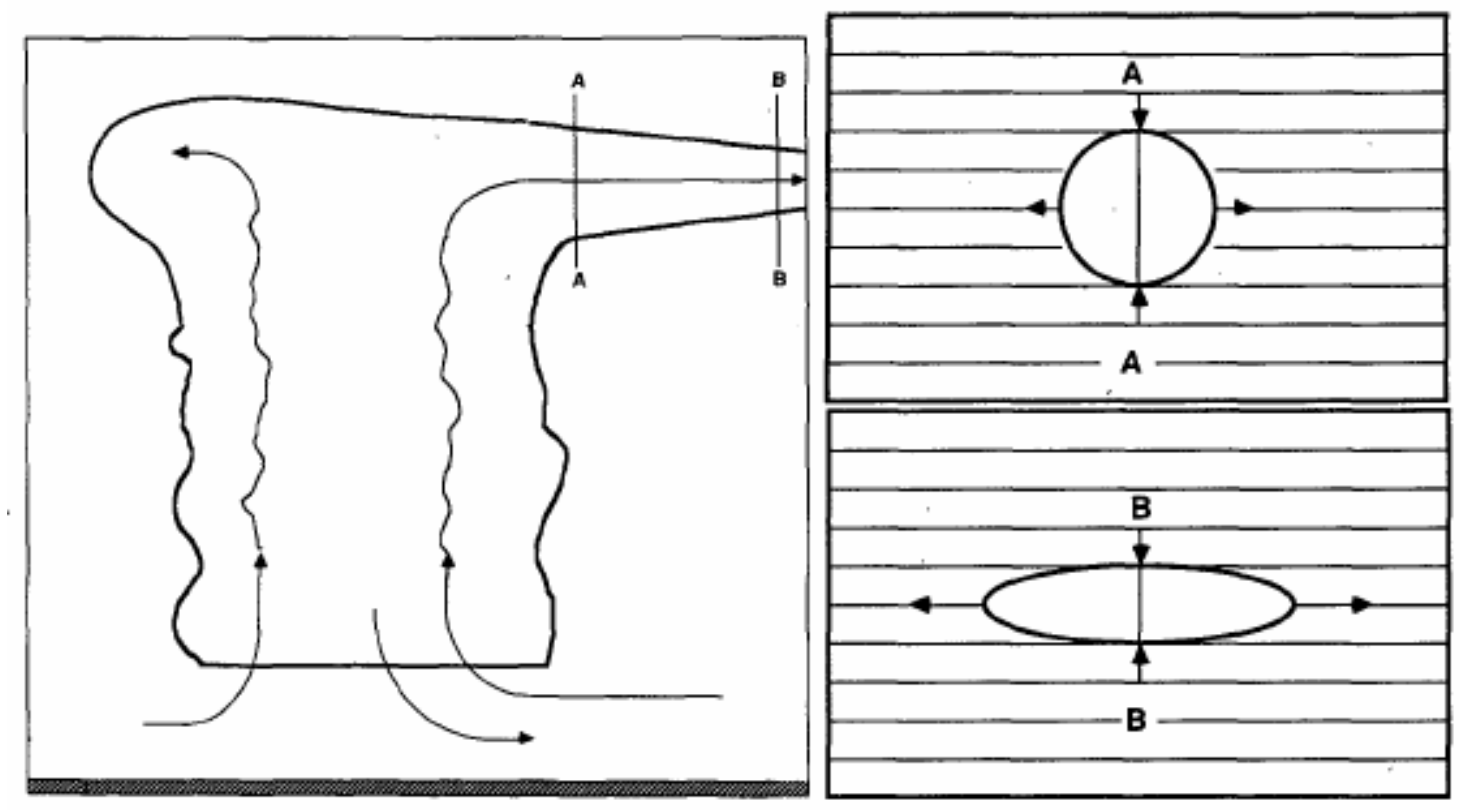

FIG. 1. (Left) Schematic thunderstorm with cirrus outflow at the upper right. (Right) Schematic outflow plume cross sections A and B. The horizontal lines indicate potential temperature surfaces in the environment; the arrows indicate the motion field induced by the buoyancy difference between the outflow plumes and the environment (Lilly 1988). 


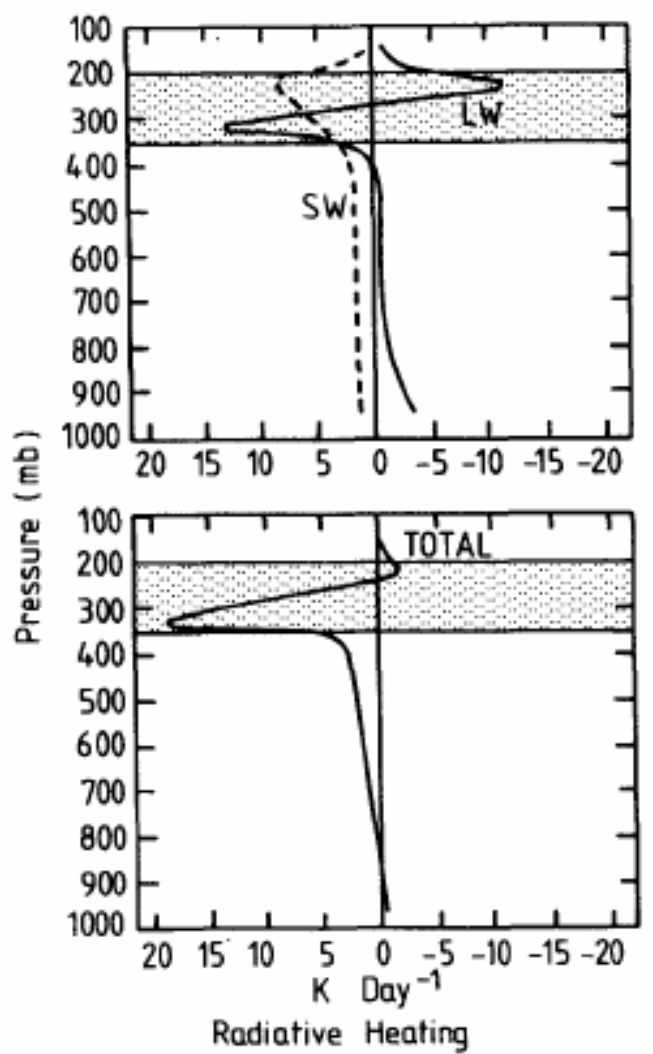

FIG. 2. Vertical distribution of radiative heating in the visible (dashed) and infrared (solid) relative to a cloud slab between 200 and $350 \mathrm{mb}$. Positive values are on the left, and negative values are on the right (Webster and Stephens 1980).

In contrast, Garrett et al. (2005) proposes that anvils are not well-mixed layers. During aircraft measurements in the Cirrus Regional Study of Tropical Anvils and Cirrus Layers-Florida Area Cirrus Experiment (CRYSTAL-FACE), Garrett et al. found that anvil maintained stratification similar to its environment. They argued that instead of turbulent mixing throughout the entire depth, mixing is concentrated at a depth $h$ at the cloud top and bottom. While the upper and lower cloud boundaries are mixed by radiative heating/cooling, the cloud interior remained stratified. This vertical temperature 
gradient sets up a frontal mechanism in which energy associated with heating drives lateral spreading instead of vertical motion.

Regardless of the mechanisms that cause anvil to spread laterally, anvil is important to the global energy balance because it is able to persist for an extended period of time, even after its parent convection has died. One of the reasons anvil is able to persist is that ice particles have a low saturation vapor pressure, thus they will be slow to sublimate. Other reasons involve self-sustaining dynamics such as effects from radiation or turbulence.

Webster and Stephens (1980) studied thick middle and upper tropospheric cloud during the Winter Monsoon Experiment (WMONEX) over the Malaysian region using data from the Geostationary Meteorological Satellite (GMS). With the cloud and atmospheric data obtained from WMONEX, they calculated the radiative heating profiles for various cloud structures. For a cloud layer between 200 and $350 \mathrm{mb}$, the combined shortwave (SW) and longwave (LW) radiative effects produce a net warming during the day (Fig. 2). They proposed that this net warming would partially maintain the cloud via lifting. Calculations from Ackerman et al. (1988) agree showing that, on average, infrared radiation exchange heats tropical anvils. Ackerman et al. also found 
solar heating in anvils to be less important than infrared heating in anvils, but not negligible.

Using a vertically pointing cloud radar, Petre and Verlinde (2004) observed a Kelvin-Helmholtz instability within a tropical anvil during CRYSTAL-FACE, which implies some type of internal dynamics contributing to anvil persistence. Figure 3b shows upward motion observed by the cloud radar that is indicative of generating cells, as indicated by the arrow in Fig. 3a. As the anvil matures, these cells sink and become deeply embedded in the anvil. The Doppler spread field (Fig. 3c) shows turbulence confined to a depth of $30 \mathrm{~m}$, suggesting that the velocity fluctuations result from turbulence generated by vertical shear. The velocity vectors in Fig. 3d clearly show a shear axis, which is further evidence for a Kelvin-Helmholtz billow. These observations indicate shear instability in the anvil interior. Since this Kelvin-Helmholtz billow existed for more than 3 hours, the observations suggest that internal anvil circulations played a role in continuously regenerating shear instability. 


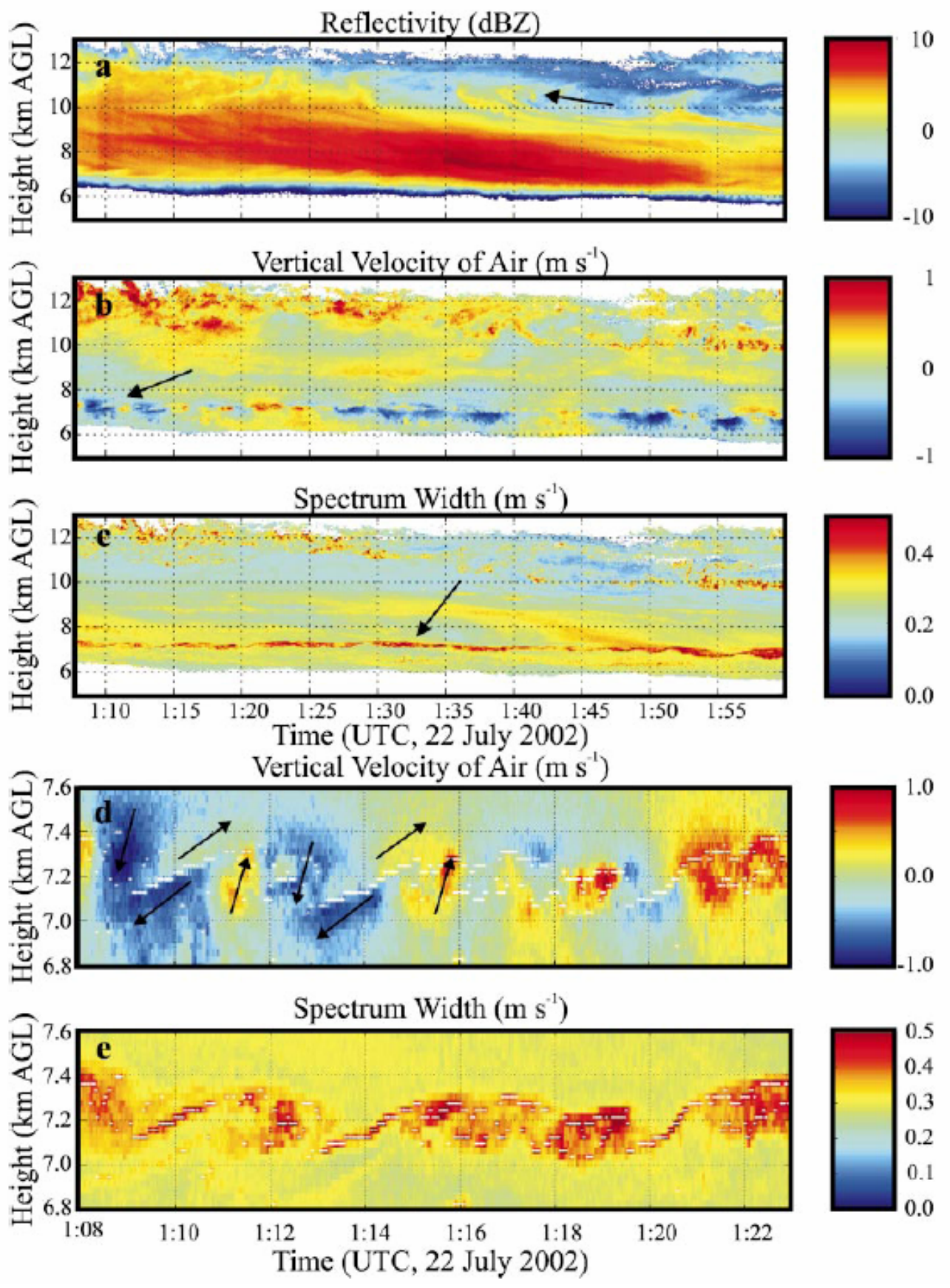

FIG. 3. Radar reflectivity (dBZ), vertical velocity of the air $\left(\mathrm{m} \mathrm{s}^{-1}\right)$, and Doppler spread $\left(\mathrm{m} \mathrm{s}^{-1}\right)$ in the anvil from the University of Miami vertically pointing cloud radar. The arrows point to (a) an embedded generating cell, and (b) and (c) a long-lasting shear line. (d) High-resolution views of the vertical velocity of the air $\left(\mathrm{m} \mathrm{s}^{-1}\right)$ and (e) Doppler spread $\left(\mathrm{m} \mathrm{s}^{-1}\right)$ fields of the well-developed shear instability. The white dots track the axis of the maximum Doppler spread (Petre and Verlinde 2004). 
The persistence of anvil in the atmosphere can lead to changes in the radiative balance throughout the atmosphere. Anvils affect the radiation balance in two ways. First, anvils will tend to increase the amount of solar radiation that is reflected back into space, thus cooling the atmosphere. Second, the anvil bottom will absorb infrared radiation from the earth while the anvil top emits infrared radiation from the top, which results in a warming of the atmosphere.

Most numerical representations of diabatic heating processes stress latent heating at the expense of radiative heating. Webster and Stephens (1980) argue that when calculating diabatic heating fields in the tropics, radiative effects cannot be ignored. This argument is especially relevant in the tropics where cloud radiative forcing (CRF), i.e., the difference between net irradiances measured with clouds and in the absence of clouds, represents the largest contribution to the total diabatic heating after latent heating (Houze 1982, Sherwood et al. 1994, Bergman and Hendon 2000). In the anvil, where vertical motions are much weaker, latent heating would be a secondary factor in the total diabatic heating compared to the radiative heating. Some studies have shown the importance of including radiative effects from tropical anvil and cirrus in global models. For example, Sherwood et al. (1994) demonstrated that general circulation models (GCMs) have a weaker Hadley and Walker circulation when the radiative heating associated with tropical anvil is excluded. While their GCM-reproduced TOA cloud radiative forcing compared reasonably well to satellite observations, the model assumptions about the vertical structure of radiative heating remain untested due to lack 
of observations. This study takes an observational approach in investigating the radiative effects of anvils including their vertical variations by using C-band radar data collected during the TWP-ICE campaign.

Not only will statistics on tropical anvils help us to understand the atmospheric radiative budget, they will help us to quantify the atmospheric water budget as well. Figure 4 is a schematic developed around the mathematical framework introduced in Houze et al. (1980, hereafter H80). The water budget equations developed in H80 are as follows:

$$
\begin{aligned}
& C_{c u}=R_{c}+E_{c d}+E_{c e}+C_{T} \\
& C_{T}+C_{s u}=R_{s}+E_{s d}+E_{s e}
\end{aligned}
$$

The H80 equations relate the efficiency of the precipitation process to the amounts of condensate left aloft and/or injected into the large-scale environment by precipitating cloud systems. The terms in the budget include the amount of convective region condensation $\left(\mathrm{C}_{\mathrm{cu}}\right)$ and the portions of the convective region condensation that are rained out $\left(\mathrm{R}_{\mathrm{c}}\right)$, evaporated in the convective downdrafts $\left(\mathrm{E}_{\mathrm{cd}}\right)$, detrained to an anvil $\left(\mathrm{E}_{\mathrm{ce}}\right)$, and transported into the stratiform region $\left(\mathrm{C}_{\mathrm{T}}\right)$. The condensate of the stratiform region includes $\mathrm{C}_{\mathrm{T}}$ plus the amount of condensate generated by the stratiform updraft $\left(\mathrm{C}_{\mathrm{su}}\right)$. Part of $\left(\mathrm{C}_{\mathrm{T}}+\mathrm{C}_{\mathrm{su}}\right)$ is rained out $\left(\mathrm{R}_{\mathrm{s}}\right)$, part is evaporated into the downdraft $\left(\mathrm{E}_{\mathrm{sd}}\right)$, and part $\left(E_{\mathrm{se}}\right)$ is detrained to or left aloft in a mixed or iced anvil. 


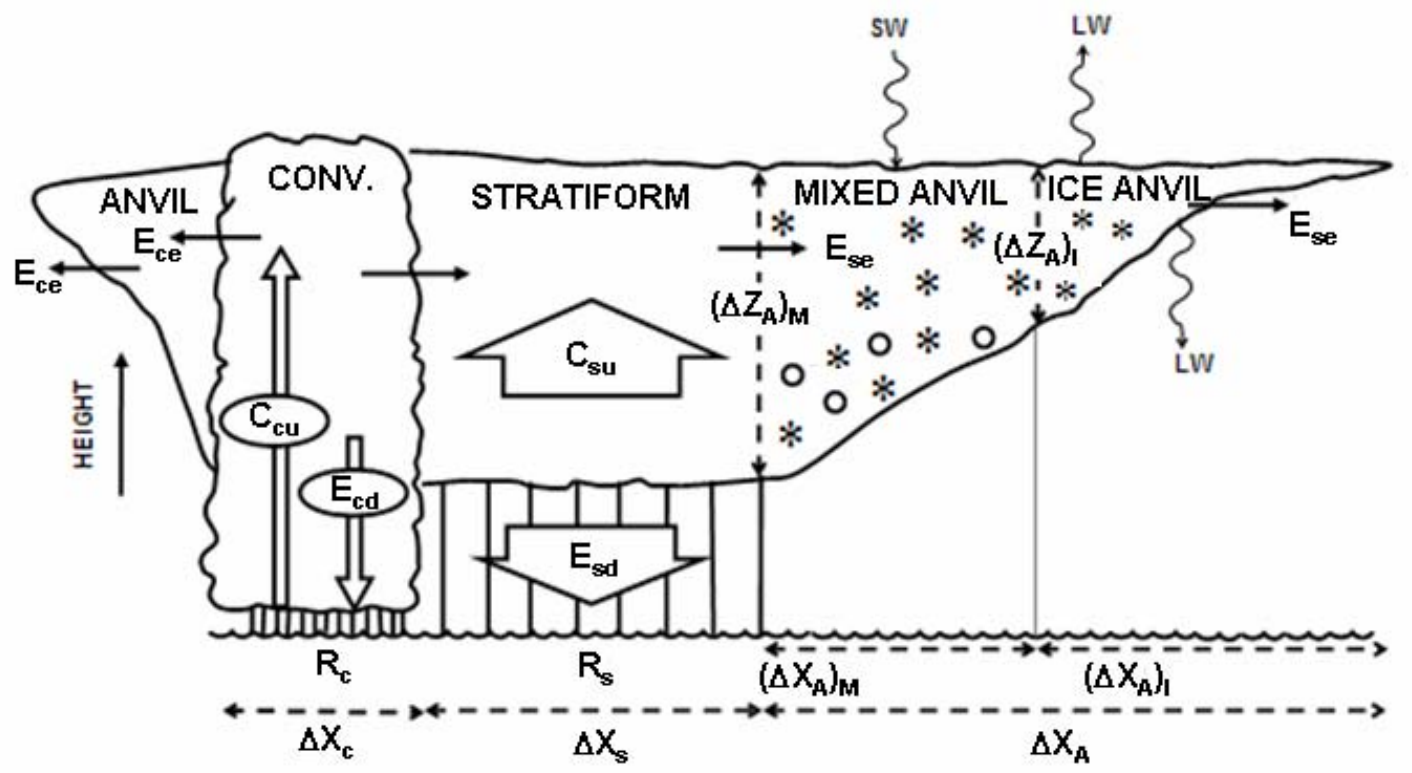

FIG. 4. Schematic vertical cross section of convective and stratiform precipitation regions and non-precipitating anvil. This schematic was adapted from Houze et al. (1980) and has been further modified to include regions of mixed and ice anvil. Symbols are defined in text.

Understanding how the anvil interacts with the rest of the precipitating system is crucial for understanding the water budget itself. Better estimates of $E_{s e}$ and $E_{c e}$ will lead to better estimates of precipitation efficiencies which are necessary to relate rain amounts to the vertical distribution of latent heat release. Determining the horizontal dimensions of the convective rain, stratiform rain, ice anvil, and mixed anvil regions along with the vertical dimensions of the ice and mixed anvil will also help quantify the water budget.

TWP-ICE provided a comprehensive data set with data from instruments such as precipitation radar, cloud radar, lidar, radiosonde, and aircraft probes. This research focuses primarily on the precipitation radar data and will attempt to quantify the horizontal and vertical dimensions of the anvil region, analyze the interaction between 
the anvil and the rest of the precipitating system, and determine the longevity, evolution, and morphology of the anvil in an attempt to better understand the radiation and water budget of tropical cloud systems. 


\section{DATA AND METHODOLOGY}

\section{a. Tropical Warm Pool International Cloud Experiment}

TWP-ICE, a joint venture between the US Department of Energy (DOE) Atmospheric Radiation Measurement (ARM) project, the Australian Bureau of Meteorology (BOM), NASA, the European Commission DG RTD-1.2 and several United States, Australian, Canadian, and European Universities, was held in Darwin, Australia from mid-January through mid-February 2006 during the Australian monsoon. The Australian monsoon season generally lasts from December to March and in particular, the wet season in Darwin is considered to occur from 1 October to 30 April (Hastenrath 1991, p. 183). The Australian monsoon is associated with the inflow of moist west to northwesterly winds, originating from the Indian Ocean, into the monsoon trough. The monsoon produces convective activity leading to large amounts of rainfall (monthly averages between 400-600 mm) over northern Australia. TWP-ICE provided one of the most complete data sets of tropical convection ever collected. An intense airborne measurement campaign was combined with an extensive network of groundbased observations to describe the evolution of tropical convection. TWP-ICE had a dual focus in being designed to study the characterization of cirrus and the upper troposphere along with the convective environment. 
Cloud properties during this experiment were observed by an extensive set of in situ and remote sensing instruments (Fig. 5). A fleet of five aircraft flew at multiple levels of boundary layer and cloud levels. The Darwin Atmospheric Radiation Measurement (ARM) site, which is located in Darwin for long-term climatological observations, retrieved a comprehensive set of radiation measurements using a micropulse lidar (MPL) and a 35 GHz millimeter-wave cloud radar (MMCR). A similar set of instruments located on a ship offshore of Darwin provided for ocean measurements. Other surface measurements included two-scanning C-band Doppler radars (allowing for dual-Doppler measurements), wind profilers, surface flux stations, and a network of five radiosonde stations encircling the station at Darwin. Radiosondes were launched every three hours providing very high temporal resolution. More details on the instrumentation during TWP-ICE can be found in the Science Plan at www.bom.gov.au/bmrc/wefor/research/twpice.htm. 


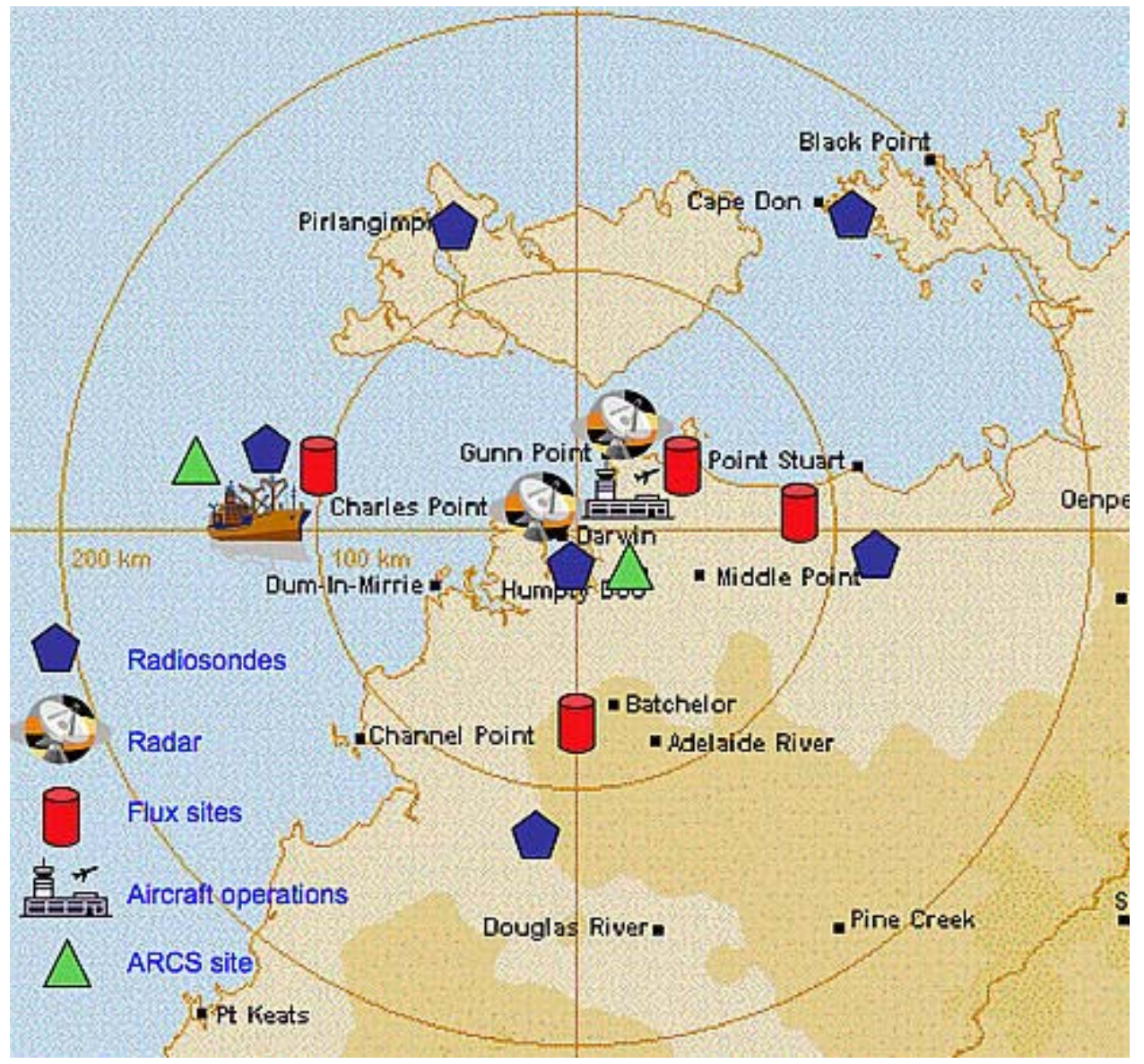

FIG. 5. Map of instruments used during TWP-CE.

\section{b. C-band polarmetric/Doppler meteorological radar system}

The C-band polarmetric/Doppler meteorological radar system (C-POL) was

developed by modifying a standard operational C-band radar employed by the Australian Bureau of Meteorology to be able to transmit linear horizontal and vertical polarizations and receiving the co- and cross polarizations on a pulse-to-pulse basis (Keenan et al. 1998). Table 1 lists the characteristics of the C-POL system (Keenan et al. 1998). The CPOL has a $1.0^{\circ}$ beamwidth, which gives the research quality spatial resolution. Assuming no path attenuation, the minimum detectable reflectivity at $10 \mathrm{~km}$ is $-29 \mathrm{dBZ}$. 
At further distances, the sensitivity decreases so a minimum reflectivity of $0 \mathrm{dBZ}$ is employed in this work. Table 1 also lists the polarmetric variables measured by C-POL. Because C-band measurements attenuate in heavier rain, these polarmetric measurements are used in C-POL's attenuation correction.

Table 1 C-POL system characteristics (Keenan et al. 1998).

\begin{tabular}{ll}
\hline \hline Antenna & \\
Size & $4.2-\mathrm{m}$ center-fed paraboloid \\
Beamwidth & $1.0^{\circ}$ \\
Gain & $45 \mathrm{~dB}$ \\
Max sidelobe & $<25 \mathrm{~dB}$ \\
Max cross polar & $<-30 \mathrm{~dB}$ \\
ICPR & $<-35 \mathrm{~dB}$ \\
Transmitter & \\
Pulse magnetron & $250 \mathrm{~kW}$ peak \\
Pulse width & $1.0-2.0 \mu \mathrm{s}$ \\
Pulse rates & $200-1200 \mathrm{~Hz}$ \\
Frequency & $5625 \mathrm{MHz}$ \\
Receiver & \\
Balanced coaxial receiver \\
Single channel (co- or cross polar) \\
Minimum detectable signal $<-115 \mathrm{dBm}$ \\
Minimum detectable reflectivity ${ }^{*}$ at $10 \mathrm{~km}-29 \mathrm{dBZ}$ \\
Bandwidth $0.5 / 1.0 \mathrm{MHz}$ \\
Channel isolation $>30 \mathrm{~dB}$ \\
Polarizations \\
Linear, horizontal and vertical \\
Pulse-to-pulse control \\
Ferrite switch on transmit \\
Variables: $Z_{\mathrm{HH},} V_{r}, \sigma_{v}, Z_{\mathrm{DR}}, \Phi_{\mathrm{DF}}, \rho_{\mathrm{HV}}(0), \mathrm{LDR}$ \\
\hline
\end{tabular}

The 10-min C-POL scan strategy during TWP-ICE began with a volume scan consisting of 17 tilts starting at $0.5^{\circ}$ and ending at $42^{\circ}$ (Fig. 6). The volume scan took eight minutes followed by a surveillance scan at $0.5^{\circ}$ that lasted less than 30 seconds. After the surveillance scan, a range-height indicator (RHI) is done over the ARM site. In 
the last seconds of the scan, the radar retrieved data from a vertically pointing $\left(89^{\circ}\right)$ position. This analysis focuses on observations from the volume scan.

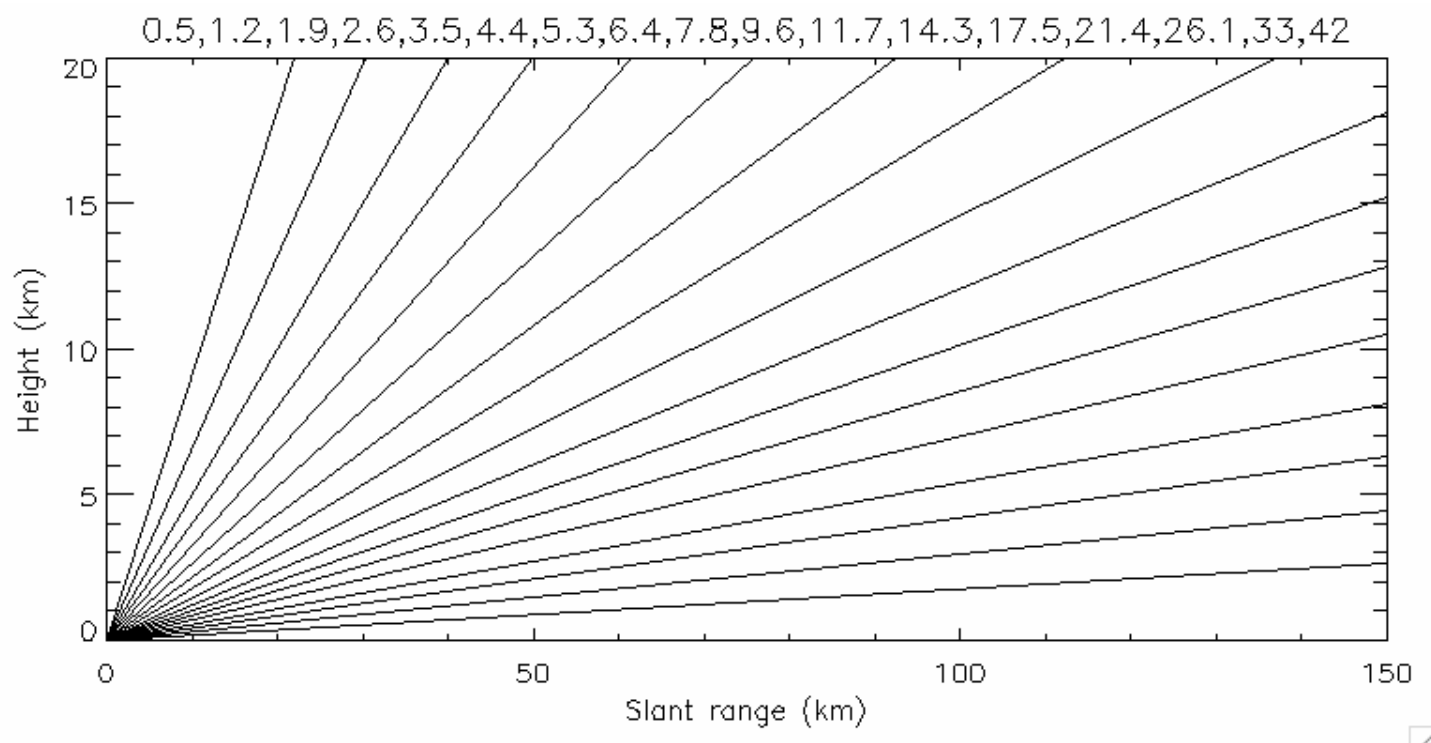

FIG. 6. Scan strategy for C-POL during TWP-ICE.

A C-band radar is a suitable radar for studying thick anvil because it transmits and receives at a 5-cm wavelength. In general, this is a short enough wavelength to allow for measurements of smaller hydrometeors as compared to a S-band $(\sim 10-\mathrm{cm}$ wavelength) radar, but is a long enough wavelength not to be attenuated during heavy precipitation like a cloud radar (i.e., a mm-wavelength radar) ${ }^{1}$. C-POL is a scanning radar so it can cover much larger areas (typically $140 \mathrm{~km}$ radius from the radar) than a vertically pointing cloud radar. Although sensitivity studies have yet to be completed, Fig. 7 presents a visual comparison of the vertically pointing cloud radar (MMCR) and the precipitation radar. At 0700 UTC the precipitation radar sees anvil $\sim 2 \mathrm{~km}$ in thick

\footnotetext{
${ }^{1}$ Other variables in the radar equation are important to consider. See table 1 for other C-POL characteristics.
} 
while the cloud radar at this time sees anvil that is $~ 3 \mathrm{~km}$ thick. At 1130 UTC the precipitation radar sees anvil $\sim 3.5 \mathrm{~km}$ in thickness while the cloud radar sees anvil that is $\sim 4.5 \mathrm{~km}$ thick. It appears then, on average, that C-POL only misses about 1 kilometer of the anvil compared to what is observed by the more sensitive MMCR.

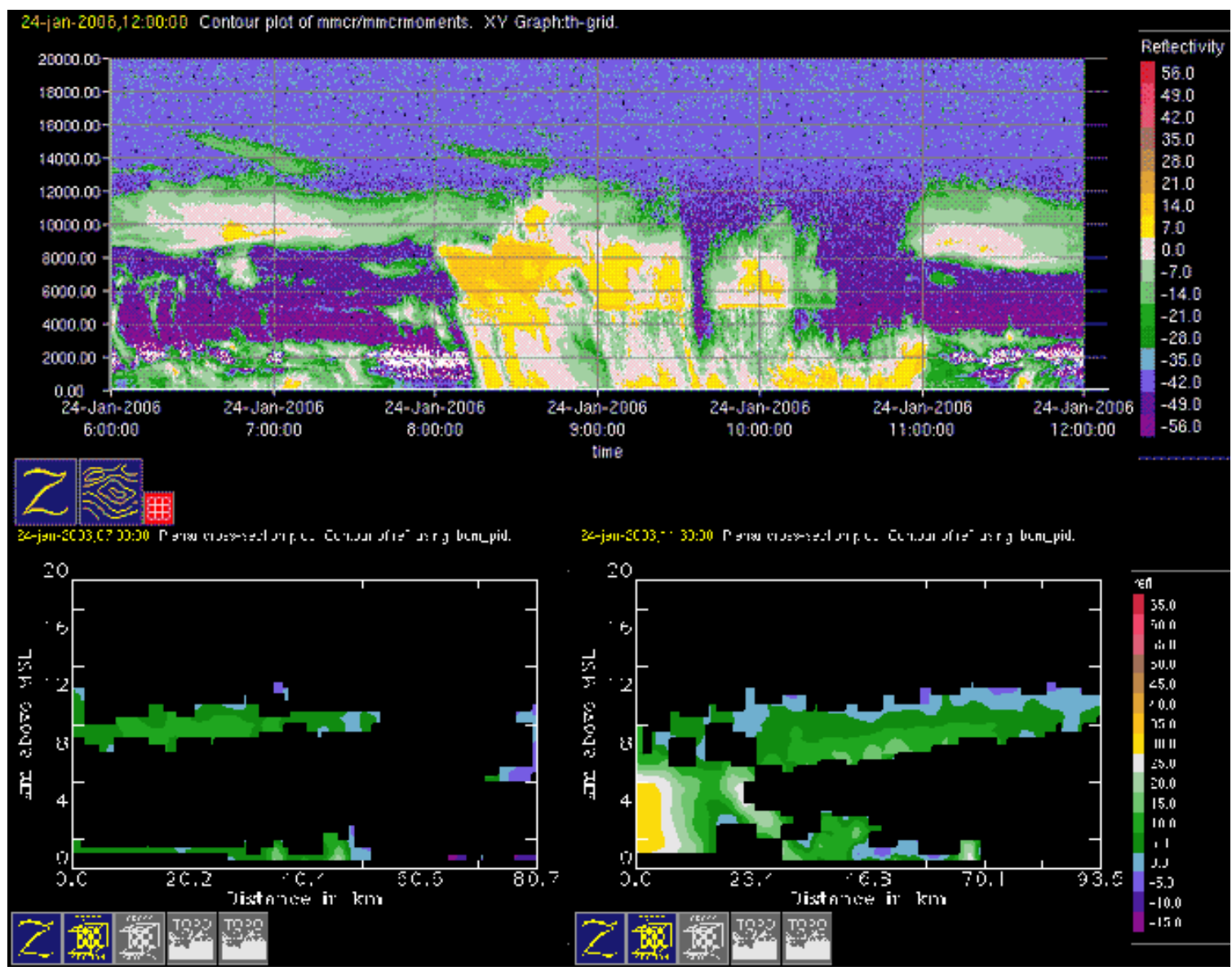

FIG. 7. Comparison of precipitation radar observations to cloud radar observations over the ARM site on 24 January 2006. The top panel is cloud radar reflectivity from 0600 UTC -1200 UTC. The bottom left panel is precipitation radar reflectivity at 0700 UTC and the bottom right panel is precipitation radar reflectivity at $1130 \mathrm{UTC}$. The ARM site is in the middle of the precipitation radar cross sections. 
The raw data collected from C-POL was converted to Universal Format (UF). In this step, signal processing was performed to remove some of the ground clutter. Next, principles from Bringi et al. (2001) were used to calculate polarmetric variables and correct for attenuation. Then a quality control method developed by the University of Washington (Houze et al. 2004) was used to remove pervasive clutter. This quality control method examines the texture of the reflectivity field in both the horizontal and vertical to determine which gates are set to missing data. Table 2 lists the parameters used for the quality control method for the TWP-ICE radar data. In the final step, the polar data was interpolated to a Cartesian grid $(2 \mathrm{~km} \times 2 \mathrm{~km}$ in the horizontal and $0.5 \mathrm{~km}$ in the vertical) using National Center for Atmospheric Research (NCAR) Reorder. The radius of influence used by Reorder was $2 \mathrm{~km}$ in the $\mathrm{x}$ and $\mathrm{y}$ dimensions and $1 \mathrm{~km}$ in the vertical dimension. Finally, data outside a radius of $120 \mathrm{~km}$ from the radar was excluded from the analysis because pervasive clutter still remained at upper levels far away from the radar. 
Table 2 QC parameters used in TWP-ICE.

\begin{tabular}{|c|c|}
\hline Parameter & Value \\
\hline \multicolumn{2}{|l|}{ 1) Input file name (universal format) } \\
\hline \multicolumn{2}{|l|}{ 2) Output file name (universal format) } \\
\hline 3) Boundary level (BL) (km) & 4 \\
\hline 4) Freezing level (FL) (km) & 20 \\
\hline 5) Dielectric flag (on or off) & Off \\
\hline 6) dBZ threshold value below BL (dBZ) & 25 \\
\hline 7) dBZ threshold value from BL to $1 \mathrm{~km}$ above BL & 20 \\
\hline 8) $\mathrm{dBZ}$ threshold value above $\mathrm{BL}+1.1 \mathrm{~km}$ and below FL & 8 \\
\hline 9) Max dBZ difference allowable between base and second tilt & 25 \\
\hline 10) Flag to apply pixel-above test between second and third tilts (0/1) & 1 \\
\hline 11) SQI filter flag (on or off0 & 1 \\
\hline 12) Max range to apply filter-above test on lowest tilt $(\mathrm{km})$ & 40 \\
\hline 13) Max radius from radar to unconditionally delete Echo (km) & 8 \\
\hline \multicolumn{2}{|l|}{ 14) Name of clutter file } \\
\hline $\begin{array}{l}\text { 15) Sweep to treat as lowest tilt (counting starts at } 0 \text {; for circumstances } \\
\text { where the SQI filter cannot be applied, this may be set to nonzero) }\end{array}$ & 0 \\
\hline 16) Save polarmetric fields flag (on or off0 & 1 \\
\hline
\end{tabular}

\section{c. Analysis of C-POL data}

Once the C-POL data was quality controlled, IDL code was created to analyze echo characteristics during TWP-ICE using the 3-D reflectivity arrays from the cartesianized C-POL data. Anvil was defined as echo aloft that had no reflectivity measurements at $2.5 \mathrm{~km}$ AMSL. Anvil top was determined by starting at the top of a given reflectivity profile and searching downward until a data value was found. This was then defined as the anvil top. The same method was used for anvil bottom except the search started from the bottom up. Anvil thickness was determined by subtracting anvil bottom from anvil top. Note that this method of defining the anvil cannot discriminate anvil located over shallow convection, however, visual observations show minimal occurrences of this situation so these events would not be statistically significant. 
Next, the anvil is separated into ice anvil and mixed anvil subcategories. Ice anvil was defined as anvil that has a base no lower than six kilometers, which in the tropics would be around $-5^{\circ} \mathrm{C}$ thus assuring that most of the hydrometeors in the anvil above this level would be ice. All other anvil is considered mixed anvil indicating a mix of water and ice hydrometeors. Anvil area was calculated summing the pixels in the anvil thickness arrays in the $\mathrm{x}$ and $\mathrm{y}$ dimensions.

Houze (1997) points out that convective regions and stratiform regions are produced from dynamically different situations. Convective rain is produced from collection and coalescence indicating strong vertical motion. Stratiform rain is produced by vapor diffusion where the vertical motions are much weaker. In order to distinguish between these dynamically different regimes, surface rain (i.e., echo observed at $2.5 \mathrm{~km}$ ) was separated into convective and stratiform regions using the algorithm from Steiner et al. (1995). This method analyzes horizontal gradients in radar reflectivity to distinguish regions of convective precipitation from stratiform precipitation. More peaked echo is classified as convective and the remaining echo is classified as stratiform. In addition, any pixel with reflectivity greater than $40 \mathrm{dBZ}$ is automatically considered convective. Once reflectivity was separated into convective and stratiform components, the same methods used to find anvil top were used to find convective and stratiform top. The number of pixels in the convective and stratiform top arrays was then summed to give convective and stratiform rain areas, respectively. 


\section{RESULTS}

The following section discusses radar data that was analyzed from 19 January to 11 February 2006. During TWP-ICE there were three distinct weather regimes. Nineteen January through 25 January was classified as the active "wet” season. This regime was characterized by westerly monsoon flow and large mesoscale convective systems (MCSs). Twenty-six January through 2 February was classified as the "dry” monsoon. During this regime the monsoon low was inland and deep, and although the westerlies were very strong during this time they were of drier origin contributing to less convection. Three February through 11 February was classified as the "break" period. During this time, the monsoonal trough had moved out of the region and an inland heat trough dominated northern Australia accompanied with easterly winds. Storms formed along both trough and seabreeze boundaries and often came in the form of squall lines. Two days from each regime were selected as case studies. Statistics encompassing the entire TWP-ICE campaign were analyzed as well.

\section{a. Case studies}

\section{1) ACTIVE MONSOON: JANUARY $23^{\text {rd }} / 24^{\text {th }}$}

The radar domain during 23-24 January experienced a great deal of convective activity. Convection first occurred over the Tiwi Islands in the afternoon. As this convective system moved westward out of the radar domain, a larger, more organized system entered the radar domain from the east. 
At 0700 UTC $^{2}$ on 23 January convection was mostly over the water, just north of the Tiwi Islands (Fig. 8a), i.e., the north-northwest region of the radar domain. The convective system had a moderate stratiform area and anvil covered $\sim 10 \%^{3}$ of the radar domain (Fig. 9). As the majority of convective activity moved westward out of the radar domain, total anvil area increased with a peak in mixed anvil area at 0900 UTC and a peak in ice anvil area at 1000 UTC. This was followed by a secondary peak in mixed anvil area at 1100 UTC. This secondary peak in mixed anvil was associated with a system consisting of a larger stratiform component which moved into the domain from the east around 1200 UTC (Fig. 8b). In addition, anvil produced between 0600-1200 UTC experienced an increase in thickness (Fig. 10). By 1300 UTC, stratiform rain covered more than half of the radar domain (Fig. 9).

\footnotetext{
${ }^{2}$ Table 3 provides a UTC to Local Time conversion.

3 Area of the radar grid is $45,216 \mathrm{~km}^{2}$.
} 
Table 3 UTC to Darwin Local Time conversion table.

\begin{tabular}{|cr|}
\hline UTC & Darwin LT \\
0000 & $9: 30 \mathrm{AM}$ \\
0100 & $10: 30 \mathrm{AM}$ \\
0200 & $11: 30 \mathrm{AM}$ \\
0300 & $12: 30 \mathrm{PM}$ \\
0400 & $1: 30 \mathrm{PM}$ \\
0500 & $2: 30 \mathrm{PM}$ \\
0600 & $3: 30 \mathrm{PM}$ \\
0700 & $4: 30 \mathrm{PM}$ \\
0800 & $5: 30 \mathrm{PM}$ \\
0900 & $6: 30 \mathrm{PM}$ \\
1000 & $7: 30 \mathrm{PM}$ \\
1100 & $8: 30 \mathrm{PM}$ \\
1200 & $9: 30 \mathrm{PM}$ \\
1300 & $10: 30 \mathrm{PM}$ \\
1400 & $11: 30 \mathrm{PM}$ \\
1500 & $12: 30 \mathrm{AM}$ \\
1600 & $1: 30 \mathrm{AM}$ \\
1700 & $2: 30 \mathrm{AM}$ \\
1800 & $3: 30 \mathrm{AM}$ \\
1900 & $4: 30 \mathrm{AM}$ \\
2000 & $5: 30 \mathrm{AM}$ \\
2100 & $6: 30 \mathrm{AM}$ \\
2200 & $7: 30 \mathrm{AM}$ \\
2300 & $8: 30 \mathrm{AM}$ \\
\hline
\end{tabular}




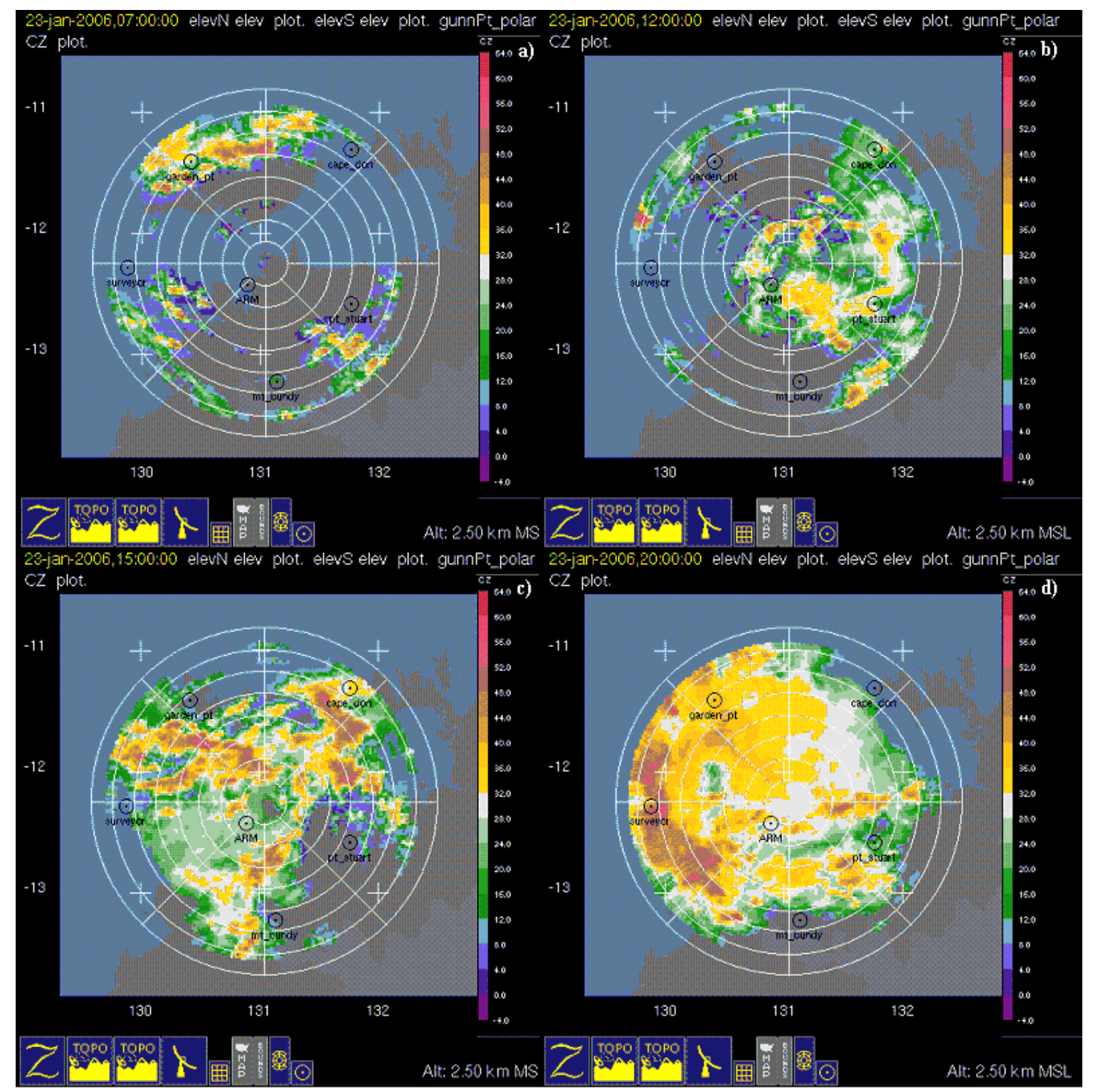

FIG. 8. C-POL horizontal cross sections at $2.5 \mathrm{~km}$ AMSL on 23 January 2006 at a) 0700 UTC, b) 1200 UTC, c) 1500 UTC, and d) 2000 UTC. 


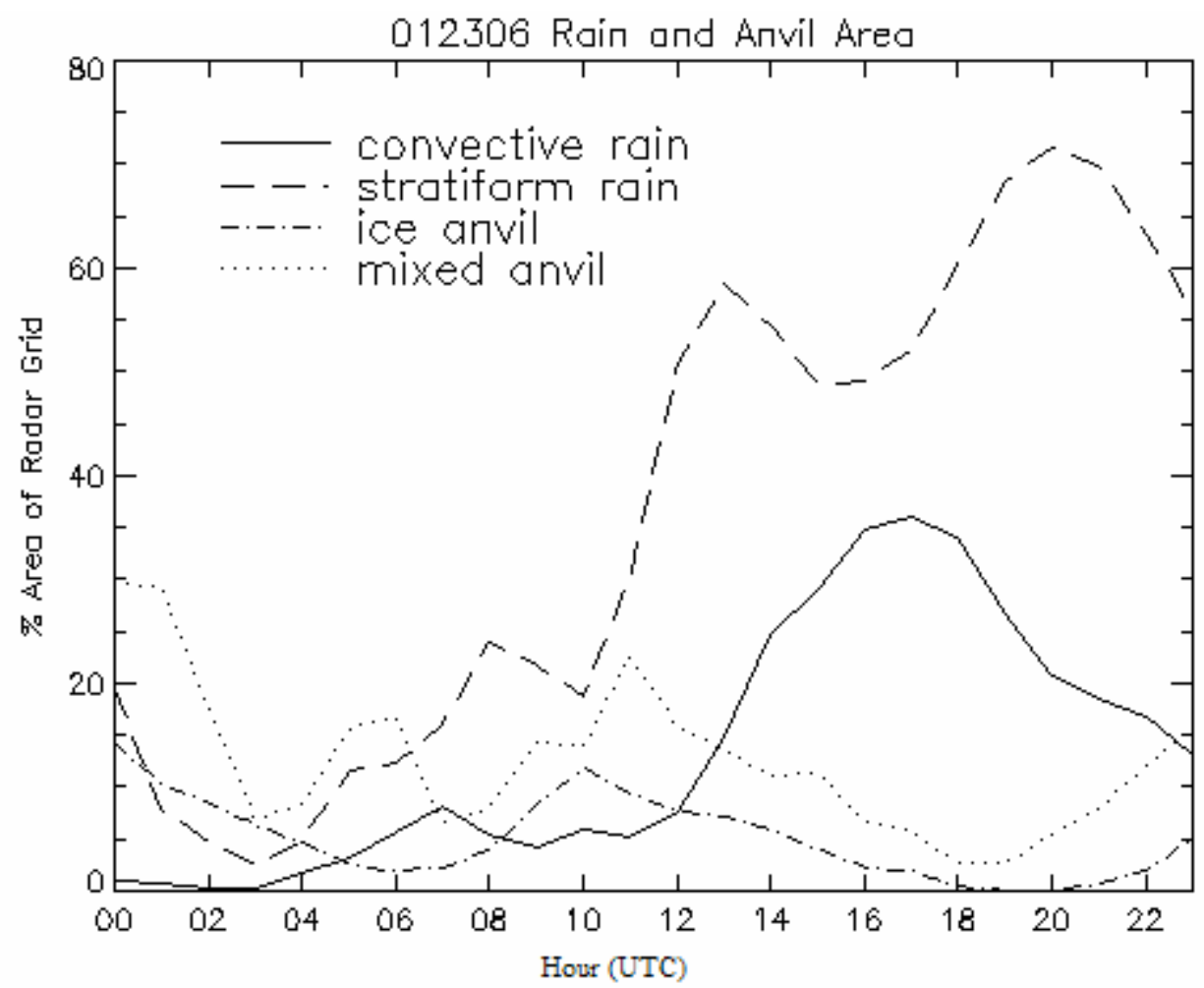

FIG. 9. Percentage of radar grid covered by rain and anvil on 23 January 2006.
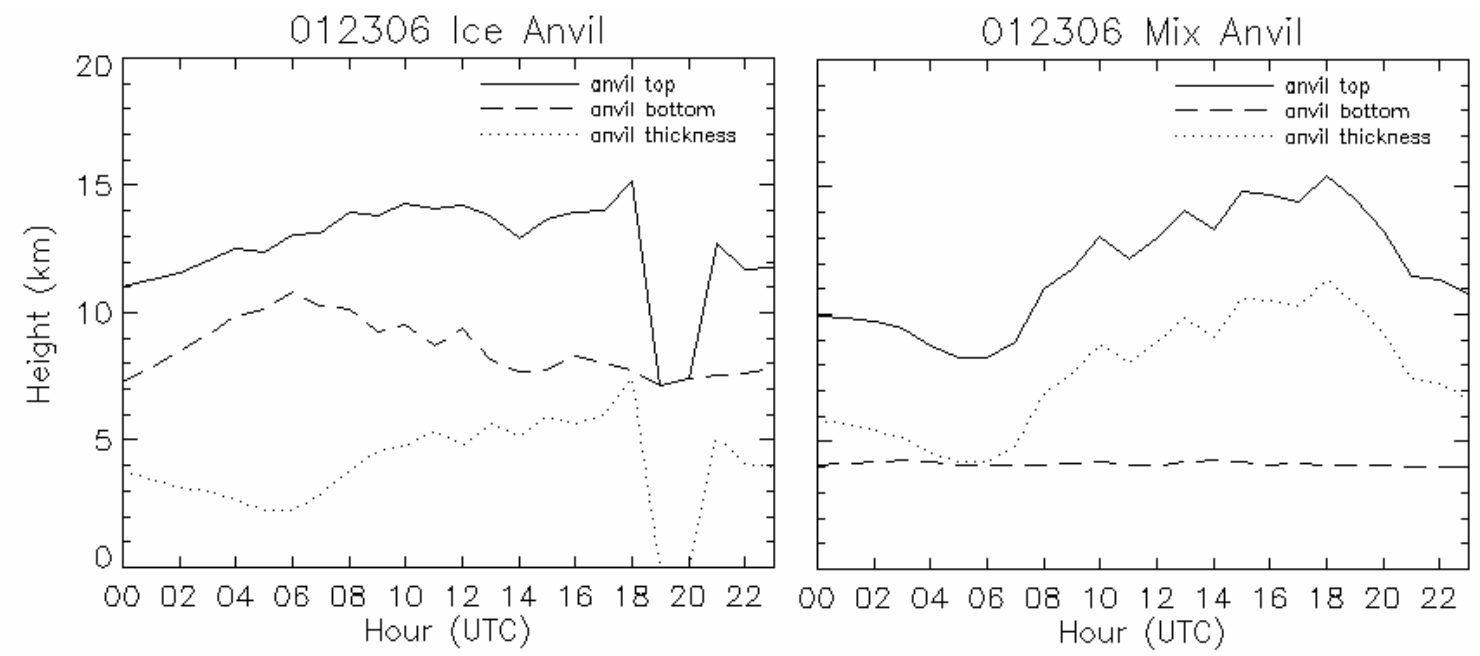

FIG. 10. Anvil top, bottom, and thickness on 23 January 2006. 
A few hours later the stratiform area southeast of the radar had either dissipated or moved westward out of the radar domain, while an intense convective line formed over the northern radar domain (Fig. 8c). A maximum in convective rain area can also be seen in Fig. 9 at 1700 UTC. Shortly after the convective rain area peak, anvil thickness began to decrease (Fig. 10). The anvil area began to decrease at this time also and continued to do so until 2000 UTC. By this time more than $70 \%$ of the radar domain was covered by stratiform precipitation (Figs. 8d and 9). The MCS persisted in the radar domain for several hours and produced ice anvil as thick as $7 \mathrm{~km}$ and mixed anvil as thick as $11 \mathrm{~km}$ (Fig. 10). The average ice anvil top varied around $13 \mathrm{~km}$ while the average ice anvil base varied around $9 \mathrm{~km}$. Mixed anvil top was more variable and at times reached $15 \mathrm{~km}$. Figure 11 shows examples of these characteristics found in both the ice and mixed anvil. Note that some echo top variability close to the radar is due to gaps in the C-POL scan strategy (Fig. 6). 


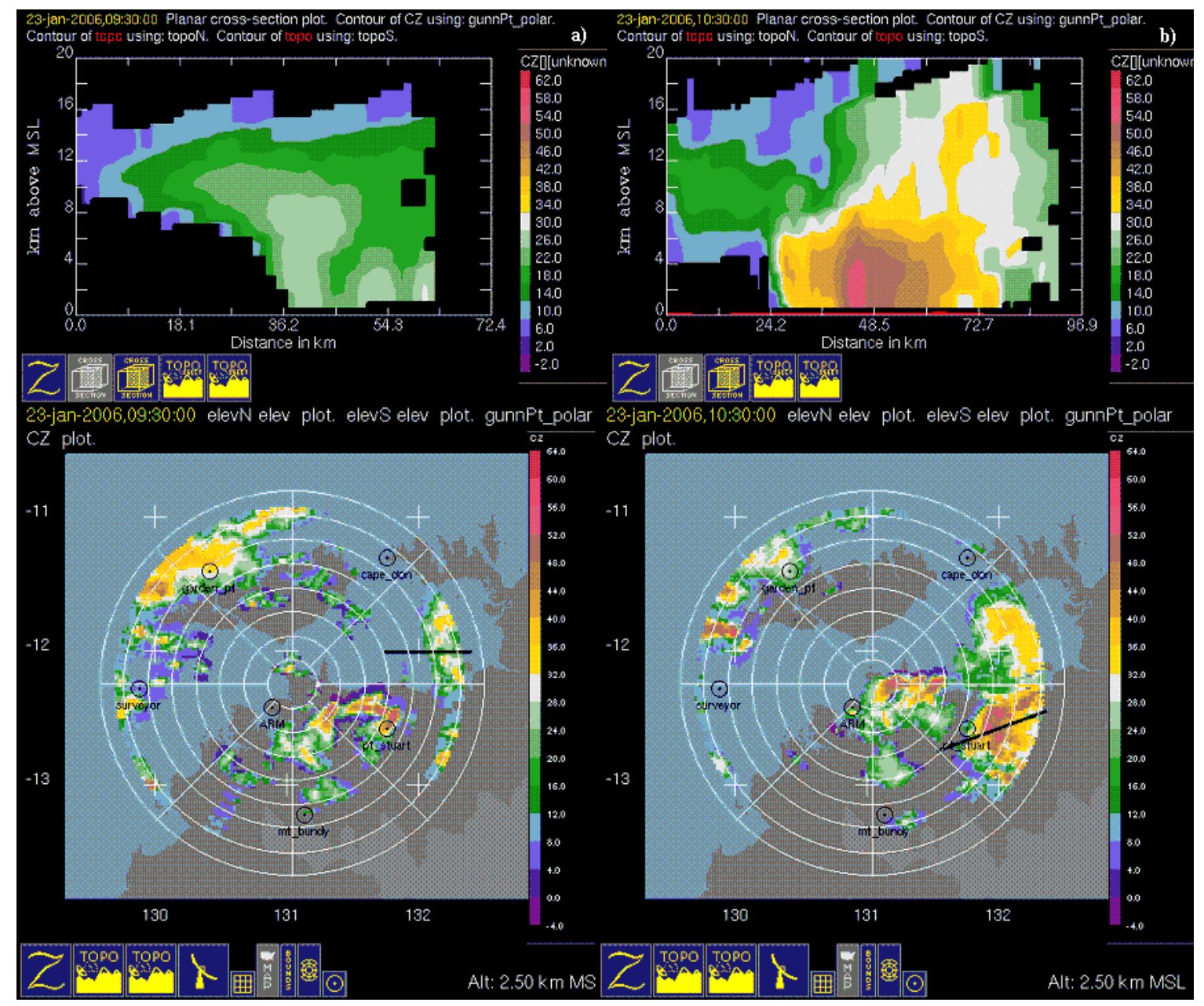

FIG. 11. C-POL horizontal and vertical cross sections on 23 January 2006 for a) ice anvil at 0930 UTC and b) mixed anvil at 1030 UTC. 
A large convective system was present in the western part of the radar domain at 0200 UTC on 24 January, which produced a large area of stratiform and convective rain. At 0600-0800 UTC, the system was progressing its way out of the radar domain (Fig. 12a and 12b). Even though most convection had moved out of the area by 1200 UTC (Fig 12c), Fig. 13 shows ice anvil covered 15-20\% of the radar domain for roughly ten hours (i.e., between 0500-1500 UTC). Mixed anvil was also present but covered a much smaller area. Ice anvil area began to taper off around 1500 UTC, just a few hours before new convection moved in from the west (Fig. 12d). This new system caused $~ 50 \%$ of the radar grid to be covered by stratiform rain with a concurrent peak in convective rain area (Fig. 13). The convective and stratiform rain area peaks were followed by first a peak in mixed anvil and then a peak in ice anvil at 2-3 hour intervals. These lags in area will be discussed in further detail in the discussion section. Anvil heights and thickness did not vary much on this day. Ice anvil mean height remained around 10-11 km while its thickness was about 4-5 km (Figs. 14 and 15a). Mixed anvil was 7 km thick on average throughout the day and had tops a little over $10 \mathrm{~km}$ (Figs. 14 and 15b). 


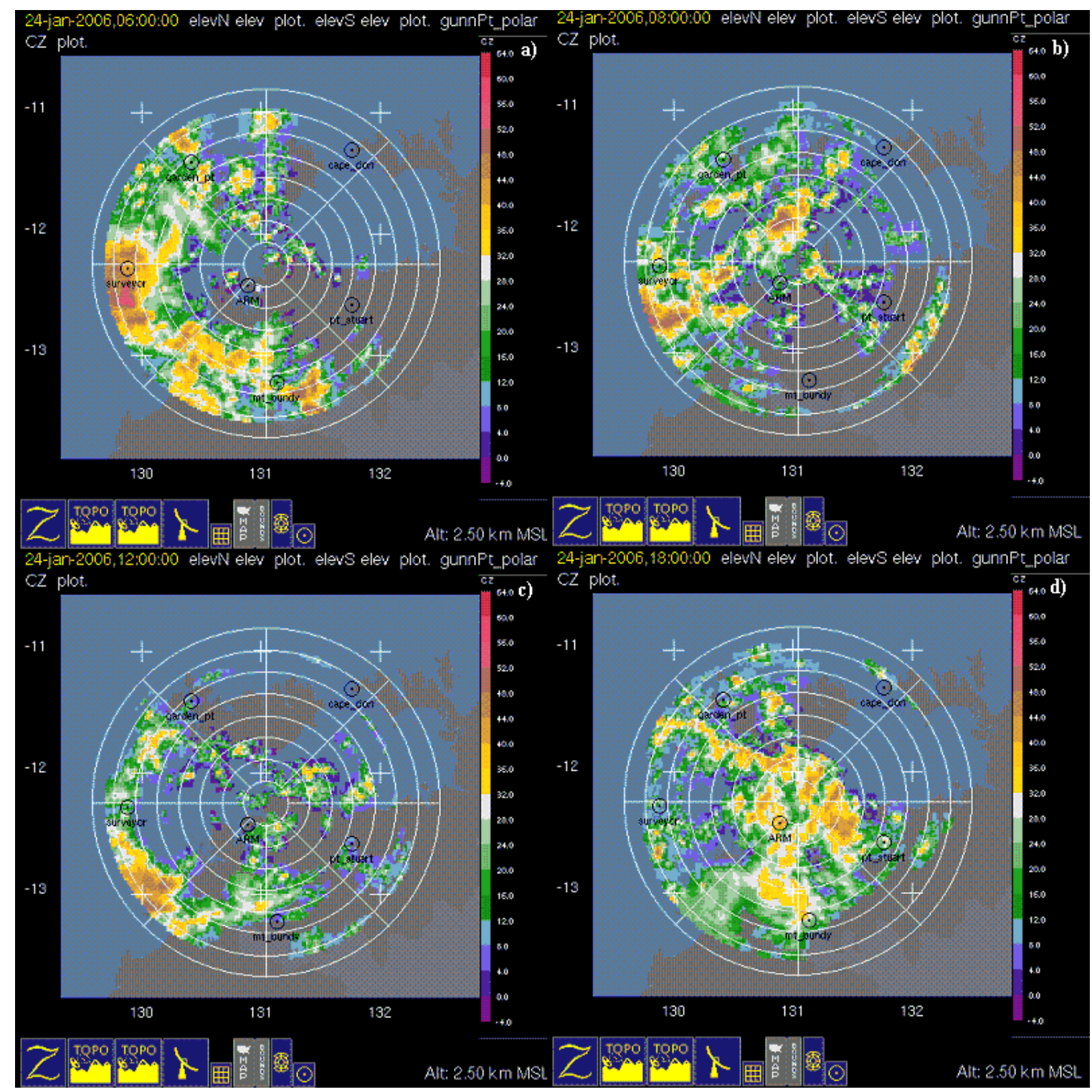

FIG. 12. C-POL horizontal cross sections at $2.5 \mathrm{~km}$ AMSL on 24 January 2006 at a) 0600 UTC, b) 0800 UTC, c) 1200 UTC, and d) 1800 UTC. 


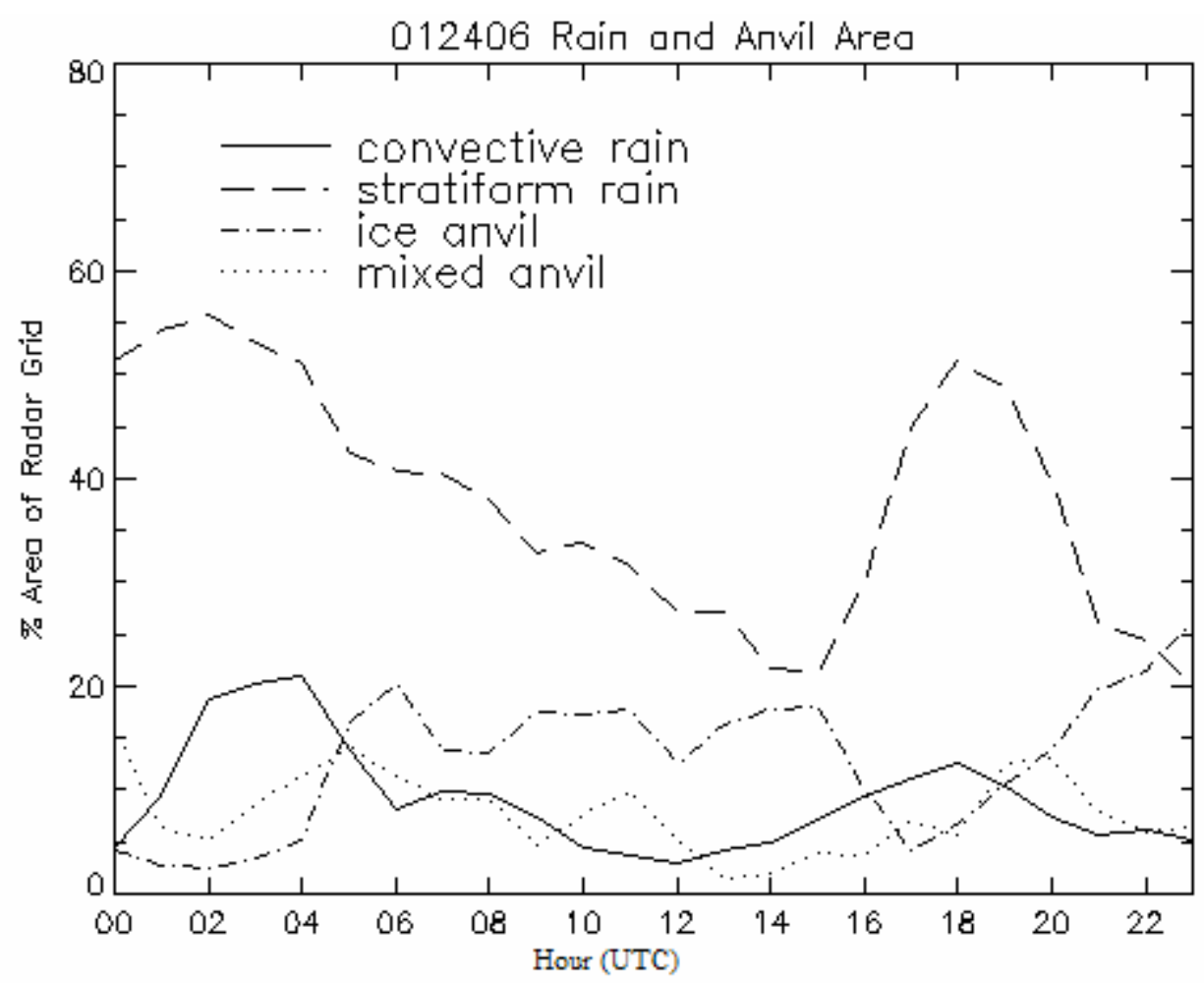

FIG. 13. Percentage of radar grid covered by rain and anvil on 24 January 2006.
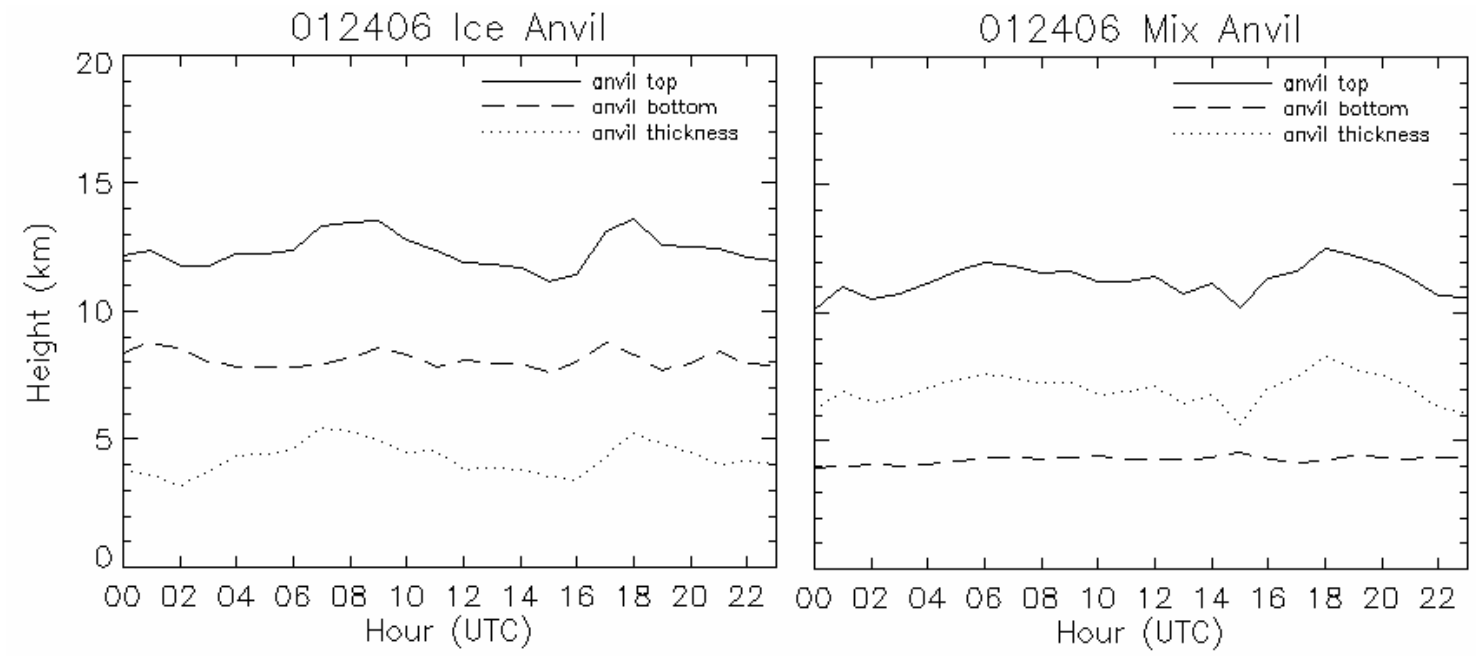

FIG. 14. Anvil top, bottom, and thickness on 24 January 2006. 


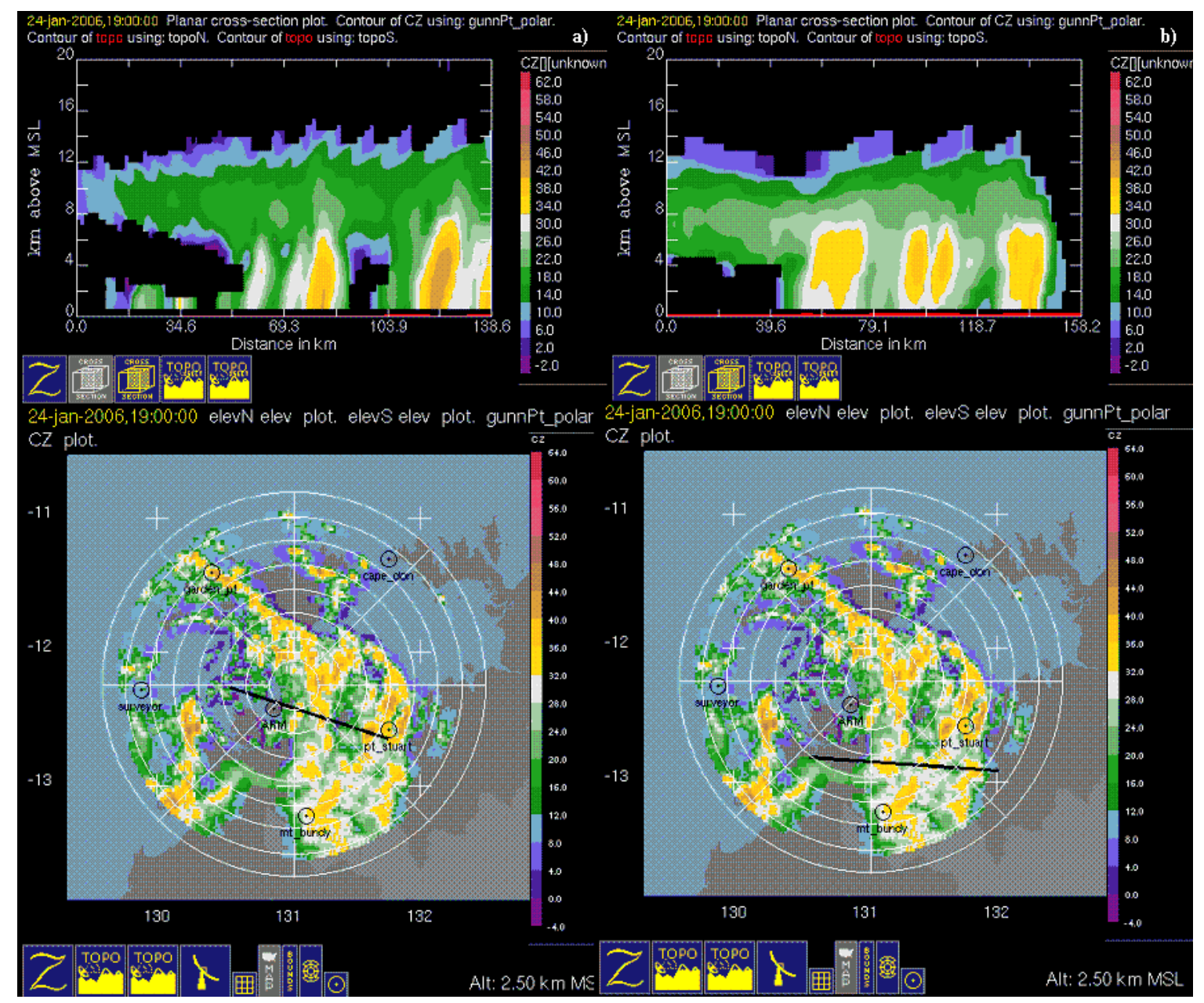

FIG. 15. C-POL horizontal and vertical cross sections on 24 January 2006 for a) ice anvil at 1900 and b) mixed anvil at 1900 .

\section{2) DRY MONSOON: JANUARY $31^{\text {st }} /$ FEBRUARY $1^{\text {st }}$}

Convective activity was more suppressed during this time period of strong

westerlies compared to the wet monsoon. Most of the convective activity on 31 January and 1 February came in the form of squall lines, as opposed to large MCSs. Four bowed squall lines moved eastward over the northern part of the radar domain between 1700 UTC and 0800 UTC. 
On 31 January (Fig. 16) very little echo covered the radar domain in comparison to the active regime. A weak peak in convective and stratiform rain area occurred at 0400 UTC (Fig. 17). Due to the shallow nature of the convection (most tops did not exceed $6 \mathrm{~km}$ ), little anvil was produced. However, anvil production increased later in the day when a series of squall lines moved through the domain. The edge of a squall line can be seen briefly in the radar domain at 1000 UTC, which caused a very subtle peak in anvil area (Figs. 16b and Fig. 17). At 1700 UTC, C-POL observed the southern end of a large squall line (Fig. 16d). At this time, there was a peak in convective and stratiform rain area, which was followed by a peak in both ice and mixed anvil at 1800 UTC (Fig. 17). Ice anvil reached its maximum thickness of $4 \mathrm{~km}$ for the day at this time (Figs. 18 and 19a), which is almost $2 \mathrm{~km}$ thicker than the average ice thickness for the dry monsoon period (Table 5). Mixed anvil was also thicker than average ( $7 \mathrm{~km}$ ) by about $1 \mathrm{~km}$ (Figs. 18 and 19b). The mean height of ice anvil was around 13-14 km. When mixed anvil was present its tops were $\sim 10 \mathrm{~km}$. 


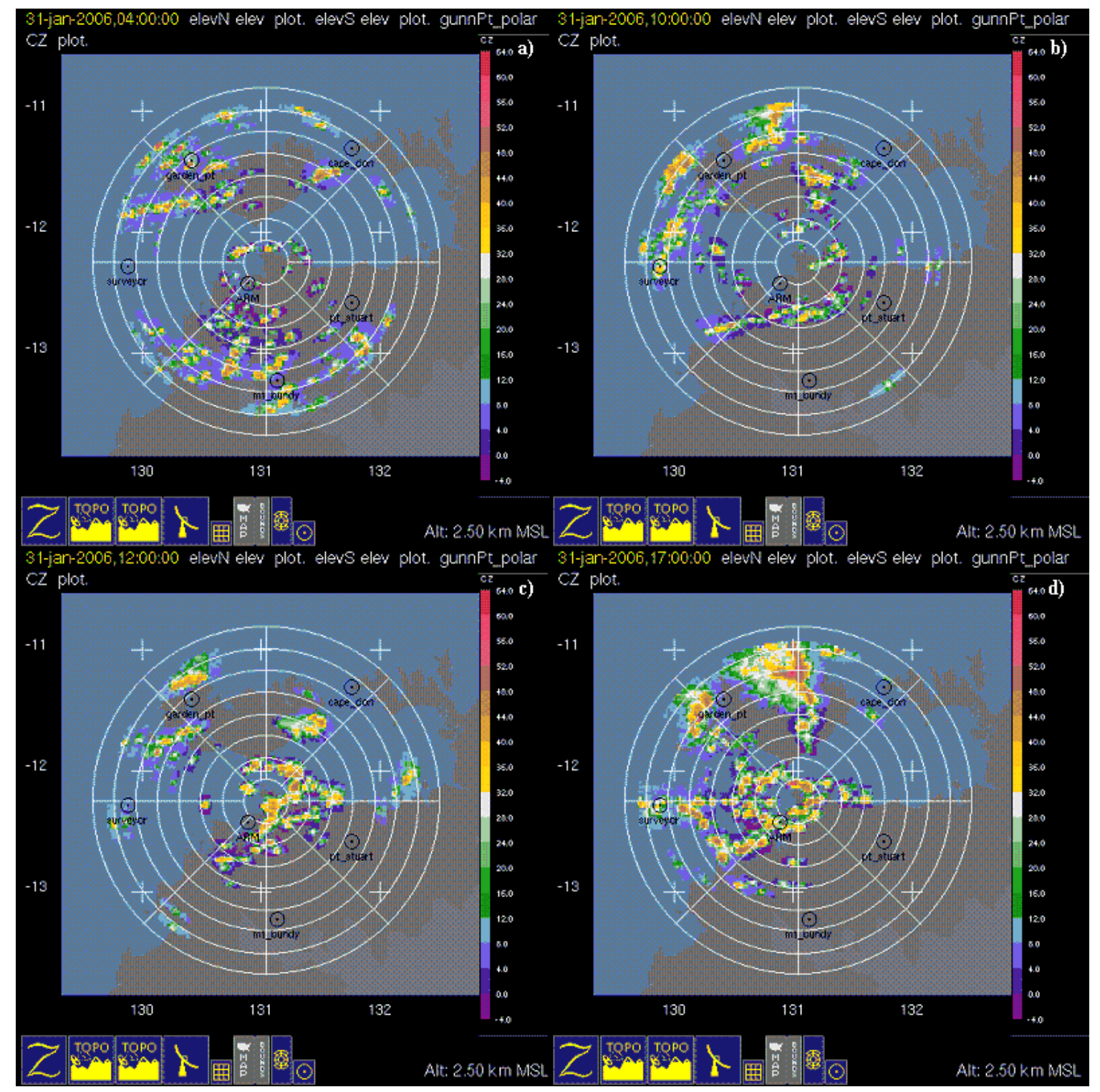

FIG. 16. C-POL horizontal cross sections at $2.5 \mathrm{~km}$ AMSL on 31 January 2006 at a) 0400 UTC, b) 1000 UTC, c) 1200 UTC, and d) 1700 UTC. 


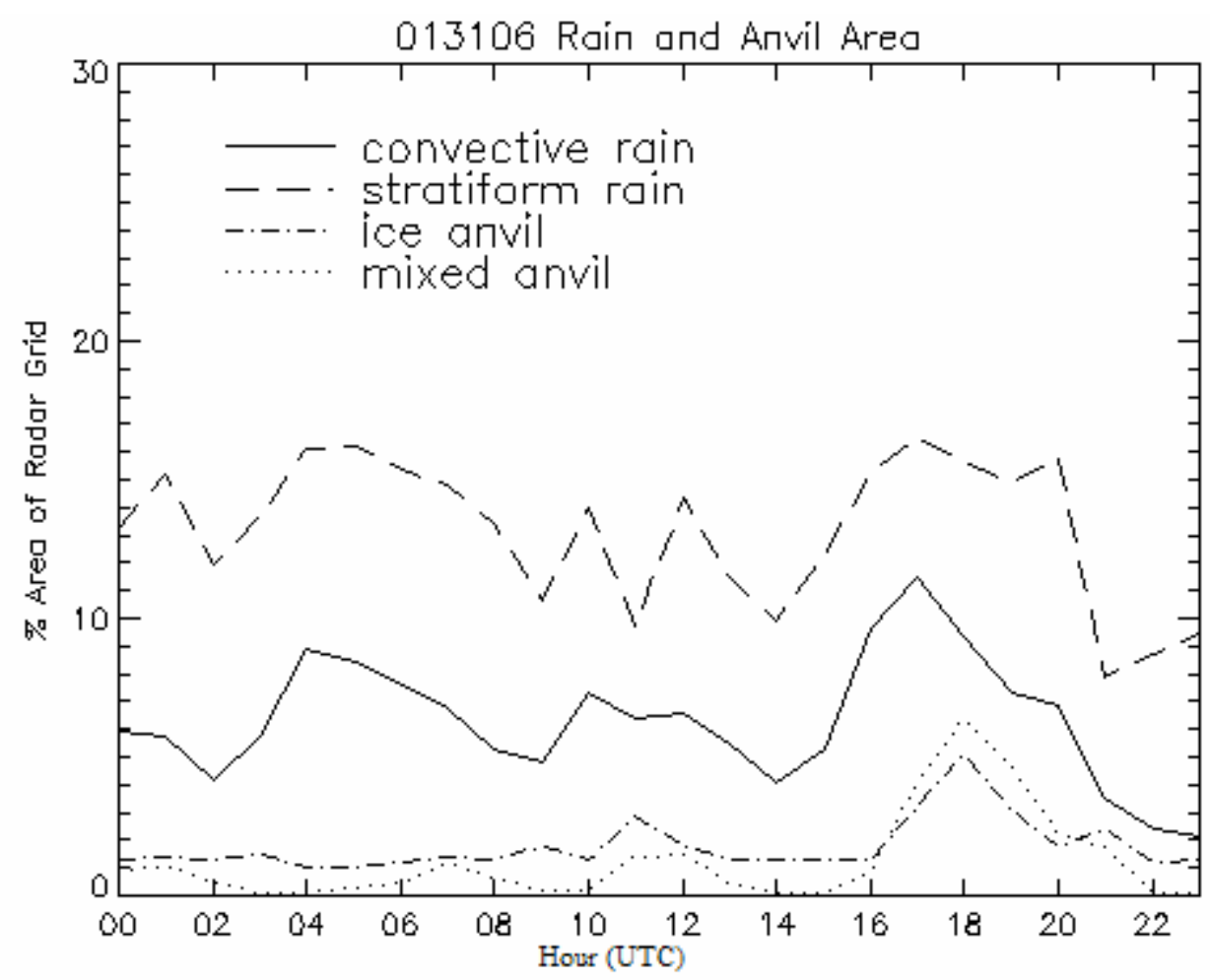

FIG. 17. Percentage of radar grid covered by rain and anvil on 31 January 2006.
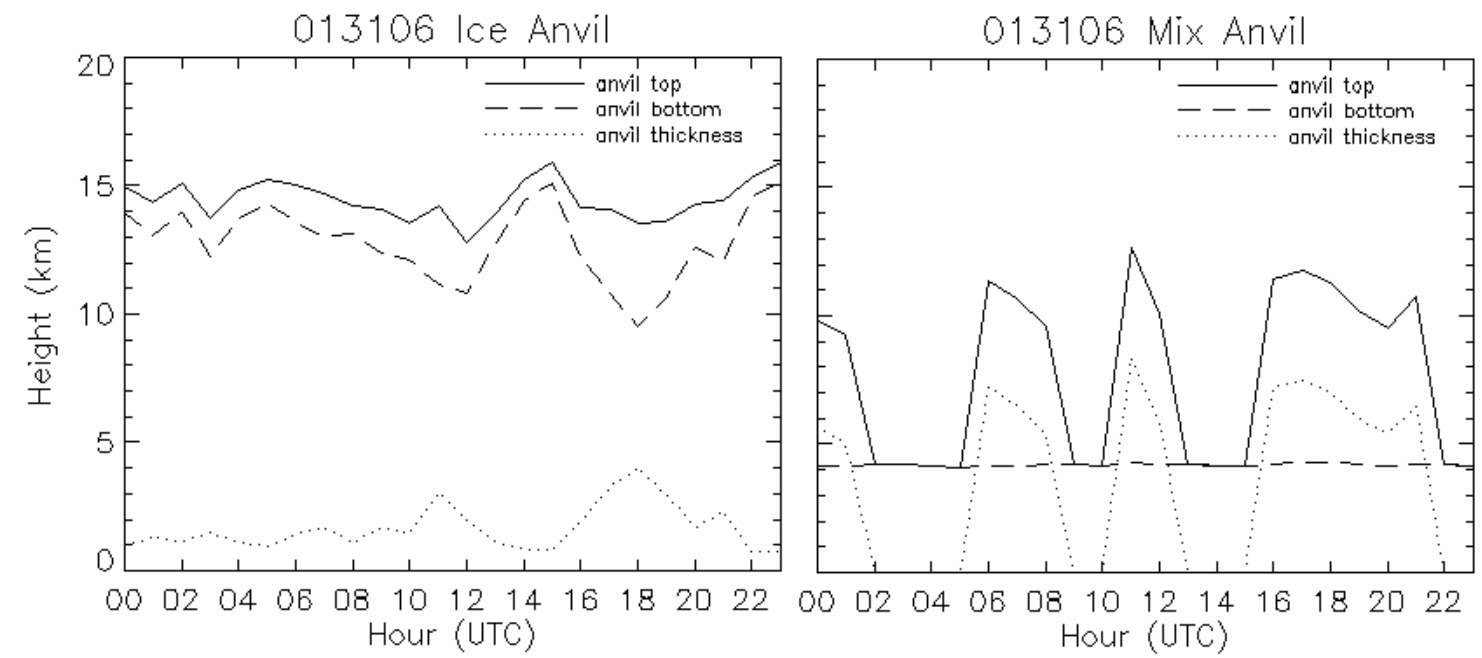

FIG. 18. Anvil top, bottom, and thickness on 31 January 2006. 


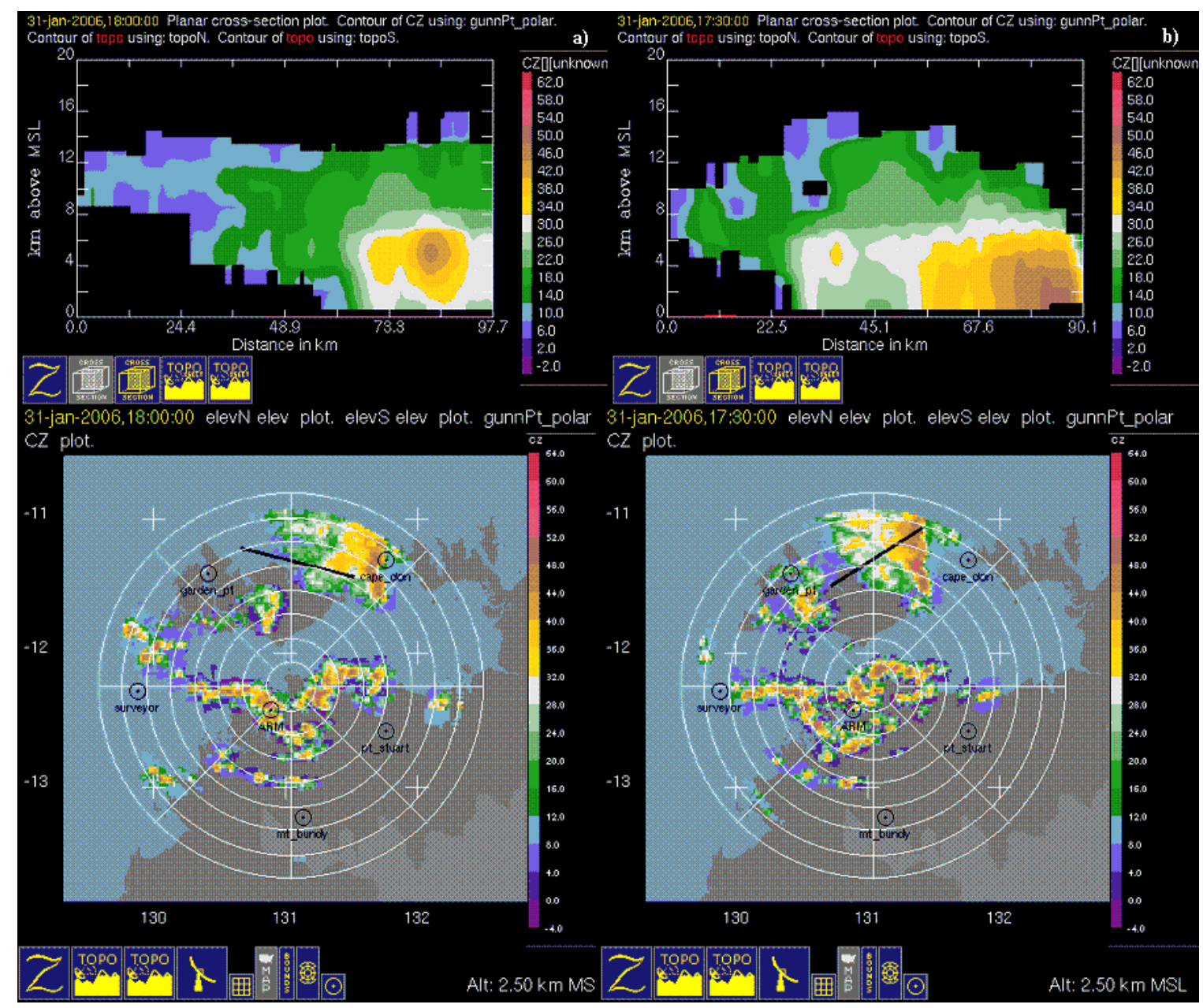

FIG. 19. C-POL horizontal and vertical cross sections on 31 January 2006 for a) ice anvil at 1800 and b) mixed anvil at 1730 .

A few hours later another squall line moved into the region with the majority of the line inside the domain (Fig. 20a). Convective rain area peaked on 1 February at 0200 UTC and the stratiform rain, mixed anvil, and ice anvil areas began to increase shortly these after (Fig. 21). Although ice anvil area was still relatively limited at this time, the ice anvil that was present increased in thickness up to $3 \mathrm{~km}$ (Fig. 22). Mixed anvil was consistently 5-6 km thick (Fig. 22). 


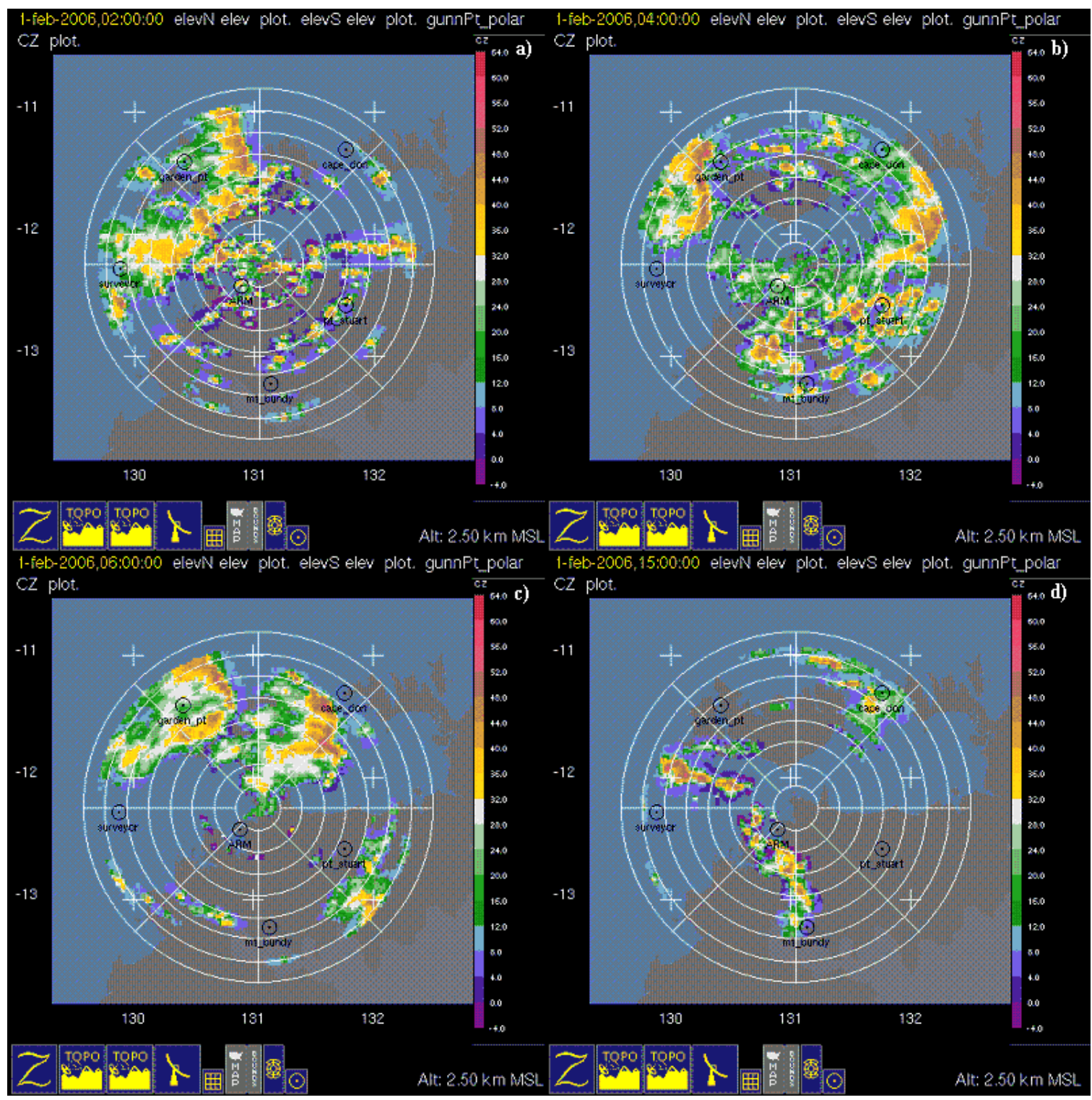

FIG. 20. C-POL horizontal cross sections at $2.5 \mathrm{~km}$ AMSL on 1 February 2006 at a) 0200 UTC, b) 0400 UTC, c) 0600 UTC, and d) 1500 UTC. 


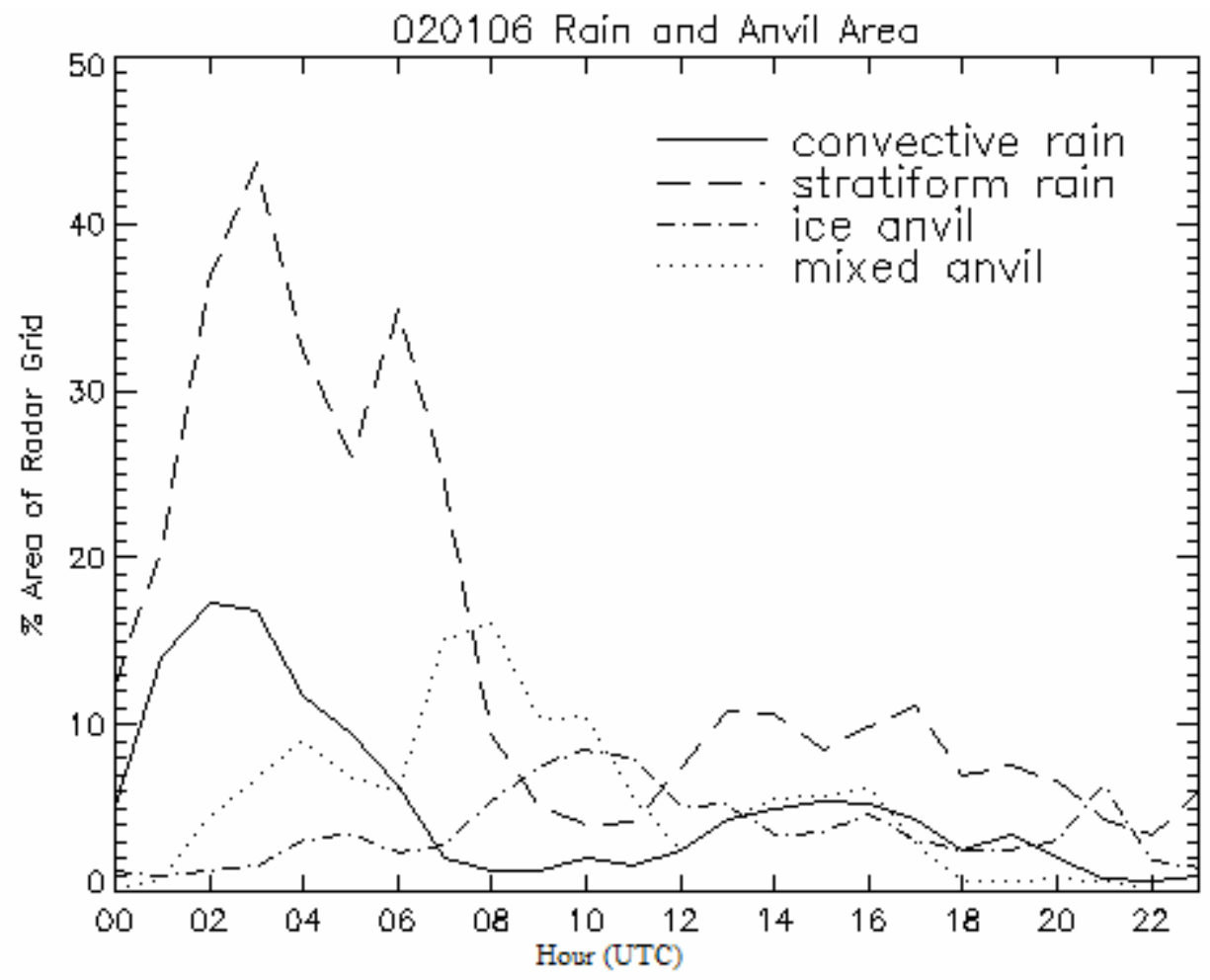

FIG. 21. Percentage of radar grid covered by rain and anvil on 1 February 2006.
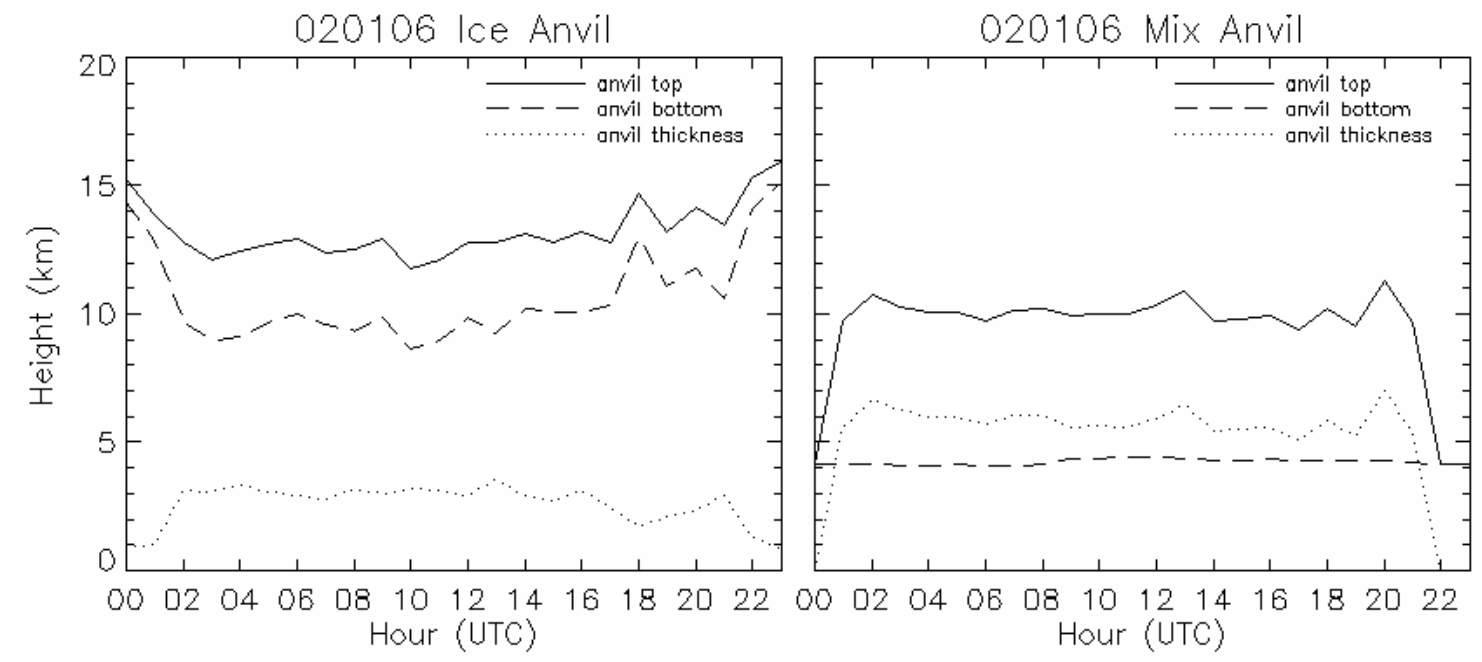

FIG. 22. Anvil top, bottom, and thickness on 1 February 2006. 
Stratiform rain area peaked at 0300 UTC (Fig. 21) as another line moved in from the west and the previous line became more stratiform in nature (Fig. 20b). A peak in mixed anvil area occurred shortly after the peak in stratiform rain area implying a link between stratiform rain and mixed anvil production. This same lag is seen again when the line that entered the radar domain at 0300 UTC moved through the northern part of the radar domain. Stratiform rain area peaked again at 0600 UTC (Fig. 20c), with a maximum in mixed anvil area lagging an hour to two hours behind followed by a peak in ice anvil at 1000 UTC (Fig. 21). As stated before, this lag will be elaborated on in the discussion section of this paper.

By 0800 UTC convection was well on its way out of the radar domain. The series of squall lines left a good portion of anvil in the atmosphere. Total anvil area coverage of $10-20 \%$ lasted for about 4 hours after the last squall line had gone through the radar domain (Fig. 21). Although the coverage was smaller (5-10\%), anvil was still present until 1600 UTC when most of the anvil had either advected off the domain or dissipated. Ice anvil mean height was around $11-12 \mathrm{~km}$ and thickness was around $3 \mathrm{~km}$ on this day with little variation (Figs. 22 and 23a). Mixed anvil top height was also steady with an average height around $10 \mathrm{~km}$ and thickness around $6 \mathrm{~km}$ (Figs. 22 and 23b). 


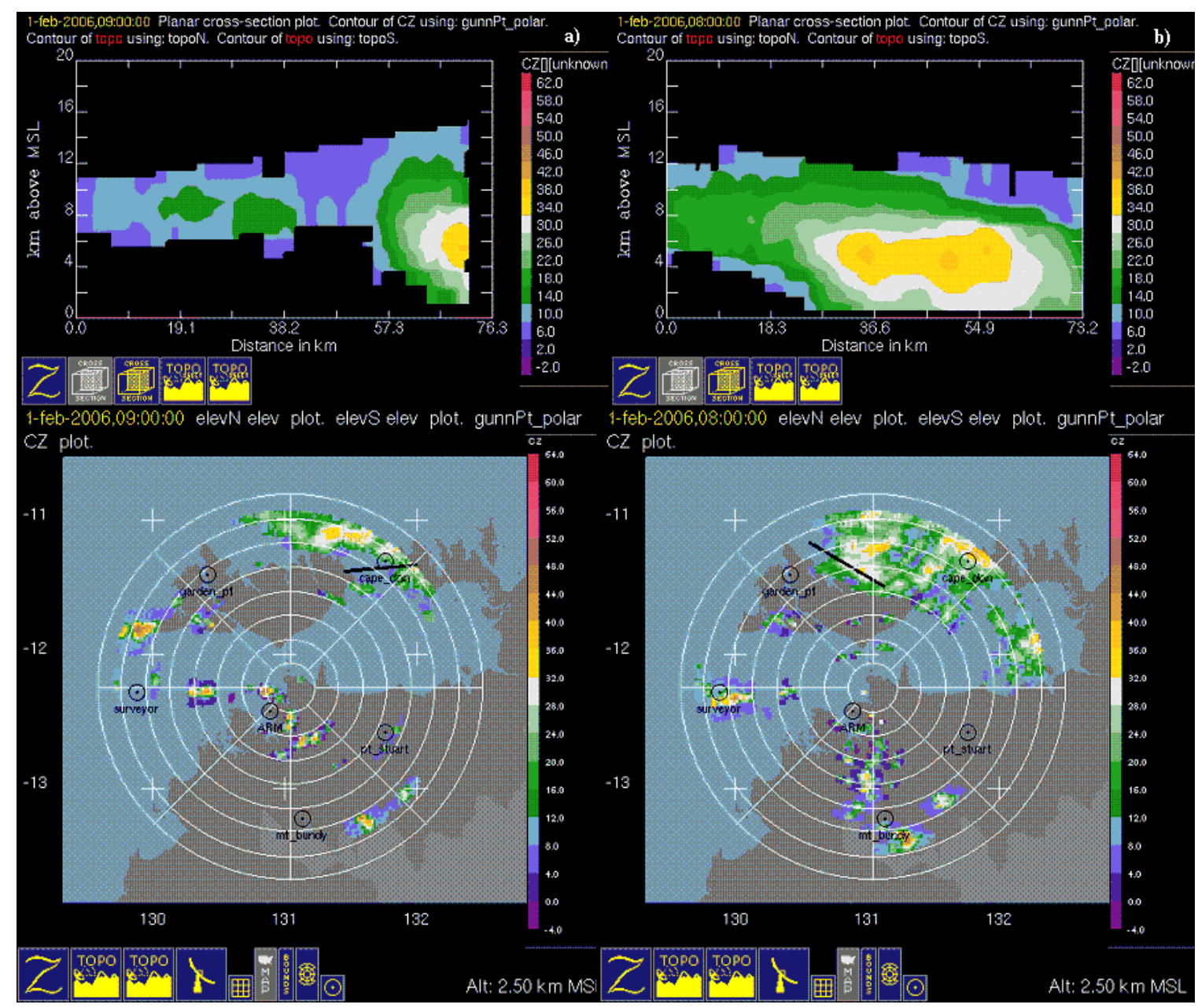

FIG. 23. C-POL horizontal and vertical cross sections on 1 February 2006 for a) ice anvil at 0900 and b) mixed anvil at 0800 .

3) BREAK PERIOD: FEBRUARY $10^{\text {th }} / 11^{\text {th }}$

Ten and 11 February experienced times of moderate convective activity which is typical for the break period. Hectors, defined as convection forming over the Tiwi Islands in the afternoon, were common during the break period. In addition to Hectors, convective activity came in the form of two squall lines that moved westward across the radar domain on 10 February and another line that came across later on 11 February. The 
convection on these days appeared to be more favorable for ice anvil production than during the other two periods.

The first peak in convective area was associated with a Hector that formed around 0600 UTC on 10 February (Figs. 24a and 25). Ice anvil thickness had increased to $5 \mathrm{~km}$ by $0700 \mathrm{UTC}$, which is about 2.5 kilometers above average for this regime and $2.2 \mathrm{~km}$ above the experiment average (Table 4). Ice anvil stayed at this average thickness for several hours (Figs. 26 and 27a). As the ice anvil thickness increased, the ice anvil also began to sink, which will be discussed further in the discussion. Even

Table 4 Average values for anvil properties during TWP-ICE.

\begin{tabular}{|lrr|}
\hline Thickness & Ice & Mixed \\
Experiment & 2.8 & 6.7 \\
Active & 4.0 & 6.6 \\
Dry & 2.1 & 6.1 \\
Break & 2.5 & 7.6 \\
Top & & \\
Experiment & 14.5 & 10.9 \\
Active & 12.4 & 10.8 \\
Dry & 14.9 & 10.3 \\
Break & 15.5 & 11.8 \\
Bottom & & \\
Experiment & 11.7 & 4.2 \\
Active & 8.4 & 4.2 \\
Dry & 12.7 & 4.2 \\
Break & 12.9 & 4.2 \\
Height & & \\
Experiment & 13.1 & 7.5 \\
Active & 10.4 & 7.5 \\
Dry & 13.8 & 7.3 \\
Break & 14.2 & 8.0 \\
\hline
\end{tabular}


though mixed anvil area was low, the mixed anvil that was present was unusually thick at $10 \mathrm{~km}$ (Figs. 26 and 27b), which is about $5 \mathrm{~km}$ above average for the break period (Table 4). Mixed anvil tops reached $15 \mathrm{~km}$ during this time.

Around 0800 UTC, the Hector convection weakened and moved northwestward (Fig. 24b). By 1100 UTC a convective system with a large stratiform region had moved into the radar domain from the south (Figs. 24c and 25). Within a couple of hours this squall line produced a very large area of both mixed and ice anvil (Fig. 25). Not only was the anvil large in areal extent, but it was quite thick for this regime (Fig. 26). Despite the anvil's thickness, it was not as long lived as in the active monsoon case and dissipated within approximately 4 hours after the initial peak in rain production. This shorter lifetime could be due to the upper atmosphere being drier during this regime or that there was simply less hydrometeors lofted into the atmosphere by this type of convection (e.g., because of shorter-lived convection or convection with a higher precipitation efficiency). 


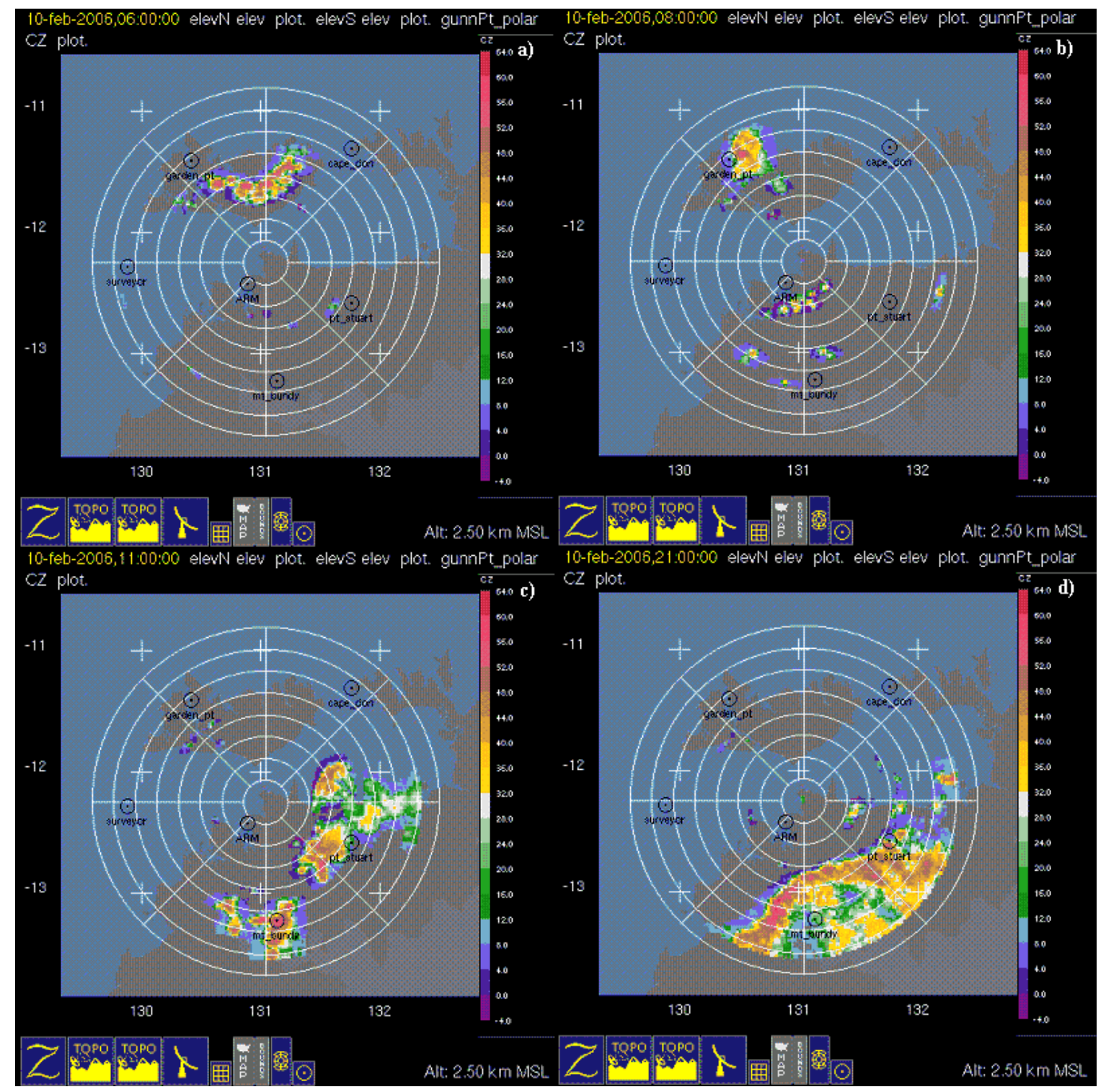

FIG. 24. C-POL horizontal cross sections at $2.5 \mathrm{~km}$ AMSL on 10 February 2006 at a) 0600 UTC, b) 0800 UTC, c) 1100 UTC, and d) 2100 UTC. 


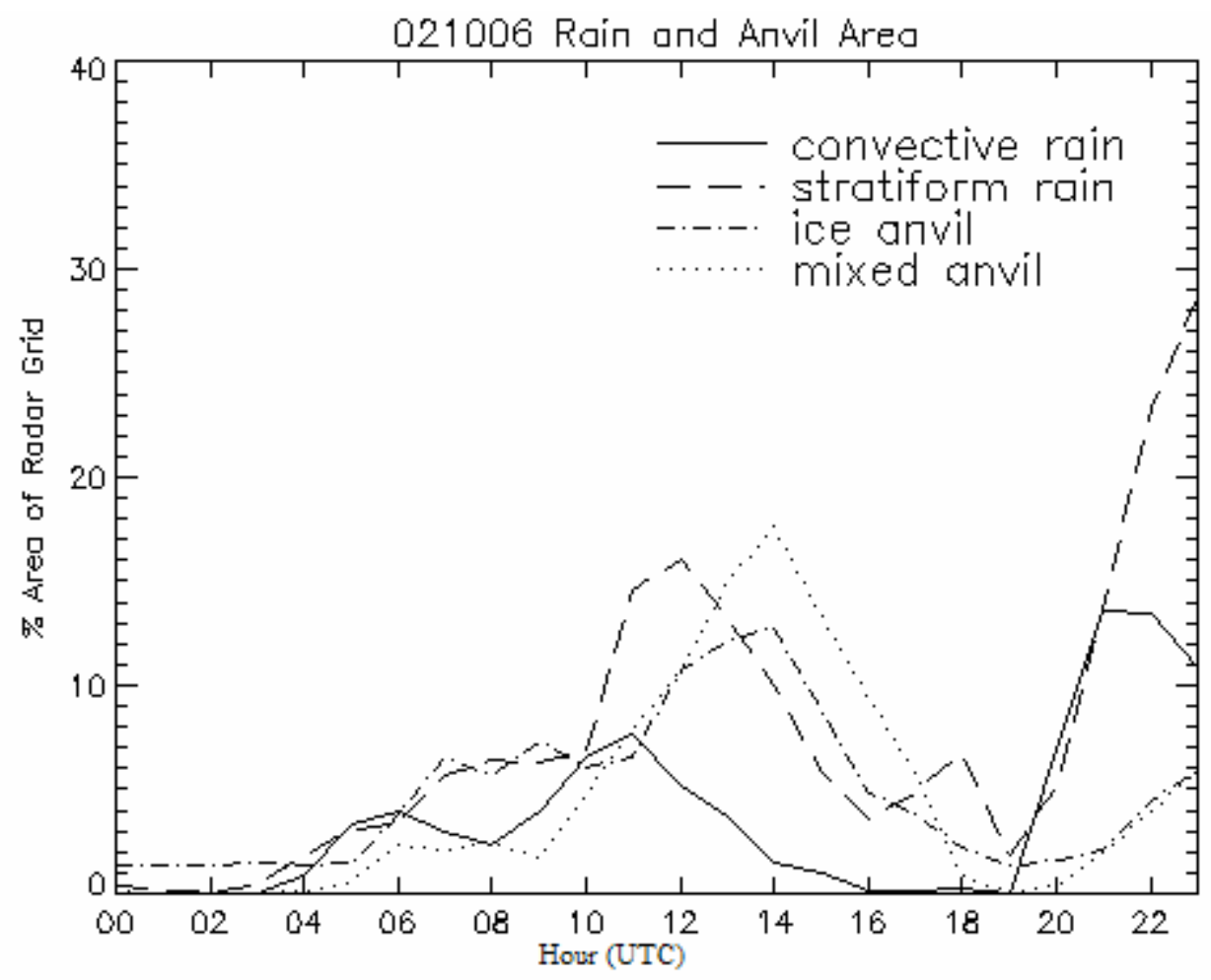

FIG. 25. Percentage of radar grid covered by rain and anvil on 10 February 2006.
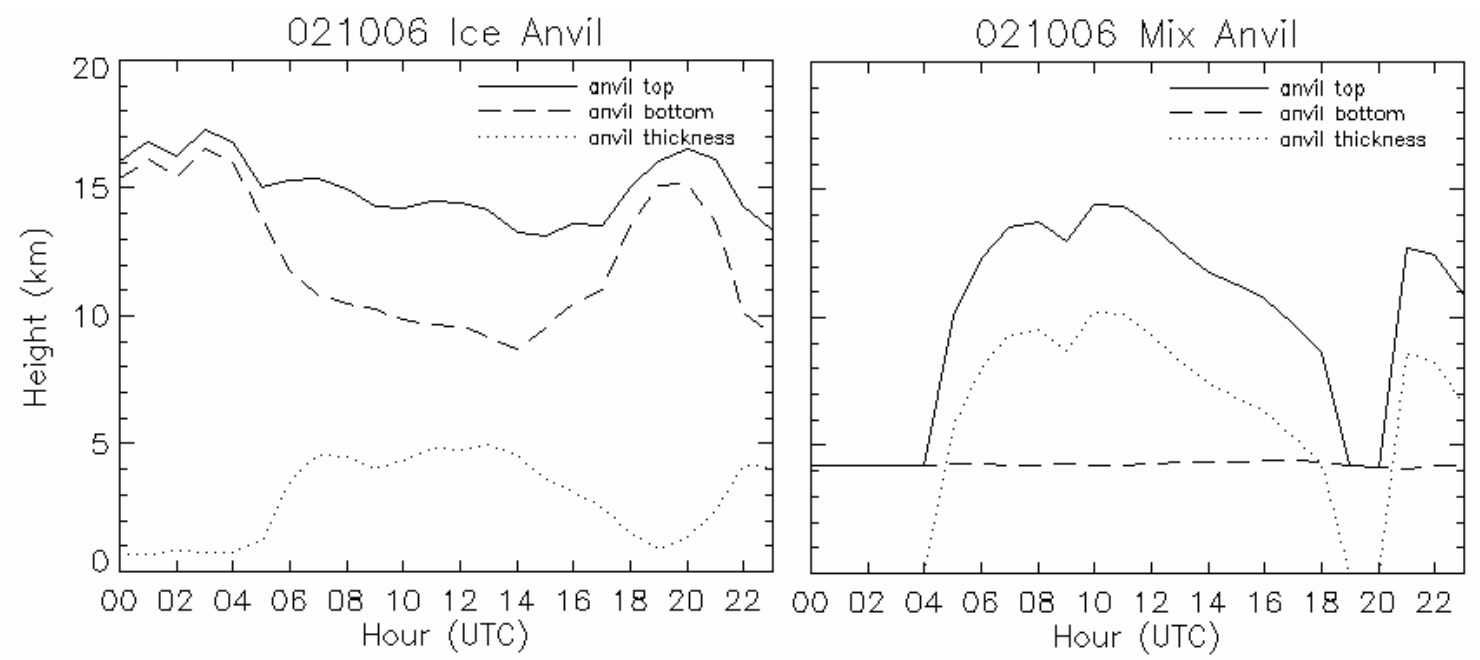

FIG. 26. Anvil top, bottom, and thickness on 10 February 2006. 


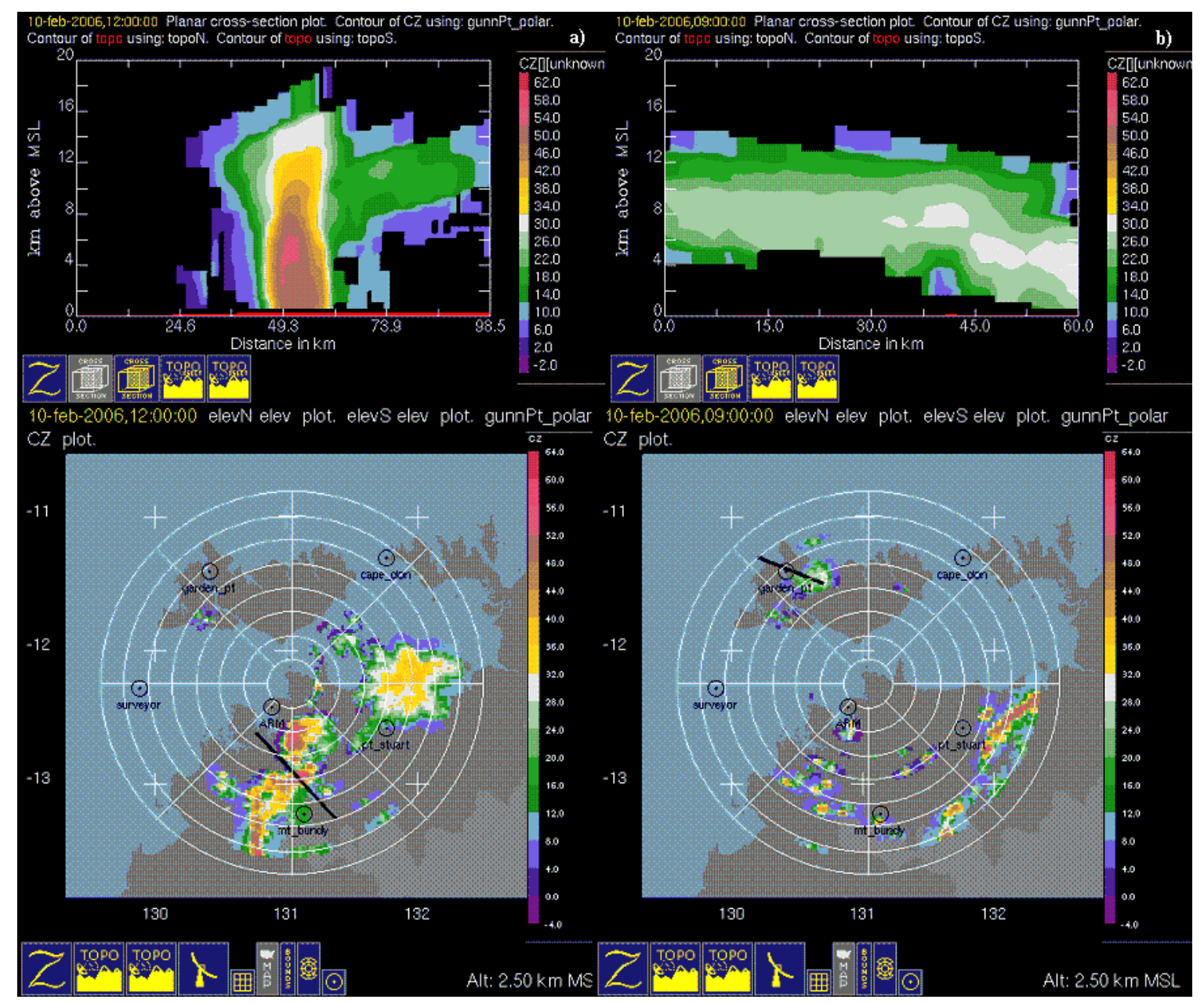

FIG. 27. C-POL horizontal and vertical cross sections on 10 February 2006 for a) ice anvil at 1200 and b) mixed anvil at 0900 .

The second squall line moved through the radar domain around 2100 UTC (Fig.

24d). Figure 25 shows a peak in convective rain area followed by a larger peak in

stratiform area a couple hours later. The squall line left some ice anvil behind, but mixed 
anvil was gone by 0300 UTC. The ice anvil that was produced from this system exhibited an increase in thickness around 0300 UTC, but only lasted about an hour or two before being advected off the radar domain or dissipating.

Small, brief convective cells punctured the radar domain at 0700 and 1300 UTC on 11 February (Figs. 28a and 28b) and were accompanied by small peaks in ice anvil coverage (Fig. 29). Around 1800 UTC another squall moved through the northern part of the radar domain (Fig. 28c). This line quickly produced a large area of 5-km thick ice anvil (Figs. 29, 30, and 31a). Mixed anvil was 9 km thick (Fig. 30 and 31b). Mixed anvil area increased steadily as the convective region outran the stratiform rain area (Fig. 29). The anvil produced from this line remained in the radar domain much longer than the previous squall line. Anvil can be seen in the radar domain until 0200 UTC February 2, 2006. Anvil heights and thickness on this day were highly variable. By 1800 UTC both mixed and ice anvil showed signs of sinking. 


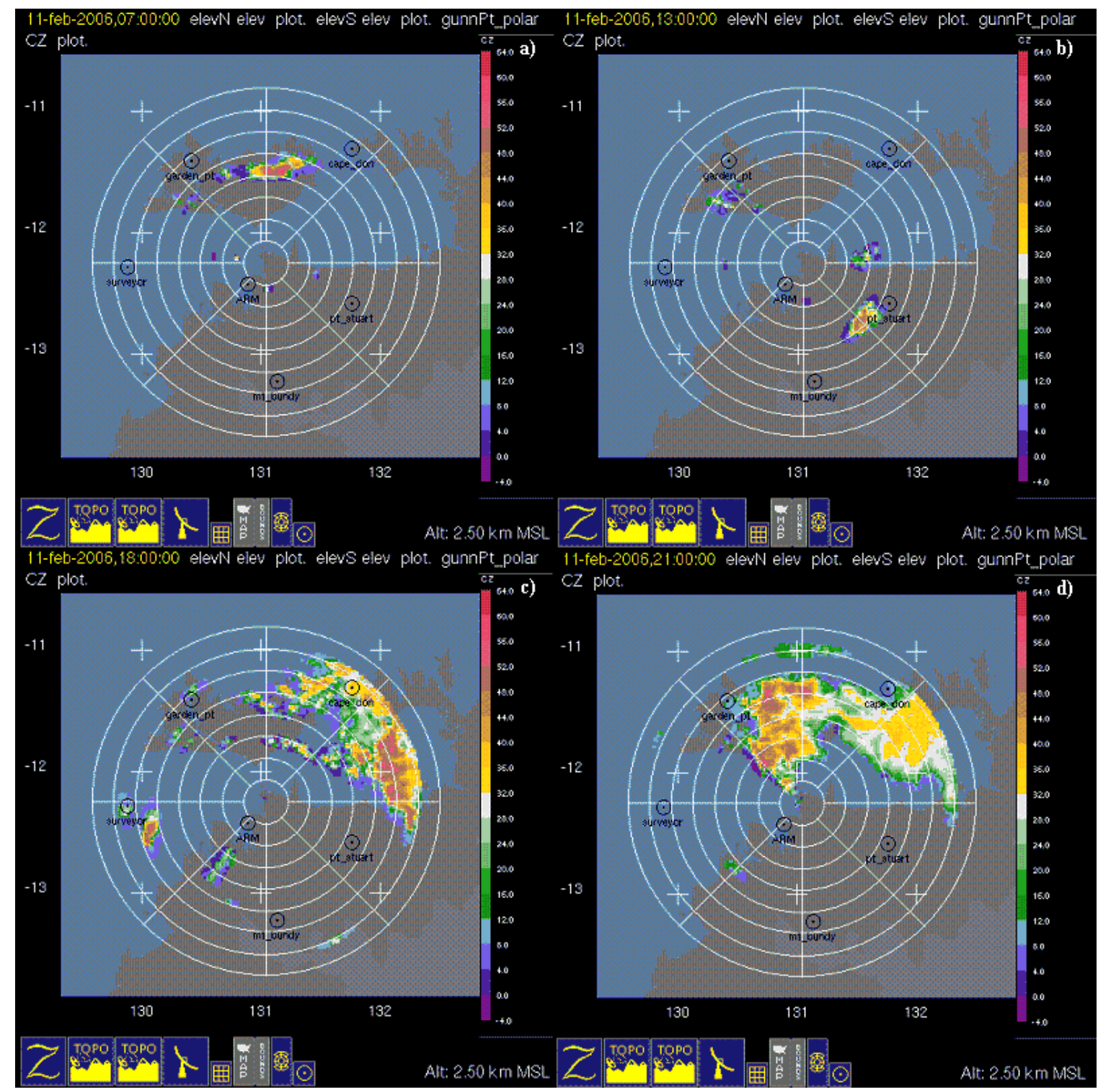

FIG. 28. C-POL horizontal cross sections at $2.5 \mathrm{~km}$ AMSL on 11 February 2006 at a) 0700 UTC, b) 1300 UTC, c) 1800 UTC, and d) 2100 UTC. 


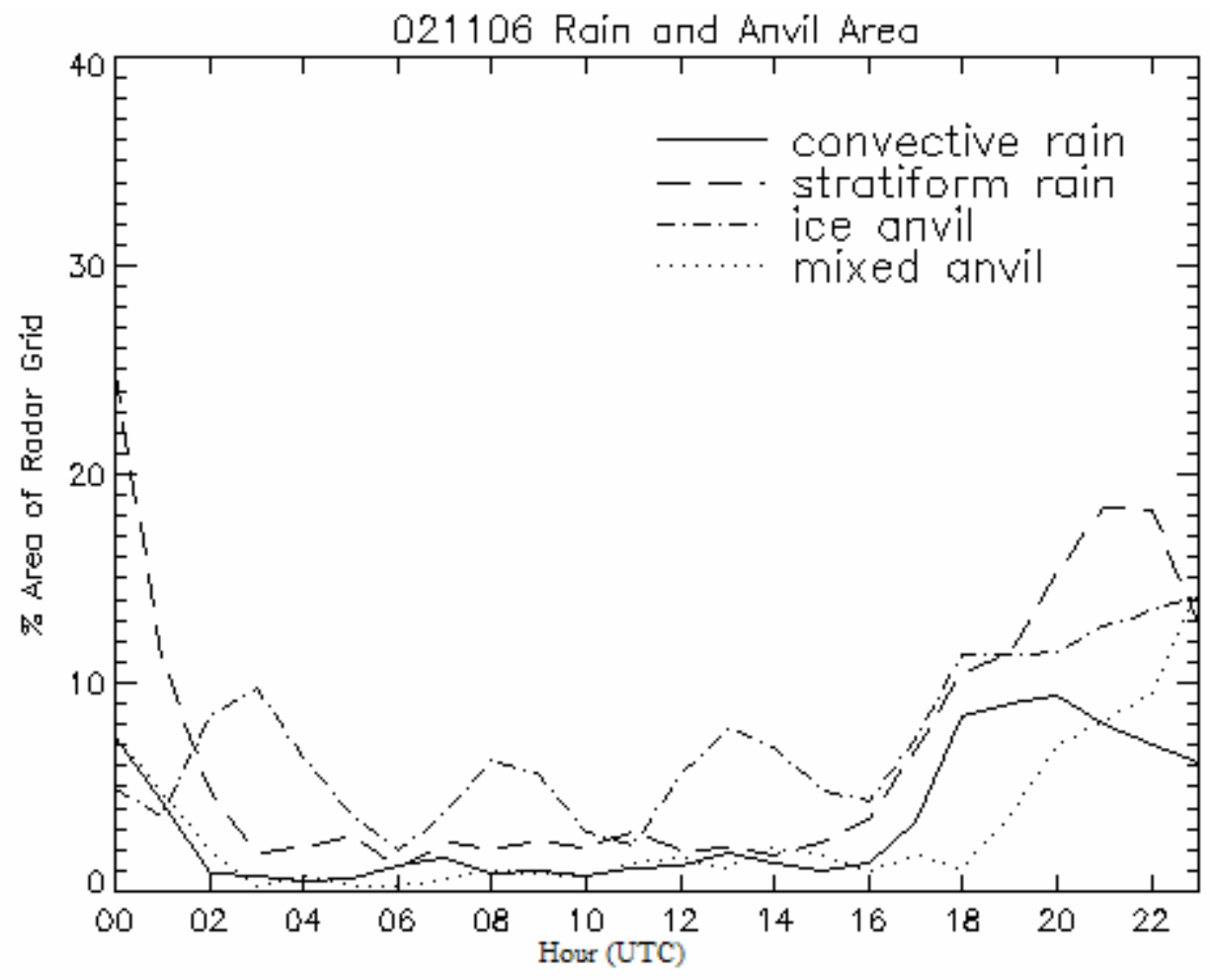

FIG. 29. Percentage of radar grid covered by rain and anvil on 11 February 2006.

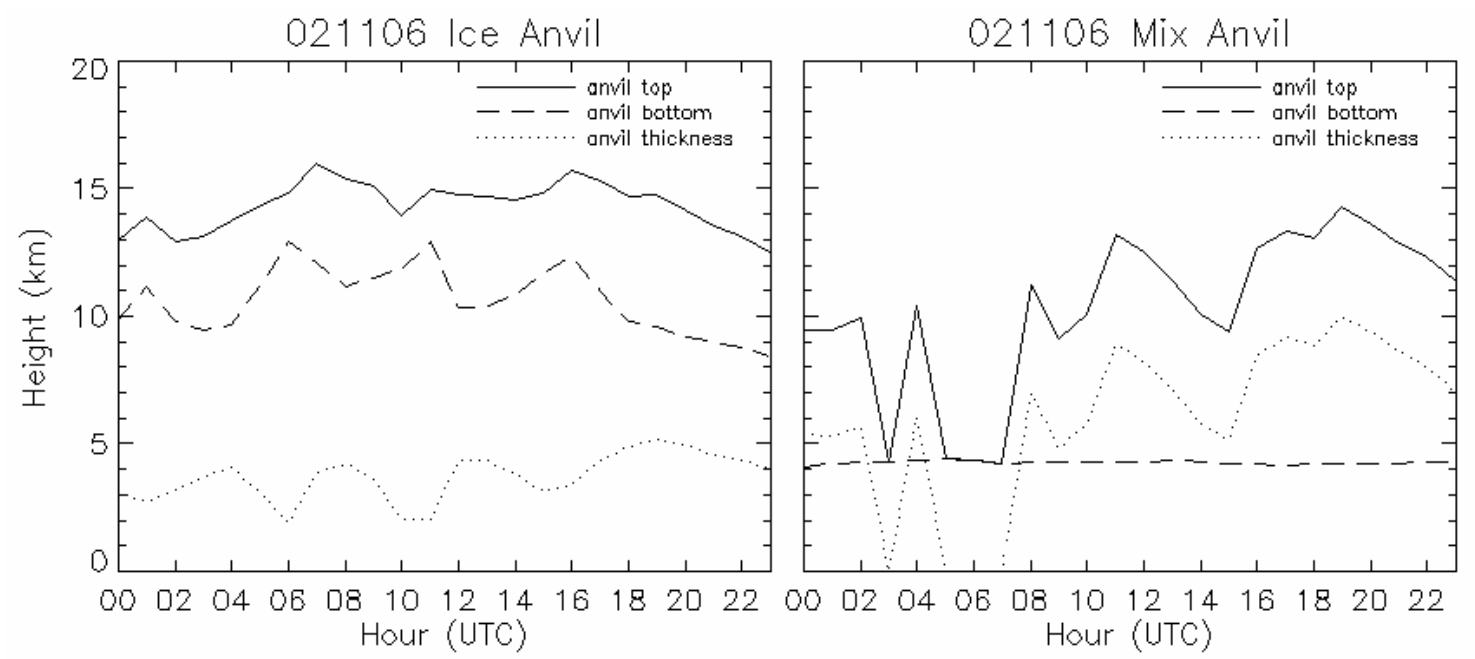

FIG. 30. Anvil top, bottom, and thickness on 11 February 2006. 


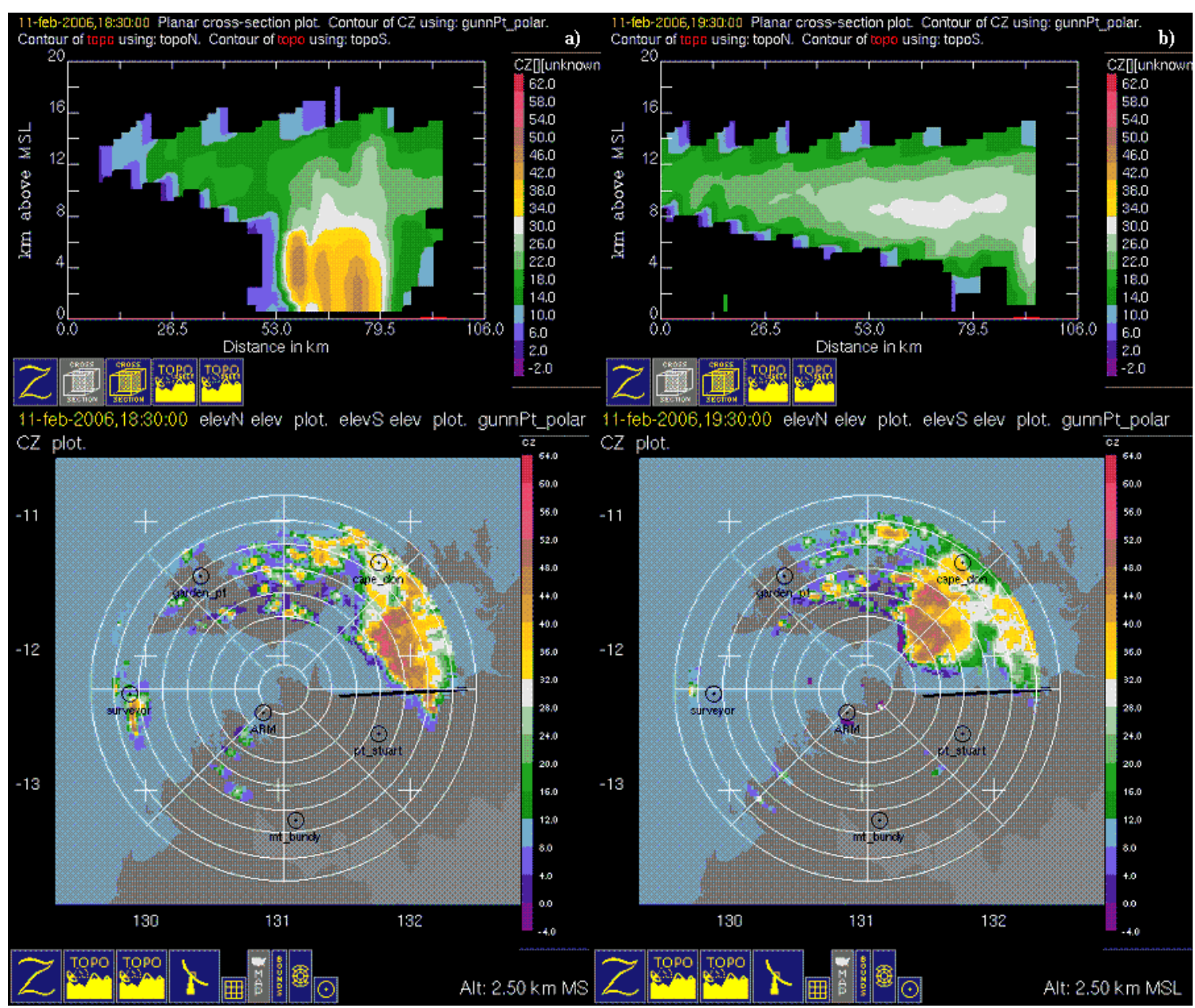

FIG. 31. C-POL horizontal and vertical cross sections on 11 February 2006 for a) ice anvil at 1830 and b) mixed anvil at 1930 .

\section{b. Entire field experiment}

1) RAIN AND ANVIL AREA RESULTS

The percent of the radar grid covered by ice anvil, mixed anvil, convective rain and stratiform rain during TWP-ICE is shown in Table 5. The table is also broken down by regime. The experiment average of area coverage for both anvil types and the 
convective rain category was between $4-5 \%$, whereas stratiform rain covered $15 \%$ of the radar grid on average.

Table 5 Average percent of the radar grid area covered during TWP-ICE.

\begin{tabular}{|lrrrrr|}
\hline Area (\%) & Ice & Mixed & Convective & Stratiform & Total \\
Experiment & 4.0 & 4.8 & 4.4 & 14.9 & 28.2 \\
Active & 7.6 & 15.6 & 8.6 & 33.2 & 65.0 \\
Dry & 2.1 & 1.3 & 3.9 & 11.9 & 19.3 \\
Break & 3.6 & 1.7 & 2.2 & 5.6 & 13.0 \\
\hline
\end{tabular}

The most coverage from all echo types occurred during the active period, which can also be seen in the time series in Fig. 32. During this period, ice anvil, convective rain, and stratiform rain area doubled compared to the overall experiment averages, while the mixed anvil area tripled. During the active phase, mixed anvil covered $15.6 \%$ of the radar grid, while ice anvil covered $7.6 \%$ of the grid (Table 5). The large coverage of mixed anvil is probably linked to the significant amount of stratiform rain production during the active monsoon. 


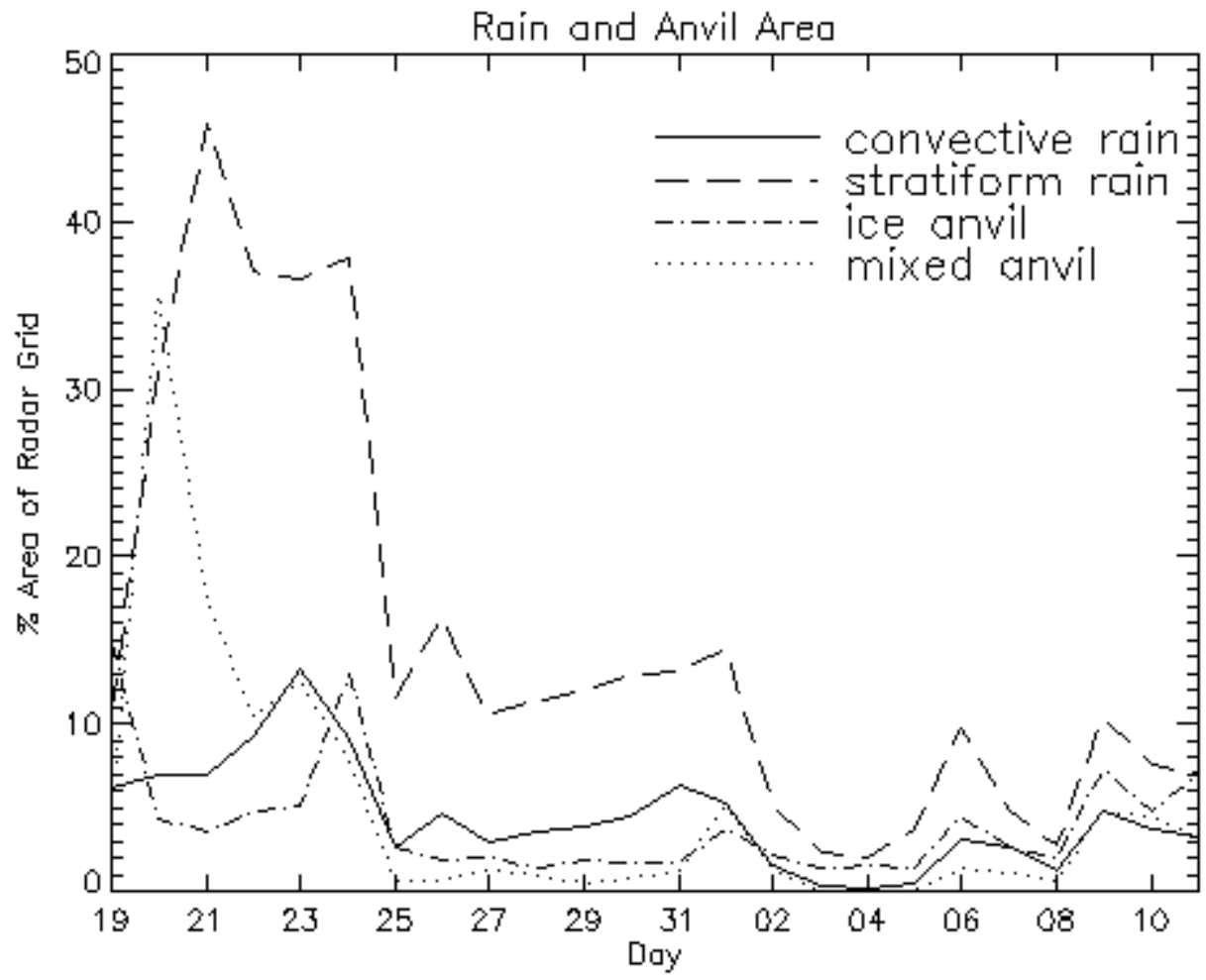

FIG. 32. Percentage of radar grid covered by rain and anvil for the whole TWP-ICE time period.

During the dry monsoon and break period, stratiform rain production was not as dominant and ice anvil covered 1-2\% more of the radar grid than mixed anvil. The anvil area was smallest during the dry period; ice anvil averaged $2.1 \%$ and mixed anvil averaged $1.3 \%$. During the break period, the ice anvil area remained close to the experiment average of 3.6\% while the mixed anvil area (1.7\%) and convective and stratiform rain areas (2.2\% and 5.6\%) decreased substantially, implying that smaller convective systems were producing proportionally large amounts of ice anvil. 


\section{2) ANVIL HEIGHT AND THICKNESS STATISTICS}

Table 4 shows the average values of anvil thickness, top, bottom, and mean height during the whole experiment and also broken down by regime. The experiment average of ice anvil thickness was $2.8 \mathrm{~km}$. For mixed anvil, the experiment average was $6.7 \mathrm{~km}$. During the active monsoon, ice anvil was much thicker and lower in height on average than during the dry monsoon and break period (Fig. 33). The average thickness for ice anvil during the active monsoon was $4 \mathrm{~km}$, compared to 2.1 and $2.5 \mathrm{~km}$ during the dry monsoon and break period, respectively (Table 4). The average height for ice anvil during the active monsoon was $10.4 \mathrm{~km}$, which was lower than dry monsoon and break period mean heights of 13.8 and $14.2 \mathrm{~km}$. Although ice anvil characteristics between the active and dry monsoon are different, mixed anvil during these two time periods show similar characteristics (Fig. 33). The average thickness during these two time periods only differed by $0.5 \mathrm{~km}$ and average heights only differed by $0.2 \mathrm{~km}$ (Table 4). The mixed anvil during the break period was $1-1.5 \mathrm{~km}$ thicker and $\sim 0.5 \mathrm{~km}$ higher compared to the active and dry monsoon. 

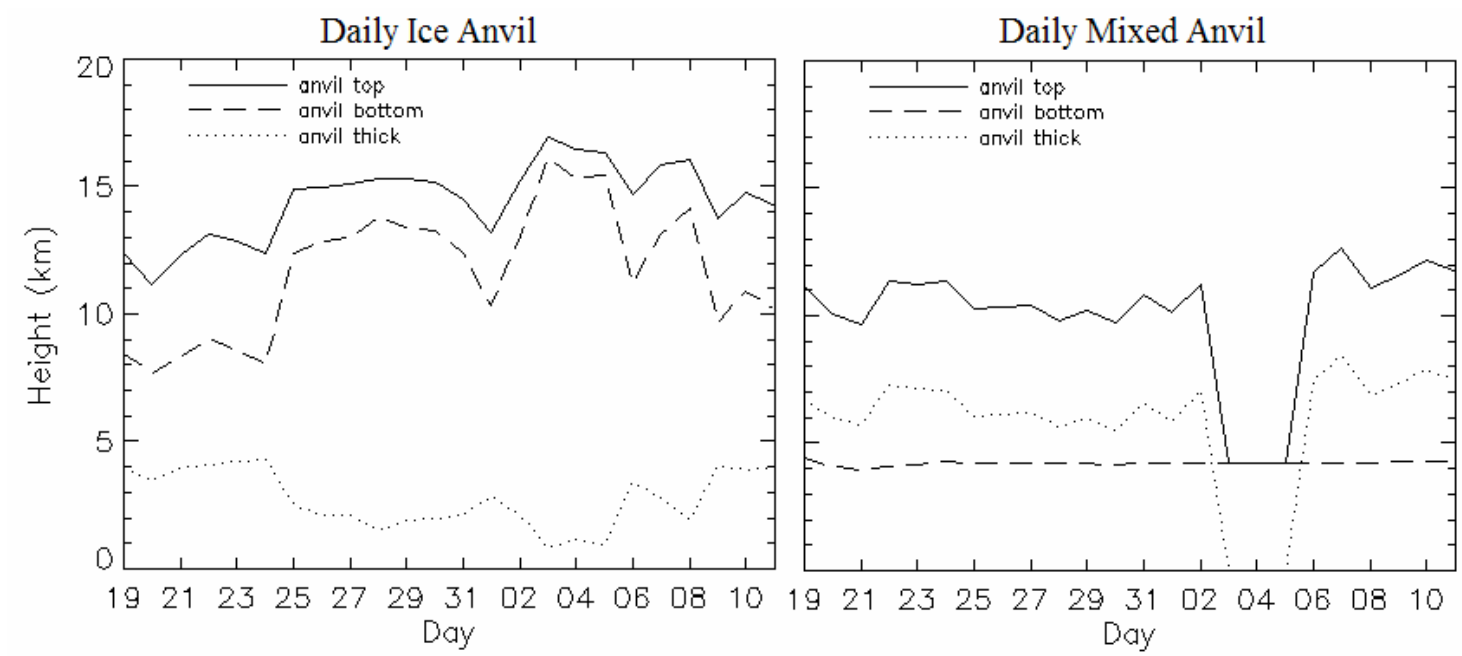

FIG. 33. Average anvil thickness during TWP-ICE.

Figure 32 and 33 implies that ice anvil thickness is negatively correlated with ice anvil height and ice anvil area is positively correlated with ice anvil thickness.

Calculations show a -0.9 correlation between daily ice anvil thickness and mean height and a 0.7 correlation for daily ice anvil area and thickness for the entire field campaign (Table 6). During the active period, the daily thickness did not vary much and the correlations do not follow the rest of the experiment. However, peaks in thickness on 1,6, and 9 February make this negative correlation to height (positive correlation to area) obvious during the dry monsoon and break period's, which have correlations of -0.9 (0.9) and -1.0 (0.9), respectively (Fig. 32, 33, and Table 6). Possible reasons for this correlation will be addressed in the discussion section. 
Table 6 Correlations during TWP-ICE for ice anvil: a) between anvil thickness and mean height and b) between anvil area and anvil mean height. Correlations for mixed are not shown because they are not as distinct due to the fact that the mixed anvil bottom is averaged between 3 and $5.5 \mathrm{~km}$.

\begin{tabular}{|lrrrr|}
\hline & Experiment & Active & Dry & Break \\
a) Thickness/Height & -0.9 & 0.7 & -0.9 & -1.0 \\
b) Area/Thickness & 0.7 & 0.3 & 0.9 & 0.9 \\
\hline
\end{tabular}

Anvil height and thickness were more variable during the break period than during the active and dry monsoon (Table 7). Mean height variance for ice anvil during the active and dry monsoon was $0.3 \mathrm{~km}$ and $0.7 \mathrm{~km}$ compared to $3.2 \mathrm{~km}$ during the break period. Ice anvil thickness variance during the break period was $1.9 \mathrm{~km}$ compared to that of $0.1 \mathrm{~km}$ for the active and dry monsoon. Mixed anvil shows similar results for height and thickness, with most variability during the break period. This variability is expected due to more isolated convection during the break period and more organized convective systems during the active monsoon. Another interesting feature in the variance is that ice anvil bottom varied more than the ice anvil top (mixed anvil bottom variance was 0 do to the method in which mixed anvil is classified). There was an exception to this type of relationship during the active period, when neither the ice anvil bottom nor top varied much. Over the entire experiment, the anvil base height had a variance of $6.4 \mathrm{~km}$ compared to the anvil top height variance of $2.3 \mathrm{~km}$. This difference was even more extreme during the break period when the ice anvil bottom had a variance $4.9 \mathrm{~km}$ greater than the top. Reasons for this difference will be discussed in the next section. 
Table 7 Variance in anvil properties during TWP-ICE.

\begin{tabular}{|lrr|}
\hline Thickness & Ice & Mixed \\
Experiment & 1.3 & 5.7 \\
Active & 0.1 & 0.4 \\
Dry & 0.1 & 0.2 \\
Break & 1.9 & 14.5 \\
Top & & \\
Experiment & 2.3 & 5.7 \\
Active & 0.5 & 0.6 \\
Dry & 0.5 & 0.2 \\
Break & 1.2 & 14.8 \\
Bottom & & \\
Experiment & 6.4 & null \\
Active & 0.2 & null \\
Dry & 1.0 & null \\
Break & 6.1 & null \\
Height & & \\
Experiment & 4.0 & 1.5 \\
Active & 0.3 & 0.2 \\
Dry & 0.7 & 0.1 \\
Break & 3.2 & 3.8 \\
\hline
\end{tabular}

Figure 34 shows ice and mixed anvil areas subset by day (0300-0900 UTC or 12:30-6:30 pm LT) and night (1500-2100 UTC or 12:30-6:30 am LT). There is a lack of diurnal variability in ice anvil area and the only marked diurnal variability in mixed anvil occurred during the active monsoon, when mixed anvil area was $20 \%$ greater at night on 20 February. Such a large production of mixed anvil at night during the active regime could be partially due to the large amount of stratiform rain production during this time. Overall, this plot does not indicate any significant diurnal variability in anvil production. Diurnal signals in anvil thickness and top are also very weak (Fig. 35). Issues with diurnal variability will be discussed in much more detail in the following section. 

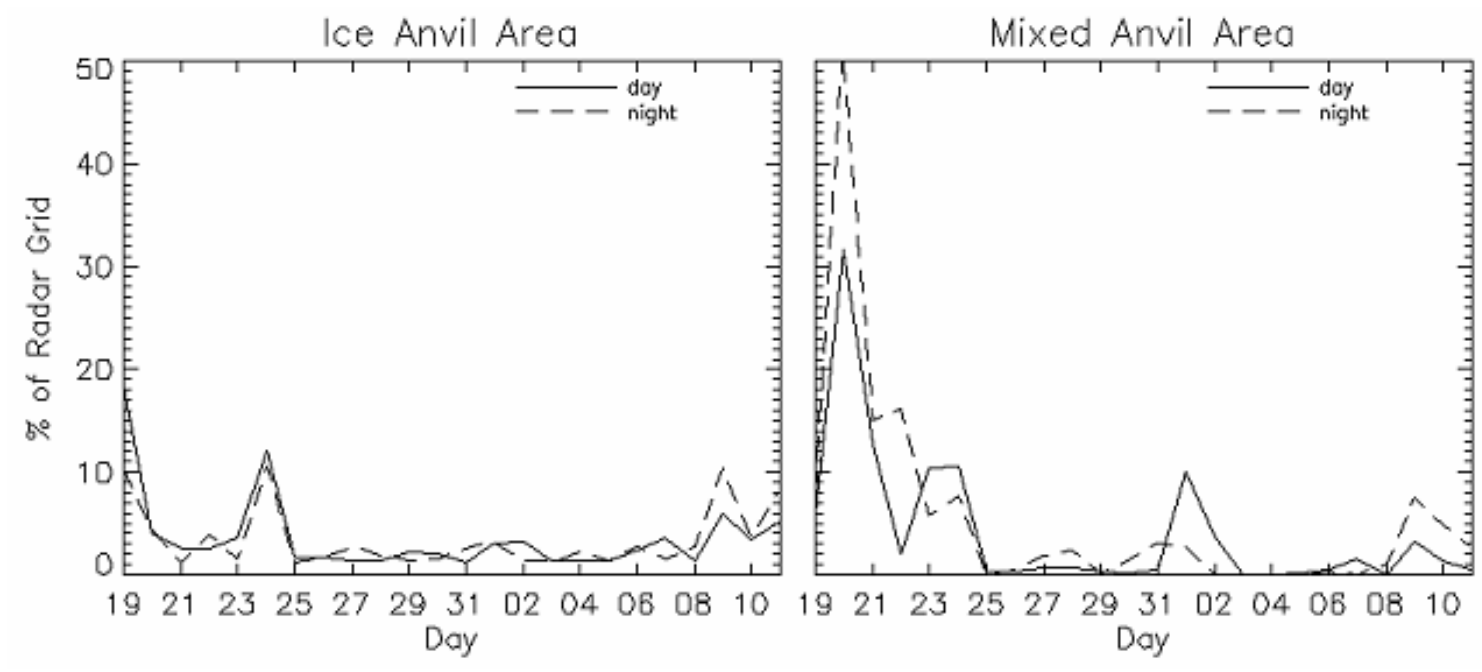

FIG. 34. Diurnal comparison in anvil area during TWP-ICE. Day is from 0300-0900 UTC (12:30 pm-6:30 pm LT). Night is from 1500-2100 UTC (12:30 am-6:30 am LT).
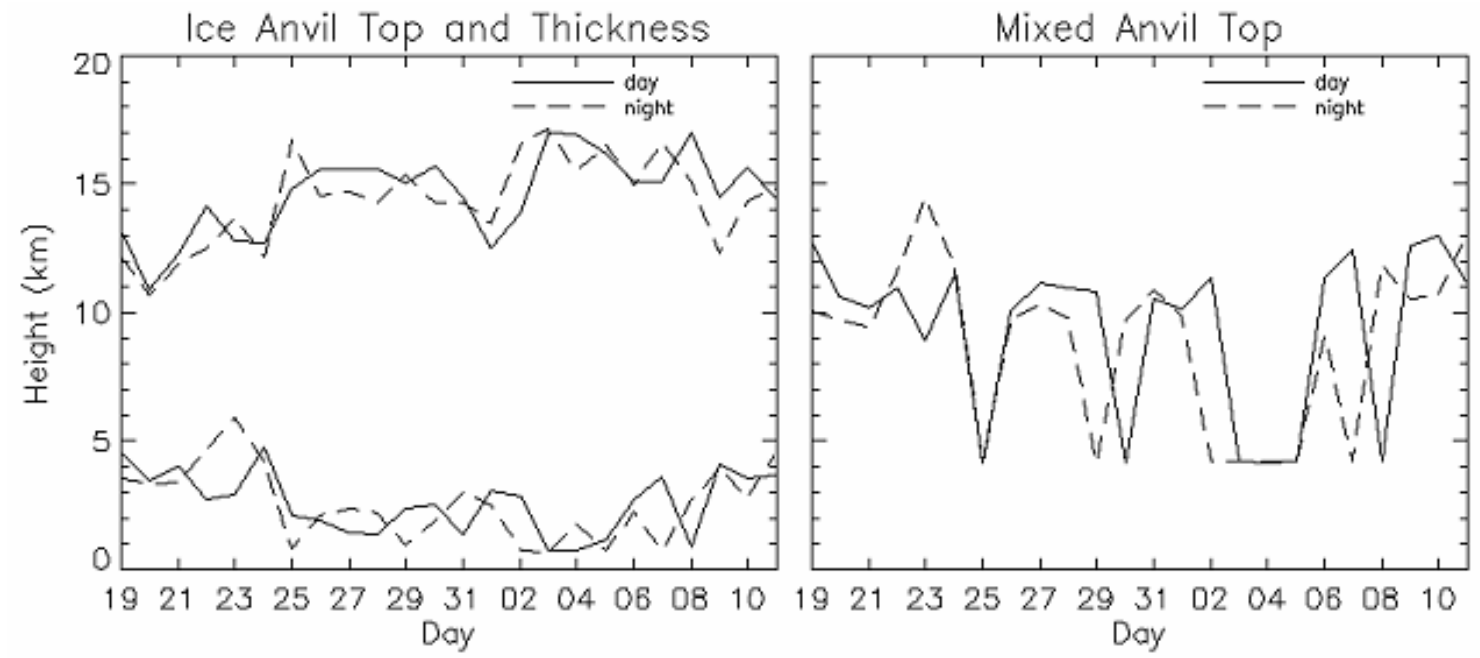

FIG. 35. Diurnal comparison in anvil top and thickness during TWP-ICE. Mixed anvil thickness will just be $4 \mathrm{~km}$ less than top height. Day is from 0300-0900 UTC (12:30 pm6:30 pm LT). Night is from 1500-2100 UTC (12:30 am-6:30 am LT). 


\section{DISCUSSION}

\section{a. Diurnal signals}

The following section further investigates anvil area and mean height statistics to search for possible diurnal evolution in the anvil. During the day, SW radiation dominates the radiative effects in the anvil. At night, in the absence of solar radiation, the earth emits LW radiation which dominates the radiative effects in the anvil (Gray and Jacobson 1977). It would be expected that the combined effects of SW and LW radiation would cause a net heating in the anvil during the day, thus producing lifting in the anvil. At night, in the absence of SW heating, the LW radiation emitted from the top of the anvil would cause a net cooling in the anvil, causing it to sink (Webster and Stephens 1980). While not much research has studied the diurnal variability of anvil area associated with tropical convection, Kossin (2002) used the National Environmental Satellite, Data, and Information Service-Cooperative Institute for Research in the Atmosphere (NESDIS-CIRA) tropical cyclone infrared satellite imagery to study the diurnal oscillation of areal extent of a hurricane cirrus canopy. His observations showed an apparent "sink and shrink" pattern in the cirrus canopy after sunset. While Kossin focused on hurricanes instead of ordinary convection, his study provides some insight into how anvil area could vary diurnally assuming a steady-state convective source.

An active monsoon case (23 January, Fig. 8) shows that the ice and mixed anvil areas decreased after sunset (1000 UTC or 7:30 pm LT) and then began to increase around sunrise (2100 UTC or 6:30 am LT) (Fig. 9). It is likely that this decrease in anvil area was due to most of the echo on the radar grid being classified as convective or 
stratiform rain, leaving less potential area to be classified as anvil. The height/thickness plot (Fig. 10) shows a slight decrease in ice anvil height after 1000 UTC. However, mixed anvil height increased after sunset. While a slight decrease in ice anvil height might be expected at night, the increase in mixed anvil height is not. It is unlikely that radiative interactions caused the decrease in anvil area or the slight decrease in ice anvil height.

The next day (24 January, Fig. 12) another system passed through the radar domain and its anvil evolution was inconsistent with what is expected to occur in an anvil region at night. Mixed anvil area decreased a couple hours after sunset, but mean anvil height stayed roughly constant around 7.5 km (Figs. 13 and 14). Ice anvil mean height decreased about $1 \mathrm{~km}$ between 1000 UTC and 1600 UTC, but its area remained about 20\% until the next convective peak. The decrease in ice anvil height could be due to net radiative cooling; however, the ice anvil height started to decrease around 0900 UTC, approximately three hours before radiation effects would be expected to occur. Once convective cells moved into the radar domain from the west around 1600 UTC, any diurnal signal in the anvil that might have existed was washed out and the characteristics of the anvil were more affected by the life cycle of the convection rather than radiative destabilization.

During the dry period, convective systems were more intermittent and did not provide the more continually produced convection that occurs in a hurricane or MCS. On 31 January, there was little convection and thus very little anvil in the radar domain (Fig. 16). A peak in anvil occurred at 1800 UTC, after a convective line moved through 
the radar domain around 1700 UTC (Fig. 17). The ice and mixed anvil area decreased as the parent convection died out, but instead of sinking, the ice anvil rose over the next six hours (Fig. 18).

A similar situation occurred the next day (1 February, Fig. 20). Convective lines moved through the radar domain during the day, but the anvil that persisted through the night did not sink (Fig. 22), despite the lack of shortwave heating. While anvil area decreased throughout the night (Fig. 21), this shrinking did not correlate to the sinking of the anvil.

Convection during the break period came mostly in the form of squall lines or Hectors over the Tiwi Islands. Ice anvil on 10 February (Fig. 24) did not follow the expected pattern of rising during the day and sinking at night. The ice anvil that was present started to sink in the afternoon around 0300 UTC (Fig. 26). In the late evening (1400 UTC), ice anvil area peaked a few hours after a convective line went through the radar domain and the ice anvil height rose until 2000 UTC, at which time it began to sink. By this time (after most of the convection died out) radiation effects could be playing a more important role on controlling the anvil height. The mixed portion of the anvil rose during the day and sank throughout the night (Fig. 26). Ice and mixed anvil area increased after 2000 UTC after the onset of new convection (Fig. 25).

On 11 February (Fig. 28), a significant amount mixed anvil did not appear in the domain until 1800 UTC (Fig. 29). However, the trend for the small amount of mixed anvil was to rise during the day until 1100 UTC ( $1 \mathrm{hr}$ after sunset) after which the mixed anvil began to sink (Fig. 30). From 1100-1600 UTC, the ice anvil also sank slightly, but 
then rose briefly around 1700 UTC when another squall line moved into the domain. The ice anvil that formed from this line sank from 1800 UTC until at least 2300 UTC. The mixed anvil that was formed also sank during this time. Even though both ice and mixed anvil sank after 1800 UTC, anvil area still increased.

By examining the case studies, it appears that there might be some diurnal variability in anvil characteristics during the break period. However, this signal is not obvious and it is more likely that the life cycle of convection is driving the anvil characteristics for at least the time that precipitation radar is able to observe the anvil. Kossin (2002) observed anvil that was consistently present because of the continual convection in the hurricane eyewall and rainbands, therefore the effects of radiation were not washed about by the convective activity itself, allowing him to see the sinking of the anvil at night. It is also important to note that Kossin’s study used IR satellite data while this study is using precipitation radar data.

Kossin (2002) also observed shrinking in the hurricane cirrus canopy at night. Despite any positive radiative influences driving the anvil up or down in the case studies, anvil area observable by C-POL does not shrink as the anvil sinks. Instead, the reverse situation is observed here. When the anvil area is greatest, the anvil is lower and vice versa. Table 6 shows that, with the exception of the active period, ice anvil area is positively correlated with thickness which is negatively correlated with height. These observations challenge whether or not the shrinking that Kossin (2002) sees is real or just apparent. Since his study was done using IR imagery, which is affected by the 
temperature of the anvil, any heating around the outer edges of the anvil could create an apparent shrinking.

\section{b. Convective pattern and longevity}

In the previous section, it was argued that the parent convection was of first order importance in determining anvil height, thickness, and areal coverage. But how and when does the anvil evolve from convection? Once anvil is formed, how long does it reside in the atmosphere?

Of the twelve MCSs observed in the case studies, eight followed a pattern in which the convective rain area would peak first, followed by a peak in stratiform area, then a peak in mixed anvil area and finally ice anvil area (Figs. 9, 13, 17, 21, 25, and 29). The peak in stratiform area occurs within an hour of the initial convective peak. These results are consistent with Houze (1997), in that stratiform rain is formed from aging convection; however, Houze (1997) did not discuss anvil evolution in relation to the parent convection. Typically, the mixed anvil area peak would lag the stratiform area by 1-2 hr. This lag implies that mixed anvil forms at the expense of stratiform rain. A peak in ice anvil area shows up anywhere within $1 \mathrm{hr}$ to as late as $3 \mathrm{hr}$ after a peak in mixed anvil area. This could be due to upper level shear advecting particles away from the parent convective system to form ice anvil or evaporation in the lower levels of the mixed anvil.

There were five cases in which the convective system was isolated enough to observe the longevity of the anvil. During these cases, anvil lasted 4-10 hr after the 
initial peak in convective rain area. Since the anvil is being measured within a set domain, it is difficult to tell how much anvil is dissipating or just advecting off of the domain.

c. Correlations between thickness, height, and area

Table 6 shows the correlations between ice anvil thickness, mean height, and area. Due to the fact that the mixed anvil averaged bottom is always at $4 \mathrm{~km}$, these correlations would not be reliable for mixed anvil and are not shown. In each regime, except the active regime, and throughout the entire experiment there is a strong negative correlation between ice anvil thickness and ice anvil height and a strong positive correlation between ice anvil area and ice anvil thickness. These correlations are evident in the daily time series of Figs. 32 and 33. The ice anvil thickness trends opposite of ice anvil height. The ice anvil area trends closely with ice anvil thickness.

These correlations likely result from how the anvil develops and evolves over time. When a convective cell first lofts hydrometeors into the upper atmosphere, the hydrometeors usually reach a level of neutral buoyancy and begin to spread out laterally. Over time, hydrometeors accumulate aloft and increase anvil areal extent. Upper level shear and a moist upper troposphere would assist in increasing and maintaining anvil areas. Eventually these hydrometeors sediment out, creating a thicker anvil with a lower base. The sinking of the anvil itself could occur if the larger particles that are usually found at the base of the anvil fallout first and evaporate hydrating the environment just under the current base of the anvil. Then when the small particles, which are normally at 
the top of the anvil, sediment out the new environment would be moist enough to sustain the particles and prevent them from evaporating. This process would cause the whole anvil to lower over time. Given an ice hydrometeor fall speed of 0.5-1.0 $\mathrm{m} \mathrm{s}^{-1}$, sedimentation could cause the anvil base to drop 2-3 km within an hour.

Figure 36 shows C-POL observing this process. On 10 February 2006 at 1130 UTC, anvil is starting to form from a convective cell. At the anvil’s initial development, its top is $~ 15 \mathrm{~km}$ with a base around $11 \mathrm{~km}$. Within $30 \mathrm{~min}$ the majority of the anvil base is below $10 \mathrm{~km}$ and the top is remaining around $15 \mathrm{~km}$. By $1230 \mathrm{UTC}$ the anvil base is $\sim 8 \mathrm{~km}$, creating a thicker anvil. The top has lowered somewhat but only the portion farthest away from the convective core. An hour and a half from the initial observation, the anvil base lies slightly above $6 \mathrm{~km}$ with the top remaining above $14 \mathrm{~km}$ but this includes reflectivity values less than $15 \mathrm{dBZ}$. Reflectivity values greater than 20 $\mathrm{dBZ}$ are below $12 \mathrm{~km}$. Figure 36 showed that the anvil became thicker and increased in area over a period of an hour and a half. Even though the anvil top did not sink as much as the anvil bottom, the mean height of the anvil decreased due to the substantial sinking of the anvil bottom. 


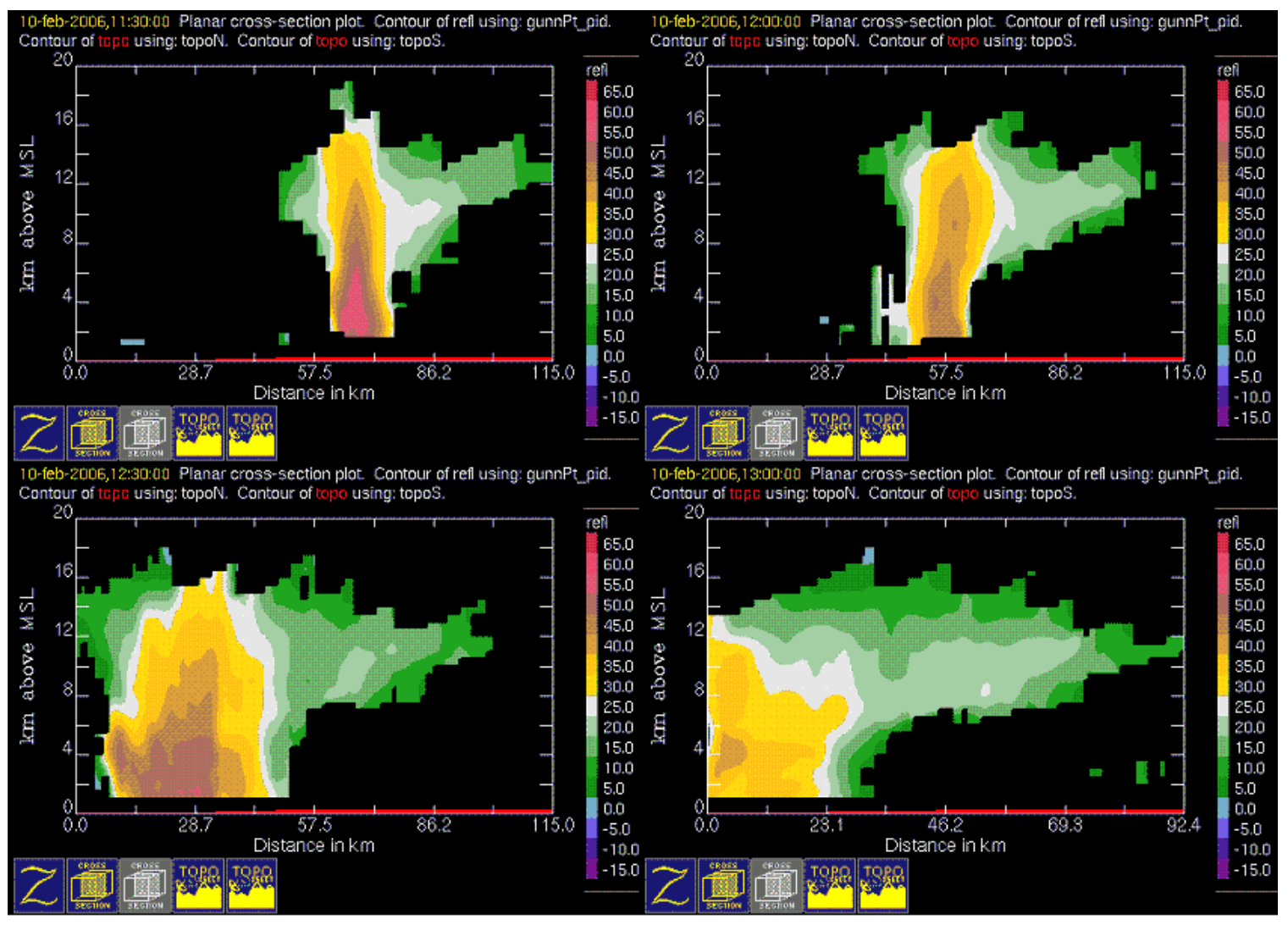

FIG. 36. A series of vertical cross sections from 10 February 2006 at 1130 UTC-1300 UTC. This series shows the sedimentation process occurring in the anvil.

\section{d. Variance in ice anvil base}

Table 7 is a list of variances in daily anvil properties observed throughout the experiment. The most notable difference is between ice anvil top and bottom (this comparison is not useful for mixed anvil since thresholds do not allow for much variability in anvil bottom). Averaged over the entire experiment, the ice anvil bottom varied significantly more than ice anvil top. When broken down by convective regimes, the same result is seen except during the active phase. The variance for both top and 
bottom is very small due to the nature of the convection, which is wider spread and longer lived during this regime. There are a few possible physical explanations for the anvil bottom being more variable than the top.

It is reasonable to assume that anvil top height is located around the level of neutral buoyancy (LNB). Therefore, any type of internal buoyant motion that occurs at the anvil top will not be able to penetrate through the stable layer. Since the anvil bottom is not constricted by this stable layer, cells would have more freedom to penetrate downward. The LNB could explain why Petre and Verlinde (2004) observed cells becoming more deeply embedded in the base of the anvil.

Another possible explanation is that there is increased ice water content (IWC) in the base of the anvil. McFarquhar and Heymsfield (1996) studied in situ measurements from three anvil cases during the Central Equatorial Pacific Experiment (CEPEX). Using an optical array probe they found that IWC increases downward in the anvil. The large IWC would cause a higher radiative destabilization rate (Lilly 1988) due to the absorption of radiation thus causing the anvil bottom to heat and rise. Their measurements also show that total cross-sectional area $\left(A_{c}\right)$ of the cloud particles per unit volume is at least one order of magnitude larger near the base of the cloud than near the top. Again, this would lead to greater radiative destabilization in the anvil base due to more absorption and extinction of radiation in the larger particles.

Of course, sedimentation would contribute to the variance of the anvil bottom. Variance may also occur in the anvil base as large ice crystals fall into a dry layer near cloud base and then sublimate (Heymsfield and Miloshevich 1995). For example, 
mammatus clouds that form from the cooling of the air as precipitation particles fall and evaporate could also cause the some of the observed variance.

\section{e. Radiative heating profiles}

As mentioned in the introduction, most numerical representations of diabatic heating processes focus on the latent heating effects at the expense of radiative heating. Radiative effects on the tropical diabatic heating field cannot be ignored, especially in the anvil where vertical motions are much weaker and latent heating is a secondary factor. Profiles of anvil characteristics observed in TWP-ICE are important for estimating the large-scale response to radiative heating. It is important to note that since this study used C-POL data to determine anvil coverage, the anvil area is underestimated, which in turn affects the radiative heating results.

In-cloud radiative heating profiles were calculated based on the profiles in Fig. 9 of Webster and Stephens (1980). No new radiative transfer calculations were performed; however, slight modifications were made based on a physical understanding of how anvil characteristics affect radiative transfer. Using anvil top and bottom averages, idealized radiative heating profiles for each anvil type were created. The magnitude of the idealized heating profile would apply if the domain was covered $100 \%$ by that particular anvil. Once the vertical heating structure of the ice and mixed anvils in each regime was determined, a heating profile was multiplied by the average areal coverage for the specific anvil type in that regime. Then the two profiles were summed to determine the net radiative forcing for that particular regime. 
Figure 37a illustrates the in-cloud radiative heating profile for the active regime. In the ice anvil profile, which had an average echo top of $12.4 \mathrm{~km}$ and base of $8.4 \mathrm{~km}$, the maximum cooling occurs a little above $12 \mathrm{~km}$, while the maximum heating occurs $\sim 10 \mathrm{~km}$. In the mixed anvil profile, which has a cloud top of $10.8 \mathrm{~km}$ and base of 4.2 $\mathrm{km}$, the maximum cooing occurs a little above $10 \mathrm{~km}$, while the maximum heating occurs $\sim 5 \mathrm{~km}$. The transition from cooling to heating in the mixed profile is not as sharp as in the ice because the mixed anvil is thicker.
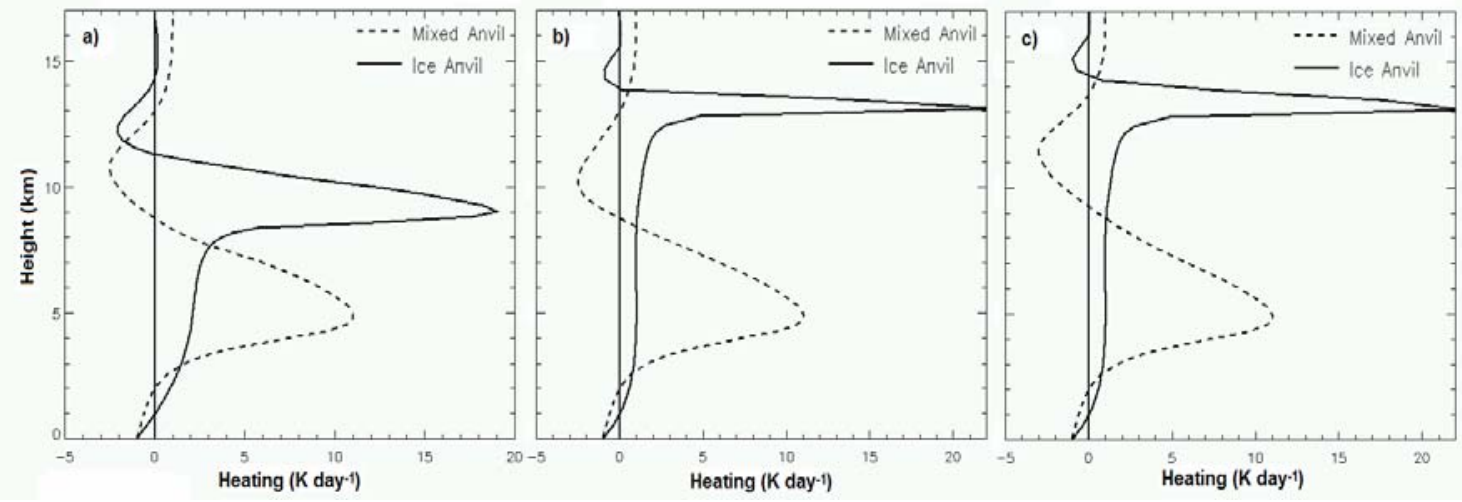

FIG. 37. In-cloud radiative heating profiles during TWP-ICE for the a) active regime, b) dry regime, and c) break. These profiles apply if $100 \%$ of the domain box is covered by the anvil type.

During the dry regime (Fig. 37b), the ice anvil is much thinner than in the active regime, creating a sharper transition from cooling to heating. The ice anvil during this regime is $3 \mathrm{~km}$ higher than in the active regime so we should expect slightly more SW heating, but this would be over come by less LW cooling due to the anvil being so thin. The mixed anvil profiles of the active and dry regimes are very similar except that the maximum cooling is shifted down $0.5 \mathrm{~km}$ in the dry regime. 
Ice anvil was highest during the break period compared to the other regimes (Fig. 37c), thus the level of maximum cooling is higher, above $15.5 \mathrm{~km}$. Since the ice anvil base is about the same as in the dry regime, the level of maximum heating is about the same as in the dry regime. Mixed anvil top is $~ 1-1.5 \mathrm{~km}$ higher and thicker than the mixed anvil in the other regimes, therefore the maximum cooling is found at a higher level and is also about $0.5^{\circ} \mathrm{K}$ cooler.

Figure 38 shows the total heating effects of the anvils combined, taking into account areal coverage. The anvils during the dry and break regimes do not provide much cooling to the atmosphere $\left(\sim 0.05-0.1^{\circ} \mathrm{K}_{\text {day }}{ }^{-1}\right)$. Their levels of maximum heating are around the same height, $~ 13 \mathrm{~km}$ and $4.75 \mathrm{~km}$. The anvil during the break regime provided about $0.4^{\circ} \mathrm{K}_{\text {day }}{ }^{-1}$ heating at $13 \mathrm{~km}$ and $4.75 \mathrm{~km}$ which is $0.1^{\circ} \mathrm{K}$ more heating than the dry regime at $13 \mathrm{~km}$ and $0.2^{\circ}$ more heating at $4.75 \mathrm{~km}$. Anvil during the active regime created the most dramatic response of heating/cooling. A maximum heating of $3^{\circ}$ $\mathrm{K} \mathrm{day}^{-1}$ is at $9 \mathrm{~km}$, with a secondary maximum of $1.2^{\circ} \mathrm{K}_{\text {day }}{ }^{-1}$ at $5 \mathrm{~km}$. This regime also provided cooling at upper levels $\left(\sim 0.45^{\circ} \mathrm{K} \mathrm{day}^{-1}\right)$. Averaged over the entire experiment, the anvil characteristics seen in TWP-ICE would cause cooling of $0.2^{\circ} \mathrm{K} \mathrm{day}^{-1}$ at $12 \mathrm{~km}$, heating of $\sim 1^{\circ} \mathrm{K} \mathrm{day}^{-1}$ at $9 \mathrm{~km}$ and $\sim 0.6^{\circ} \mathrm{K} \mathrm{day}^{-1}$ at $5 \mathrm{~km}$. 


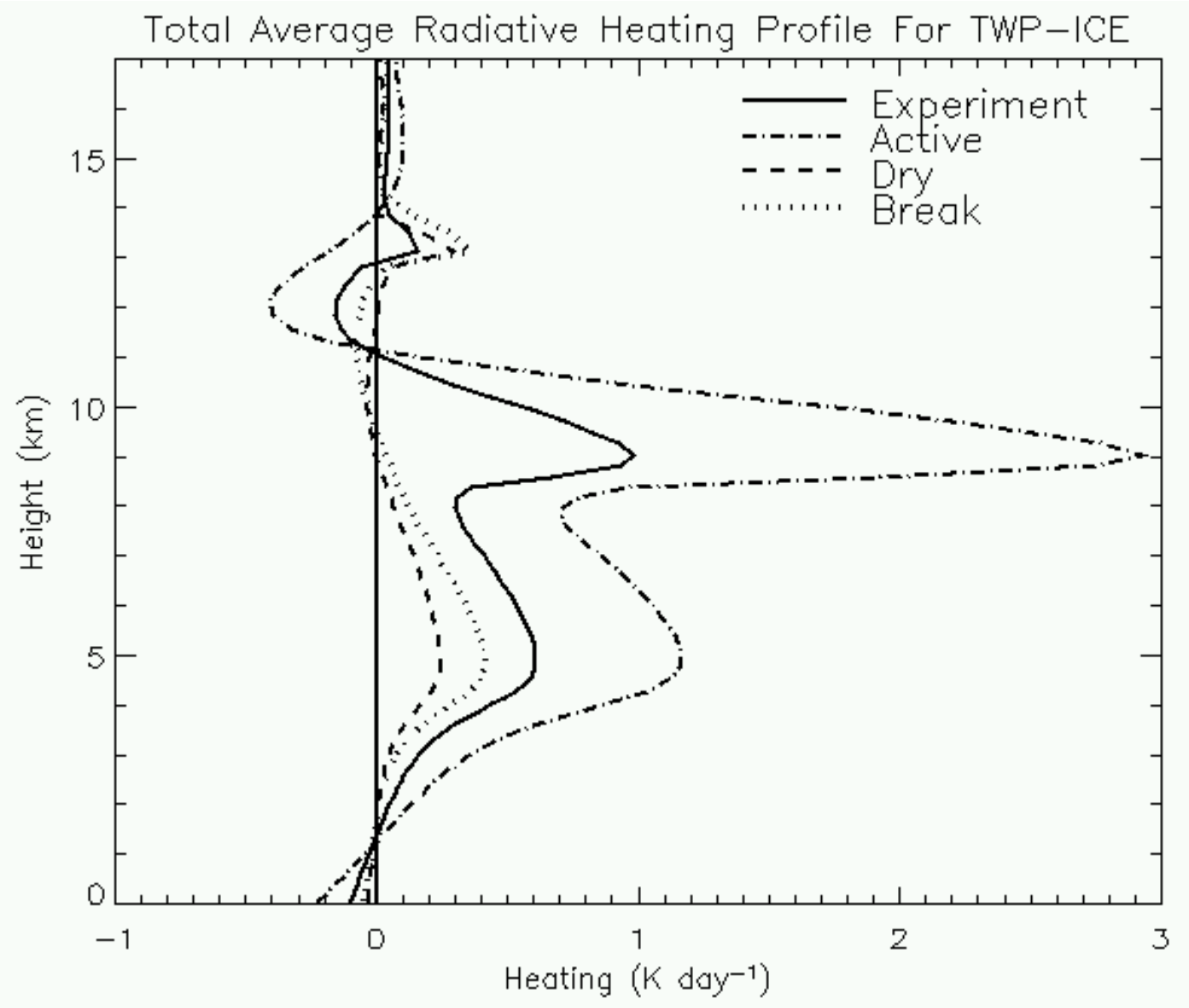

FIG. 38. In-cloud radiative heating during each regime during TWP-ICE. 


\section{CONCLUSIONS}

The horizontal and vertical dimensions of the anvil region can be used to determine the radiative impact of tropical anvil and better quantify the water budget of tropical convective systems. The experiment average of area coverage for mixed and ice anvils were between $4-5 \%$ of the radar grid. Due to the robust nature of the convection, the largest areal coverage occurred during the active monsoon with ice anvil covering $7.6 \%$ of the radar grid and mixed anvil covering $15.6 \%$ of the grid. With little convection, the smallest amount of anvil was produced during the dry monsoon; ice and mixed anvil covered $2.1 \%$ and $1.3 \%$ of the radar grid, respectively. Break period ice anvil coverage was closer to the experiment average at a value of $3.6 \%$ while the mixed anvil area decreased to only $1.7 \%$ of the radar grid. Ice anvil thickness was $2.8 \mathrm{~km}$ and mixed anvil thickness was $6.7 \mathrm{~km}$ averaged over the experiment. The thickest ice anvil was produced during the active monsoon, with ice anvil thickness averaging $4 \mathrm{~km}$, compared to only 2.1 and $2.5 \mathrm{~km}$ during the dry monsoon and break period, respectively. Due to higher cloud tops, the thickest mixed anvil was produced during the break period with an average thickness of $7.6 \mathrm{~km}$, compared to $6.6 \mathrm{~km}$ and $6.1 \mathrm{~km}$ during the active and dry monsoon. Applying these results to Fig. 4 will help to quantify the pictured water budget (Fig. 39). 


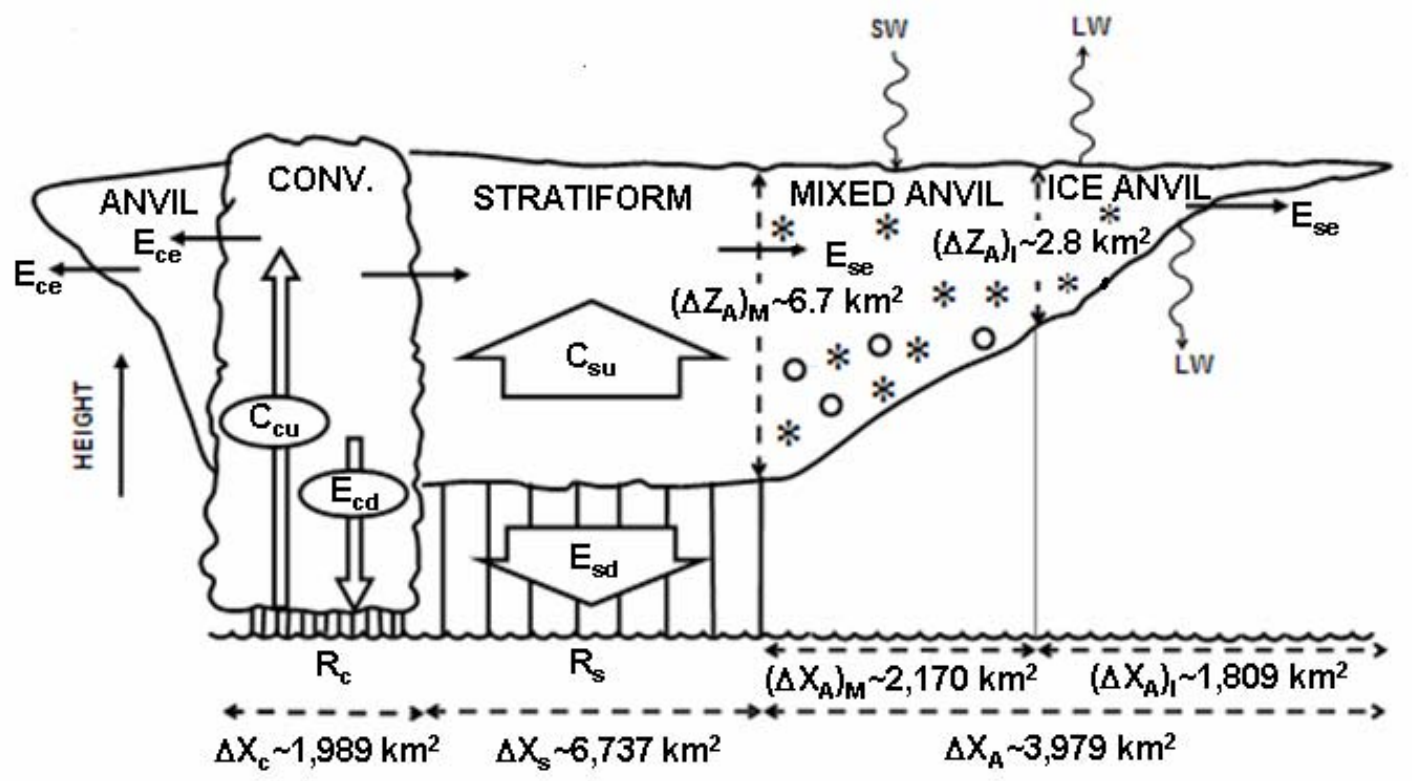

FIG. 39. Figure 4 with added values based on observations of this study.

Neither case studies nor daily plots showed any consistent diurnal signal in the anvil properties. It is more likely that the life cycle of the parent convection, instead of internal radiative influences, determined the anvil characteristics for at least the time that C-POL was able to observe the anvil. Further, anvil area observable by C-POL did not shrink as the anvil sank, implying that the nighttime shrinking of hurricane cirrus canopies observed in Kossin (2002) does not apply to regular tropical convective systems.

Since parent convection is likely of first order importance in determining anvil height, thickness, and areal coverage, it is important to show how anvil evolves from the parent convection and how long the anvil persists. Eight out of the twelve MCSs observed in the case studies followed a pattern in which the convective rain area peaked first, followed by a peak in stratiform rain area, then a peak in mixed anvil area typically 
lagging 1-2 hr behind the stratiform rain area peak, and finally ice anvil area peak occurring 1-3 hr after a mixed anvil area peak. Five convective systems were isolated enough to observe the longevity of the anvil. During these systems, anvil typically lasted 4-10 hr after the initial convective rain area peak. Understanding the interaction between the anvil and the rest of the precipitating system will lead to more realistic numerical representations of anvil properties associated with deep convection in the tropics.

Information about the evolution of the anvil could lead to a better understanding of what sustains the anvil. A strong positive correlation between ice anvil area and thickness and a strong negative correlation between ice anvil thickness and height was found throughout the entire experiment (with the exception of the active monsoon). These correlations most likely result from sedimentation occurring in the anvil over time. During the lifetime of the anvil, as more hydrometeors collect aloft (increasing anvil areal coverage), larger particles fallout of the anvil first, evaporating and moistening the atmosphere underneath the anvil. Once the smaller particles fallout, they do not evaporate due to the moister environment beneath the anvil. This sedimentation process creates a lower base and thicker anvil.

During the entire experiment (except during the active monsoon) the ice anvil bottom varied significantly more than ice anvil top. Several explanations were proposed for this, the most likely being that the anvil top is located around the level of neutral buoyancy where it is not free to penetrate above that level. Another possible cause is larger amounts of IWC in the base of the anvil causing greater radiative destabilization 
due to more absorption and extinction of radiation in the larger particles. Sedimentation would also be a factor leading to this observation.

The vertical profiles of in-cloud radiative heating give us information as to how these anvils affect the radiative budget and where to expect the large-scale response to this radiative heating. The total anvil characteristics seen in TWP-ICE would cause cooling of $0.2^{\circ} \mathrm{K} \mathrm{day}^{-1}$ at $12 \mathrm{~km}$, heating of $1^{\circ} \mathrm{K} \mathrm{day}^{-1}$ at $9 \mathrm{~km}$ and $\sim 0.5^{\circ} \mathrm{K} \mathrm{day}^{-1}$ at 5 $\mathrm{km}$. Anvil during the active regime had the largest radiative heating and would thus cause the greatest large-scale response. A maximum heating of $3^{\circ} \mathrm{K} \mathrm{day}^{-1}$ was estimated at $9 \mathrm{~km}$, with a secondary maximum of $1^{\circ} \mathrm{K} \mathrm{day}^{-1}$ at $5 \mathrm{~km}$. The active regime was also unique in that it was the only regime to provide significant cooling into the atmosphere. This type of profile would be expected to enhance circulations such as the Hadley or Walker circulations (Sherwood et al. 1994). Hartmann et al. (1984) found a larger midlatitude response with an elevated heating profile. Therefore, it is expected that the radiative heating during the active monsoon would have important impacts on tropicalextratropical interactions. The dry monsoon and break regimes show the highest heating maximum, but with smaller magnitudes, thus the large-scale response would occur higher in the atmosphere than in the active regime, but would be of smaller magnitude. 


\section{REFERENCES}

Ackerman, T. P., K. N. Liou, F. P. J. Valero, and L. Pfister, 1988: Heating rates in tropical anvils. J. Atmos. Sci., 45, 1606-1623.

Bergman, J. W. and H. H. Hendon, 2000: Cloud radiative forcing of the low-latitude tropospheric circulation: Linear calculations. J. Atmos. Sci., 57, 2225-2245.

Bringi, V. N., G. Huang, V. Chandrasekar, and T. D. Keenan, 2001: An areal rainfall estimator using differential propagation phase: Evaluation using a C-band radar and a dense gage network in the Tropics. J. Atmos. Oceanic Technol., 18, 18101818.

Gamache, J.F., and R. A. Houze, Jr., 1983: Water budget of a mesoscale convective system in the tropics. J. Atmos. Sci., 40, 1835-1850.

Hartmann, D. L., H. H. Hendon, and R. A. Houze, Jr., 1984: Some implications of the mesoscale circulations in tropical cloud clusters for large-scale dynamics and climate. J. Atmos. Sci., 41, 113-121.

Hastenrath, S., 1991: Climate Dynamics of the Tropics. Kluwer Academic Publishers. $488 \mathrm{pp}$.

Heymsfield, A. J., and G. M. McFarquhar, 1996: High albedos of cirrus in the tropical Pacific warm pool: Microphysical interpretations from CEPEX and from Kwajalein, Marshall Islands. J. Atmos. Sci., 53, 2424-2451.

Houze, R. A., Jr., 1982: Cloud clusters and large-scale vertical motions in the Tropics. J. Meteor. Soc. Japan, 60, 396-410.

Houze, R. A., Jr., 1997: Stratiform precipitation in regions of convection: A meteorological paradox? Bull. Amer. Meteor. Soc., 78, 2179-2196.

Houze, R. A., Jr., S. Brodzik, C. Schumacher, S. E. Yuter, and C. R. Williams, 2004: Uncertainties in oceanic radar rain maps at Kwajalein and implications for satellite validation. J. Appl. Meteor., 43, 1114-1132.

Keenan T., K. Glasson, and F. Cummings, 1998: The BMRC/NCAR C-Band polarmetric (C-POL) radar system. J. Atmos. Oceanic Technol., 15, 871-886.

Lilly, D. K., 1988: Cirrus outflow dynamics. J. Atmos. Sci., 45, 1594-1605.

Liou, K.N., 2002: An Introduction to Atmospheric Radiation. Academic Press, 583 pp. 
Massie, S., A. Gettelman, W. Randel, and D. Baumgarder, 2002: Distribution of tropical cirrus in relation to convection. J. Geophys. Res., 107.

McFarquhar, G. M., and A. J. Heymsfield, 1996: Microphysical characteristics of three anvils sampled during the Central Equatorial Pacific Experiment. J. Atmos. Sci., 53, $2401-2423$.

Petre J. M., and J. Verlinde, 2004: Cloud radar observations of Kelvin-Helmholtz instability in a Florida anvil. Mon. Wea. Rev., 132, 2520-2523.

Randall, D.A., Harshvardhan, D. A. Dazlich, and T.G. Corsetti, 1989: Interactions among radiation, convection, and large-scale dynamics in a general circulation model. J. Atmos. Sci., 46, 1943-1970.

Sherwood, S. C., V. Ramanathan, T. P. Barnett, M. K. Tyree, and E. Roeckner, 1994: Response of an atmospheric general-circulation model to radiative forcing of tropical clouds. J. Geophys. Res., 99, 20829-20845.

Slingo, A., and J.M. Slingo, 1988: The response of a general circulation model to cloud longwave radiative forcing. 1. Introduction and initial experiments. Quart. J. Roy. Meteor. Soc., 114, 1027-1062.

Steiner, M., R. A. Houze, Jr., and S. E. Yuter, 1995: Climatological characterization of three-dimensional storm structure from operational radar and rain gauge data. $J$. Appl. Meteor., 34, 1978-2007.

Webster, P. J. and G. L. Stephens, 1980: Tropical upper-tropospheric extended clouds: Inferences from winter MONEX. J. Atmos. Sci., 37, 1521-1541. 


\section{VITA}

Kaycee Loretta Frederick

\section{ADDRESS:}

Department of Atmospheric Sciences

Texas A\&M University

3150 TAMU

College Station, TX 77843-3150

\section{EDUCATION:}

B.S. Atmospheric Sciences, University of North Dakota Graduated May 2004

M.S. Atmospheric Sciences, Texas A\&M University Graduated December 2006 